
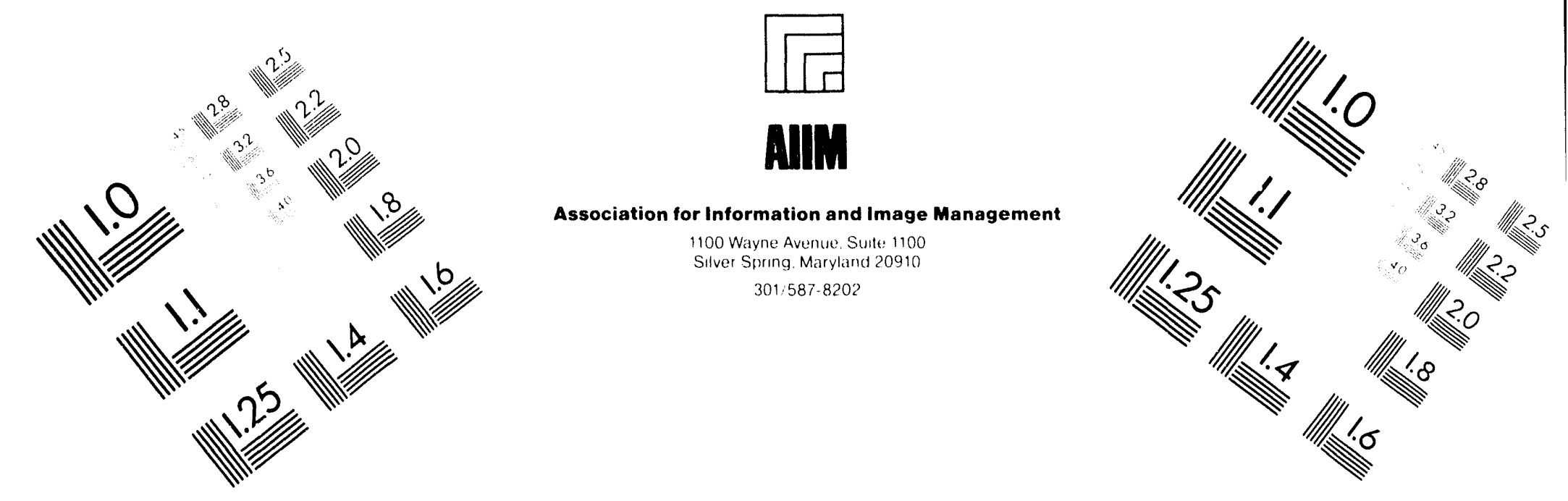

Centimeter

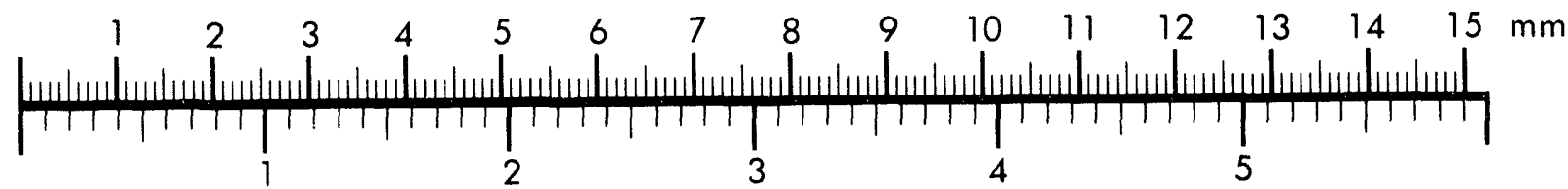

Inches
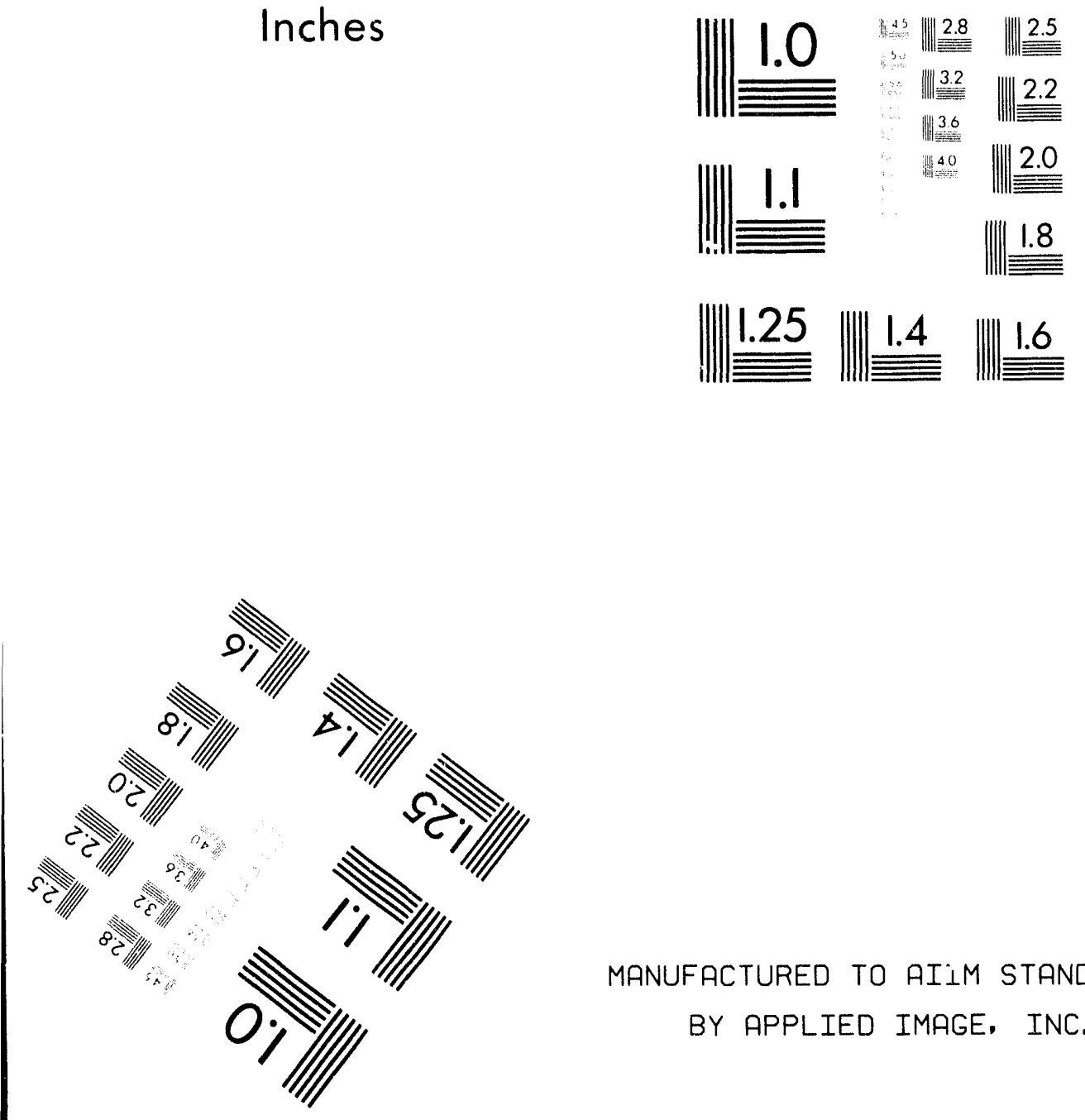

MANUFACTURED TO AILM STANDARDS

BY APPLIED IMAGE, INC.

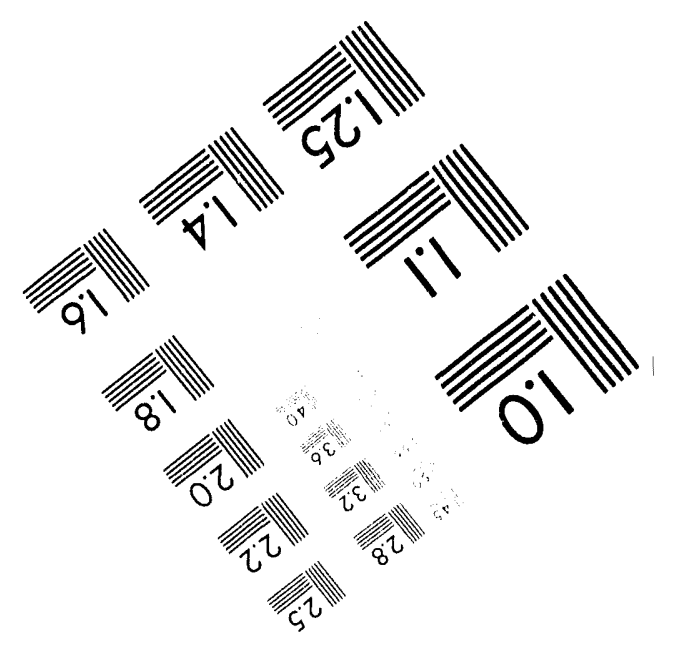



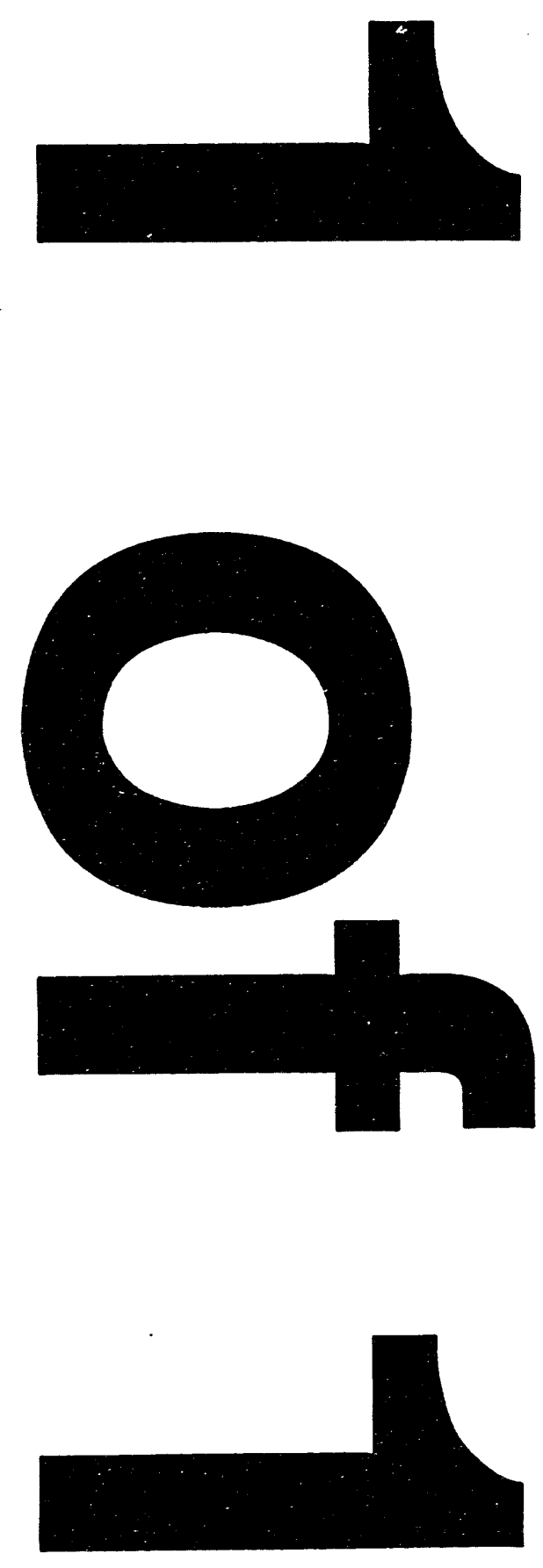
SAND93-2675

Unlimited Release

Printed April, 1994

\section{Total-System Performance Assessment for Yucca Mountain - SNL Second Iteration (TSPA-1993)}

Executive Summary

Michael L. Wilson, John H. Gauthier ${ }^{\dagger}$, Ralston W. Barnard, George E. Barr, Holly A. Dockery, Ellen Dunn, Roger R. Eaton, David C. Guerin $\ddagger$, Ning Lu* , Mario J. Martinez, Robert Nilson, Christopher A. Rautman, Thomas H. Robey ${ }^{\dagger}$, Benjamin Ross ${ }^{*}$, Eric E. Ryder, Albert R. Schenker $\ddagger$, Sharon A. Shannon, Lee H. Skinner ${ }^{\dagger}$ (Sandia National Laboratories)

William G. Halsey, James D. Gansemer, Lynn C. Lewis, Alan D. Lamont (Lawrence Livermore National Laboratory)

Inés R. Triay, Arend Meijer $§$, David E. Morris (Los Alamos National Laboratory)

$\dagger$ Spectra Research, Inc.

$\ddagger$ Los Alamos Technical Associates, Inc.

* Disposal Safety, Inc.

$\S$ Jacobs Engineering, Inc.

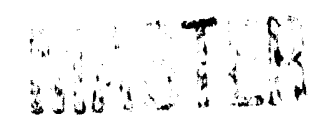




\begin{abstract}
Sandia National Laboratories has cumpleted the second iteration of the periodic total-system performance assessments (TSPA-93) for the Yucca Mountain Site Characterization Project (YMP). These analyses estimate the future behavior of a potential repository for high-level nuclear waste at the Yucca Mountain, Nevada, site under consideration by the Department of Energy. TSPA-93 builds upon previous efforts by emphasizing YMP concerns relating to site characterization, design, and regulatory compliance.

Scenarios describing expected conditions (aqueous and gaseous transport of contaminants) and low-probability events (human-intrusion drilling and volcanic intrusion) are modeled. The hydrologic processes modeled include estimates of the perturbations to ambient conditions caused by heating of the repository resulting from radioactive decay of the waste. Hydrologic parameters and parameter probability distributions have been derived from available site data. Possible future climate changes are modeled by considering two separate groundwater infiltration conditions: "wet", with a mean flux of $10 \mathrm{~mm} / \mathrm{yr}$, and "dry", with a mean flux of $0.5 \mathrm{~mm} / \mathrm{yr}$. Two alternative wastepackage designs and two alternative repository areal thermal power densities are investigated. One waste package is a thin-wall container emplaced in a vertical borehole, and the second is a container designed with corrosion-resistant and corrosion-allowance walls emplaced horizontally in the drift. Thermal power loadings of $57 \mathrm{~kW} /$ acre (the loading specified in the original repository conceptual design) and $114 \mathrm{~kW} / a c r e$ (a loading chosen to investigate effects of a "hot repository") are considered.

TSPA-93 incorporates significant new detailed process modeling, including two- and threedimensional modeling of thermal effects, groundwater flow in the saturated-zone aquifers, and gas flow in the unsaturated zone. The saturated-zone model is used to estimate travel times for contaminants through layered, dipping formations. Coupled calculations of gas and heat flow are used to estimate travel times for gaseous $\mathrm{CO}_{2}$. Time-dependent temperature dist.ibutions in the rock surrounding the potential repository are calculated, using the four repository layouts. A phenomenological model for waste-package degradation is implemented; the model includes temperature-dependent corrosion, fuel alteration, and dissolution.

Probabilistic analyses are performed for aqueous and gaseous flow and transport, human intrusion, and basaltic magmatic activity. Repository performance estimates are sensitive to assumptions made about unsaturated-zone water flow and contact with waste. Two conceptual models of unsaturated-zone water flow are considered - the composite-porosity model, which treats fracture and matrix flow as being strongly coupled; and the weeps model, which allows for flow only through locally saturated zones. The weeps aqueous releases and the human-intrusion direct releases are sensilive to the size of the waste packages that are affected: the larger horizontally-emplaced containers produce greater releases. Releases are generally insensitive to repository thermal effects: a hotter thermal loading protects parts of the repository from contact with liquid water, but other parts experience enhanced water flow due to condensation and diversion. The volcanic scenario, which investigates the effects of magmatic volatiles on the degradation of the waste packages, does not contribute significantly to releases.

Results of the calculations done for TSPA-93 lead to a number of recommendations concerning studies related to site characterization. Primary among these are the recommendations to obtain better information on percolation flux at Yucca Mountain, on the presence or absence of flowing fractures, and on physical and chemical processes influencing gaseous flow. Near-field thermal and chemical processes, and waste-container degradation are also areas where additional investigations may reduce important uncertainties. Recommendations resulting from TSPA-93 for repository and waste-package design studies are: 1) to evaluate the performance implications of large-size containers, and 2) to investigate in more detail the implications of high repository thermal power output on the adjacent host rock and on the spent fuel.

If future repository performance regulations are based on individual dose rather than cumulative release, results suggest that future site-characterization efforts should emphasize investigations of groundwater contact with waste packages in the unsaturated zone and examinations of saturated-zone flow paths. Because dose rates are dependent on the rate of radionuclide releases, it would be useful to investigate container designs that fail "slowly" over long periods of time.
\end{abstract}




\section{Volume 1 \\ contains Chapters 1 through 12}

\section{Volume 2}

contains Chapters 13 through 25

and the Appendices 
This report was prepared under the Yucca Mountain Site Characterization Project WBS 1.2.5.4.1. QAGR 1.2.3.4.1 was applied, however, the information and data documented in the report were not developed to meet quality affecting standards. Not all the work activities were subject to QA controls. The information in this report is not qualified and is not to be used for licensing. 


\section{Contents}

\section{Contents of Volume 1}

List of Figures

xiv

List of Tables

xxvi

Glossary

$\mathbf{x x x}$

Part I: Introduction

Chapter 1 Introduction...

1.1 Evolution of SNL total-system performance assessments .

1.1.1 PACE-90

1.1.2 TSPA-91

$1-3$

1.2 TSPA-93

$1-5$

1.2.1 Caveats

1.3 Issues considered when planning TSPA-93

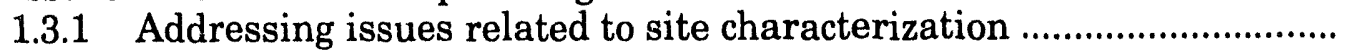

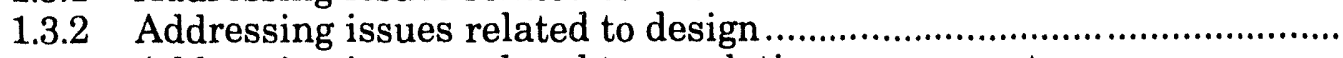

1.3.3 Addressing issues related to regulation assessment .

1.4 Participants in SNL TSPA-93

1.5 Organization of the TSPA-93 report

Chapter 2 Site Description and Regulatory Context .......................................... $2-1$

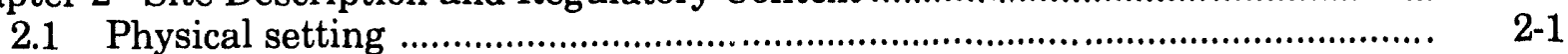

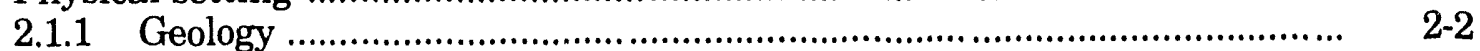

2.1.2 Geohydrology ....................................................................... $2-5$

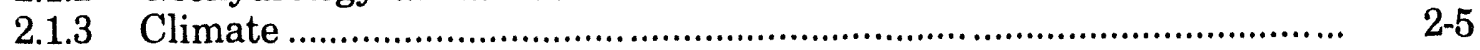

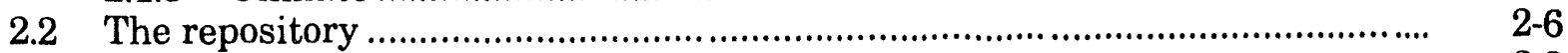

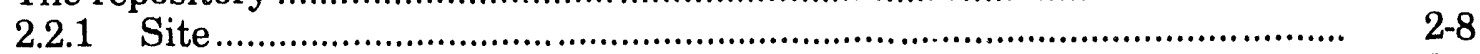

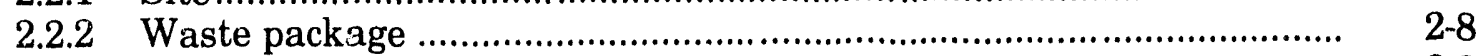

2.2.3 Emplacement .................................................................... $2-8$

2.2.4 Waste description ....................................................................... $2-9$

2.2.5 TSPA-93 modeling domains ............................................................ $\quad 2-9$

2.3 Regulatory context ....................................................................... $2-10$

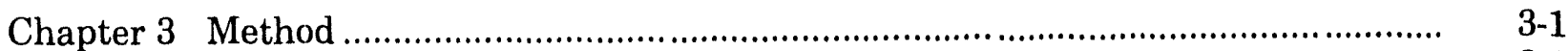

3.1 Performance assessment .....................................................................

3.2 Scenarios .................................................................................. $3-5$

3.2.1 Nominal flow ........................................................................ $3-7$

3.2.2 Human intrusion .................................................................. $3-9$

3.2.3 Basaltic volcanism .................................................................. $3-11$

3.3 Processes, modals, and computer programs …......................................... $3-11$

3.4 Incorporation of uncertainty .............................................................. $3-19$ 
Part II: Data Development

Chapter 4 Repository Areas and Layouts .................................................................... 4-.

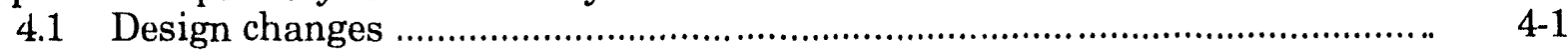

$4.2 \quad$ Waste-package design ..........................................................................

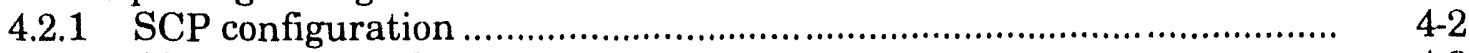

4.2.2 Alternative configuration .............................................................

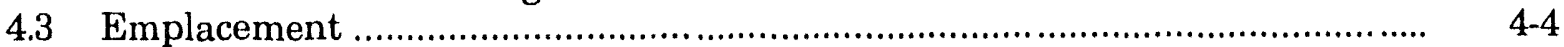

4.3.1 SCP emplacement .................................................................

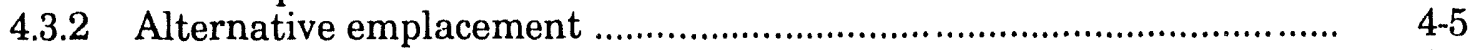

4.4 Other issues affecting thermal loading .........................................................

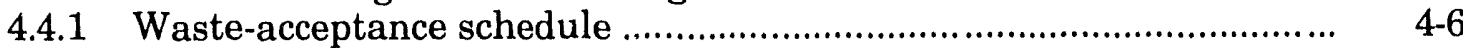

4.4.2 Waste-emplacement density .............................................................

4.4.3 Repository layout assumptions .................................................... $\quad 4-10$

4.5 Emplacement/thermal-loading cases analyzed in TSPA-93 ……………….. $4-10$

4.6 Repository areas ....................................................................................... 4

Chapter 5 Radionuclide Inventory .............................................................................

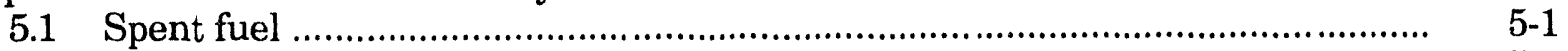

5.1.1 Spent-fuel inventory ..................................................................

5.1.2 Inventory parameters for the source-term module ..............................

$5.2 \quad$ Vitrified high-level waste .............................................................................. 5

5.2.1 Vitrified high-level waste stream ...................................................... $5-5$

$5.2 .2 \quad$ High-level waste inventory ............................................................... $5-6$

5.3 Combined inventory ............................................................................... 5

5.4 Radionuclides used in analyses ............................................................... $5-8$

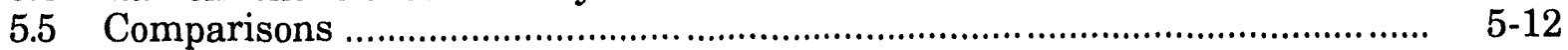

5.5.1 Comparison of inventories for TSPA-93 and TSPA-91 ....................... $5-12$

5.5.2 Comparison of HLW and spent-fuel inventories .................................. $5-14$

Chapter 6 Geostatistically Based Stratigraphic Model .................................................. 6- 6-1

6.1 Geostatistical methods ......................................................................... 6-2

6.2 Lithologic data ......................................................................................

6.3 Spatial continuity ...............................................................................

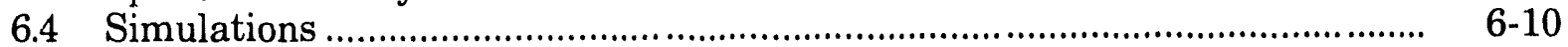

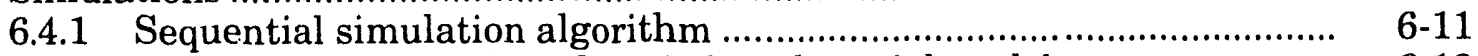

6.4.2 Empirical modification of the inferred spatial model ............................ $6-12$

6.5 Development of stratigraphic columns for performance $\ldots$

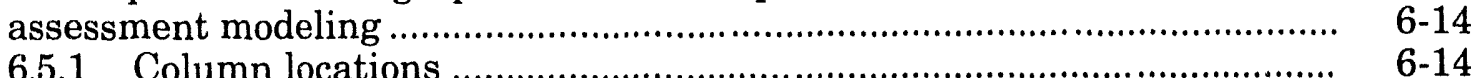

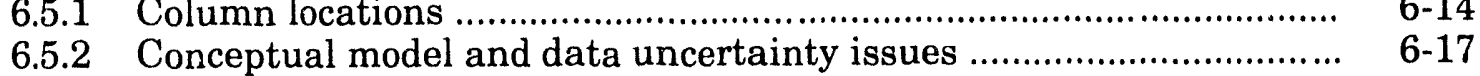

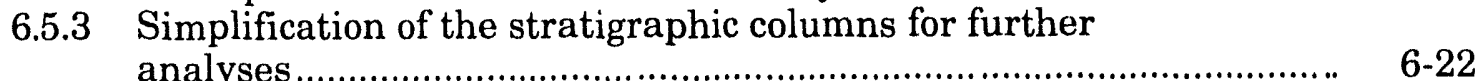

6.5.4 Introduction of deterministic stratigraphic features ............................ $\quad 6-22$

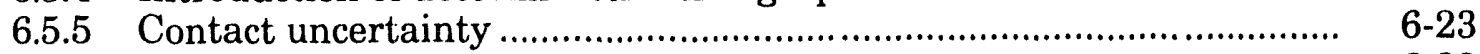

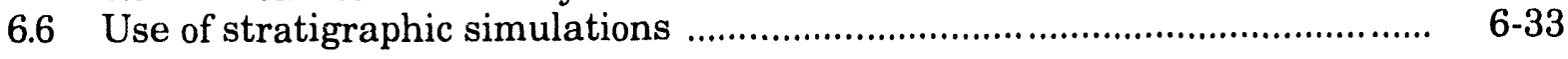

Chapter 7 Hydrogeologic Parameter Development ........................................................

7.1 Overview of parameter development .........................................................

7.1.1 Hydrologic properties considered......................................................

7.1.2 Development method ..................................................................

7.1.3 Scaling ..........................................................................................

7.1.4 Hydrologic units parameterized …………………..........................

7.2 Matrix parameter distributions ............................................................... 


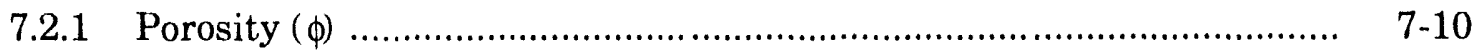

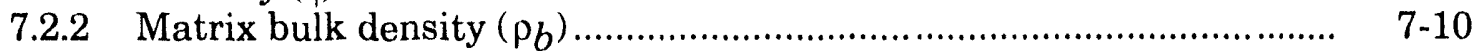

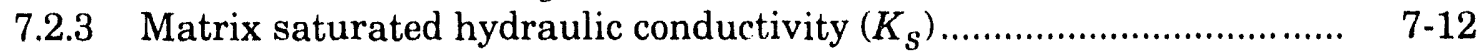

7.2.4 Matrix water-retention parameters (van Genuchten model).............. $\quad$ 7-14

7.3 Bulk hydraulic-parameter development …………......................................... $\quad$ 7-16

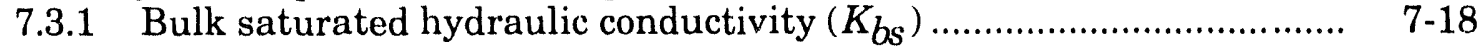

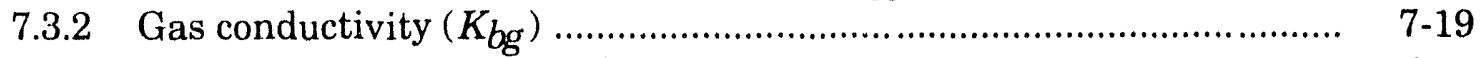

7.3.3 Analog bulk saturated hy raulic conductivity …….............................. $\quad 7-20$

$7.4 \quad$ F racture parameter development ………………........................................ $\quad$ 7-22

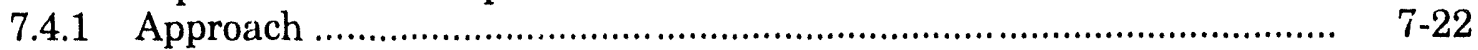

7.4.2 Available fracture data ................................................................. $\quad$ 7-23

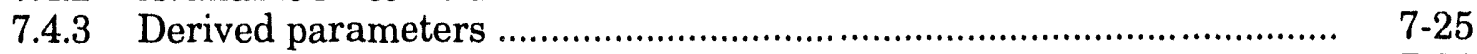

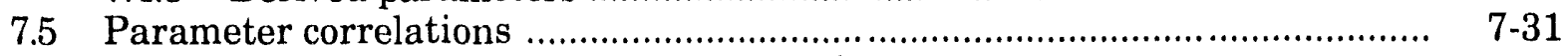

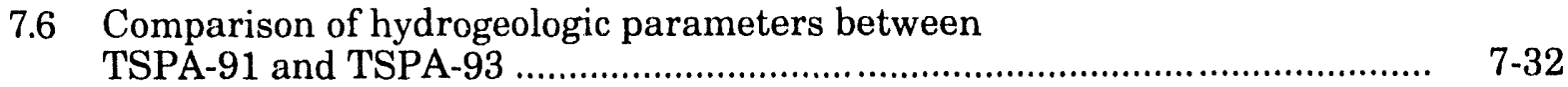

7.6.1 Matrix porosity ............................................................................... $\quad$ 7-33

7.6.2 Matrix saturated hydraulic conductivity ........................................... $\quad 7-34$

7.6.3 Water retention (van Genuchten) parameters ..................................... $\quad 7-35$

7.6.4 Fracture parameter comparisons ……………….............................. $\quad$ 7-36

Chapter 8 Infiltration and Percolation Rates ............................................................... 8-1

8.1 Definitions ...............................................................................................

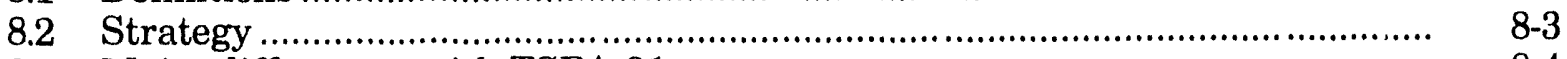

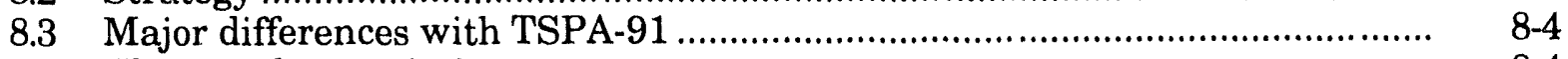

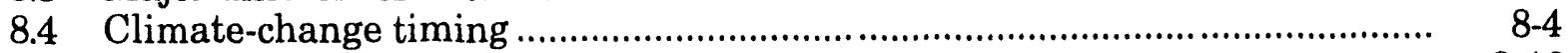

8.5 Infiltration rates for climate change ........................................................... 8 -

8.6 Dry-climate infiltration .......................................................................... $\quad 8-10$

8.7 Wet-climate infiltration ......................................................................... 8 8-11

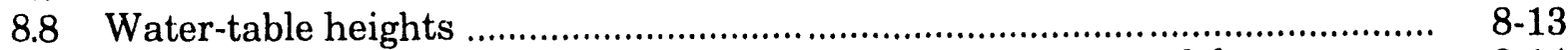

8.9 Infiltration versus percolation for the composite-porosity model .................... 8-14

Chapter 9 Geochemistry: Solubility and Sorption Parameters ................................... $9-1$

9.1 Elicitation method .......................................................................................

9.2 Solubility ............................................................................................

9.2.1 Assumptions ..............................................................................

9.2.2 Solubility values ....................................................................... 9

9.2.3 Correlations................................................................................... 9

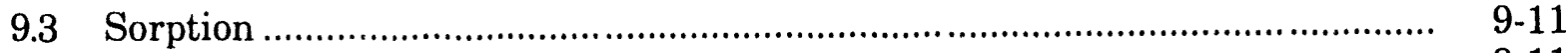

9.3.1 Assumptions ............................................................................... 9

9.3.2 Sorption coefficients ....................................................................... $9-12$

9.3.3 Correlations ............................................................................... 9

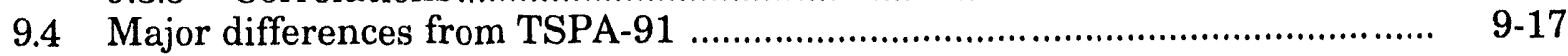

Part III: Detailed Modeling and Abstraction

Chapter 10 Thermal Effects ...................................................................................... 10-1

10.1 Important thermally driven processes ..................................................... 10-1

10.2 Abstracted hydrothermal model ............................................................... 10-3

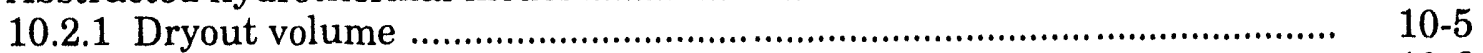

10.2.2 Dryout fraction ........................................................................ 10-6

10.2.3 Container-wall and fuel-rod temperature ........................................ $10-6$

10.3 Detailed thermal modeling ……............................................................... 10-6

10.3.1 Background on repository thermal design ....................................... 10-7

10.3.2 Thermal loading cases chosen for TSPA-93 …………..................... 10 10 
10.4 Implementation of conceptual hydrothermal model

$10-31$

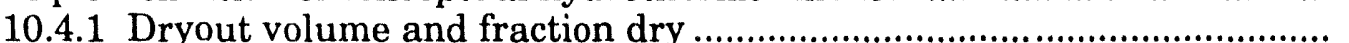

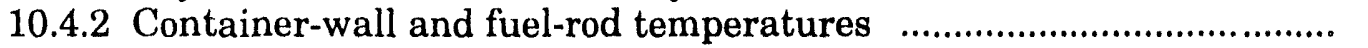

10.5 Conclusions

$10-31$

$10-35$

$10-36$

Chapter 11 Saturated-Zone Models …................................................................. 11-1

11.1 Three-dimensional geological model …................................................. $11-2$

11.1.1 Model thickness ............................................................................. 11-2

11.1.2 Model stratigraphy ....................................................................... 11-3

11.2 Calibration of the non-diversionary model ............................................ 11-3

11.3 Transport calculations using the non-diversionary model ............................ $11-9$

11.4 Calibration of the diversionary model .................................................... $11-13$

11.5 Transport calculations using the diversionary model ............................... 11-21

11.6 Abstraction of results for the TSA ..................................................... 11-27

11.6.1 Velocity and dispersivity ....................................................... 11-28

11.6.2 Transport area ................................................................... 11-35

11.6.3 Porosity, bulk density, and sorption coefficients .............................. 11-36

Chapter 12 Gaseous Flow and Transport ....................................................... 12-1

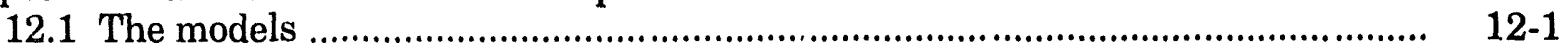

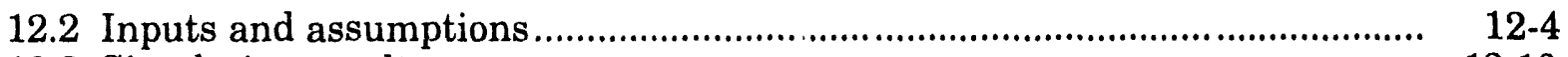

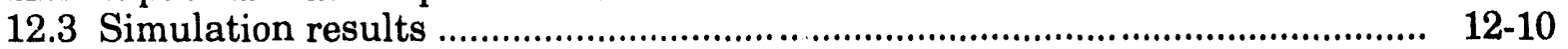

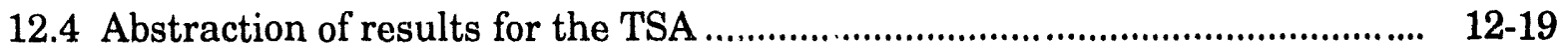

\section{Contents of Volume 2}

Part IV: Probabilistic Modeling and Results

Chapter 13 Source-Term Model.....

13.1 Functional description of the YMIM code

13.1.1 Comparison with TSPA-91 source term

13.2 Description of YMIM modules and model inputs .

13.2.1 Near-field hydrology

13.2.2 Near-field geochemistry

$13-1$

$13-1$

$13-3$

13-5

$13-6$

13.2.3 Temperature

13-7

13.2.4 Container failure

$13-7$

13.2.5 Kadionuclide properties

13-8

13.2.6 Internal-container flow

$13-16$

13.2.7 Waste-form dissolution

$13-17$

13-17

Chapter 14 Nominal-Case Releases: Composite-Porosity Model

14-1

14-1

14.1 Similarities to and differences from TSPA-91

14.1.1 Similarities

$14-2$

14.1.2 Differences

14-3

14.2 Dose calculation

14-4

14-6

$14-9$

14.4 Radionuclide source term

14-10

14.4.1 YMIM capabilities not used

14-11

14.4.2 Container groups

14-13 
14.5 Problem setup and parameter values ................................................ 14-16

14.5.1 Repository layout, column stratigraphies, and SZ flow tubes ........... 14-17

14.5.2 Dryout fraction and shedding volume ......................................... 14-21

14.5.3 Inputs for YMIM .................................................................. 14-27

14.5.4 Inputs for TOSPAC ….......................................................... 14-34

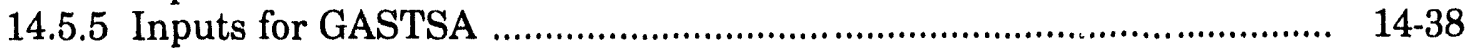

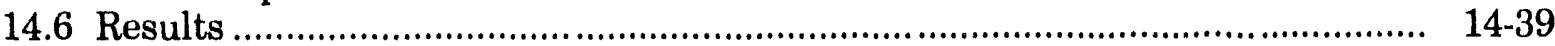

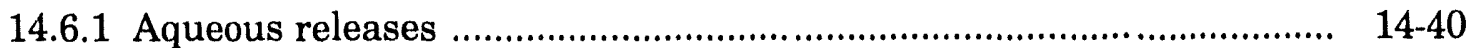

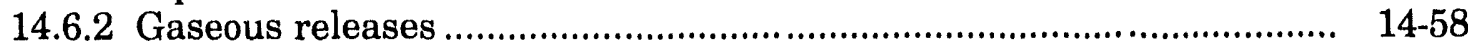

14.6.3 Parameter sensitivities .............................................................. 14-60

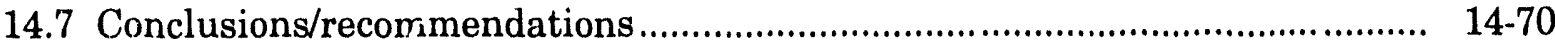

Chapter 15 Nominal-Case Releases: Weeps Model ….......................................... 15-1

15.1 Brief description of the weeps model ......................................................

15.2 Major differences with TSPA-91 …........................................................ 15-6

15.3 Incorporation of hydrothermal model and YMIM .................................. 15-7

15.3.1 YMIM implementation .................................................................. 15-8

15.3.2 Hydrothermal model implementation ............................................. $\quad 15-10$

15.4 Parameters ............................................................................................ 15-13

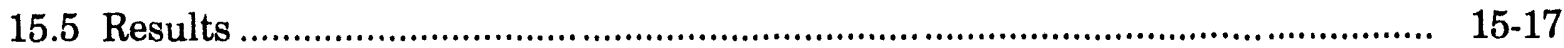

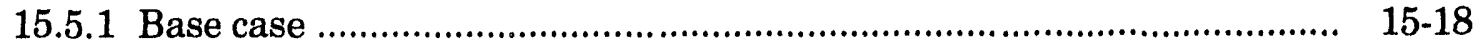

15.5.2 Comparison of the four repository cases .................................. 15-42

15.5.3 Thermal modeling sensitivities ................................................ 15-58

15.5.4 Parameter sensitivities .......................................................... 15-61

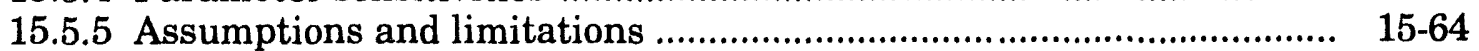

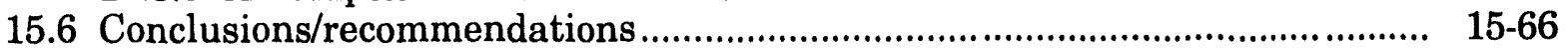

15.6.1 Site characterization ................................................................. 15-68

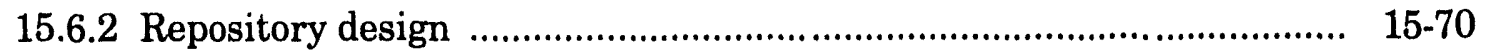

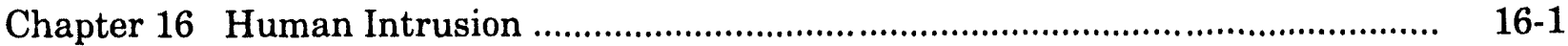

16.1 Parameter definition ............................................................................ 16-2

16.1.1 Probability of hitting a container ................................................. 16-2

16.1.2 Analysis parameters .................................................................. 16-4

16.1.3 Measurements of performance ....................................................... 16-6

16.2 Waste-container lifetime studies ......................................................... $16-7$

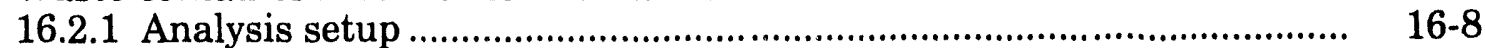

16.2.2 Lifetime predictions ............................................................... 16-10

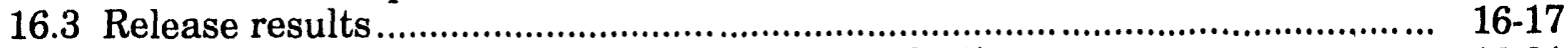

16.3.1 Results for borehole-emplacement, $57-\mathrm{kW} /$ acre case ......................... 16-21

16.3.2 Results for borehole-emplacement, 114-kW/acre case ...................... 16-25

16.3.3 Results for in-drift-emplacement cases .......................................... 16-26

16.4 Sensitivity studies .............................................................................. 16-29

16.4.1 Amount of waste released by a drilling hit .................................. 16-29

16.4.2 Size of drill bit ............................................................................. $\quad 16-30$

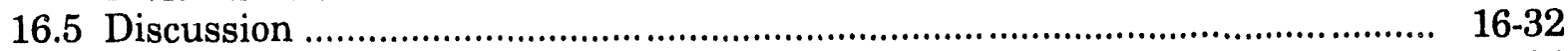

16.5.1 Lifetime studies .................................................................... 16-34

16.5.2 Drilling releases ...................................................................... 16-35

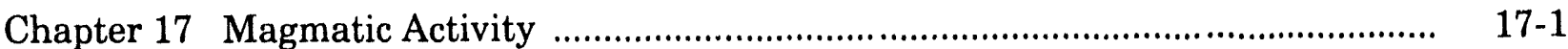

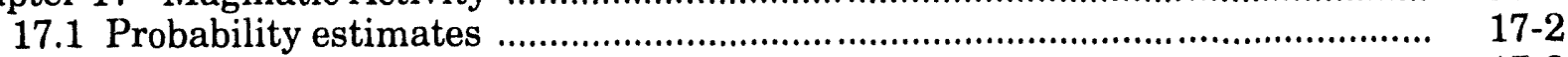

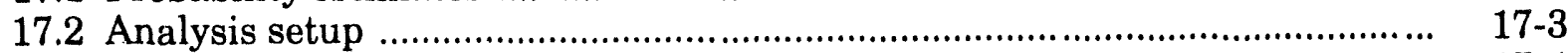

17.2.1 Calculation of temperature excursion .......................................... $17-4$

17.2.2 Dike-waste-package interactions ............................................... 17-7 
17.3 Results

Part V: Summary and Conclusions

Chapter 18 Discussion and Conclusions

18.1 Discussion of results .

18.1.1 Aqueous and gaseous releases based on composite-pornsity model....

18.1.2 Aqueous and gaseous releases based on weeps model....

18.1.3 Releases due to human intrusion

18-1

18-1

$18-1$

$18-2$

18-3

18.1.4 Releases due to magmatic activity

$18-4$

18.1.5 Supporting analyses

18.2 Comparison of results from the two flow models

18.3 Combination of CCDFs

18.4 Conclusions from the TSPA-93 study

18-5

$18-8$

18-12

$18-18$

Chapter 19 Recommendations

19-1

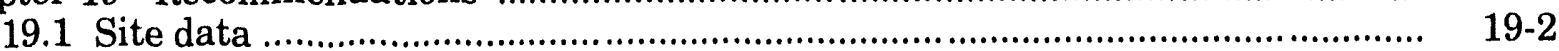

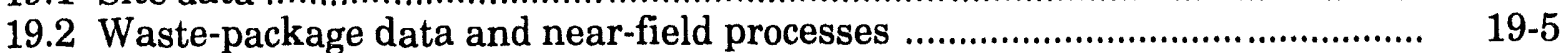

19.3 Repository and waste-package design ...................................................... 19-6

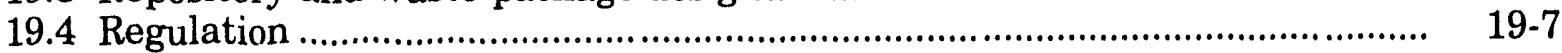

Chapter 20 Future TSPA Work ........................................................................ 20-1

20.1 General ...................................................................................... $20-1$

20.2 Thermal modeling …............................................................................ $20-2$

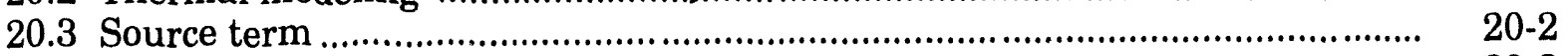

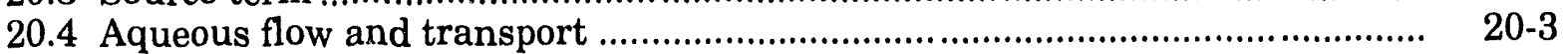

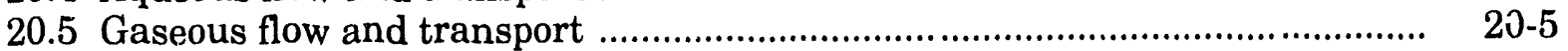

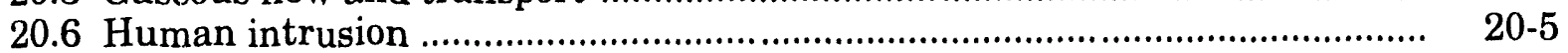

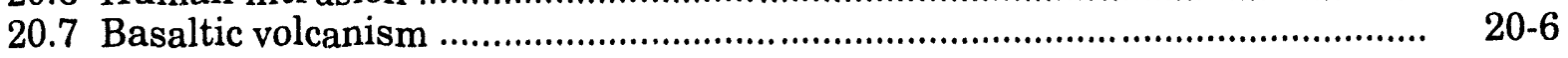

Part VI: Ancillary Calculations

Chapter 21 Barometric Pumping of Contaminated Gases Through

Unsaturated Fractured Rock

21-1

21.1 Repository geometry and rock properties ................................................ $21-3$

21.2 Conceptual model .................................................................................. $21-4$

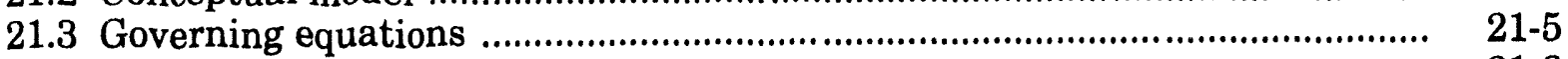

21.4 Numerical procedure .............................................................................. $21-8$

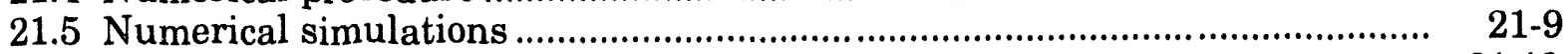

21.5.1 The baseline case ................................................................... 21-10

21.5.2 Comparison with Nevada Test Site experience ............................... 21-14

21.5.3 Retardation effects .................................................................. 21-16

21.6 Quasi-steady transport calculations ................................................. 21-16

21.7 Single-horizon models ......................................................................... $21-23$

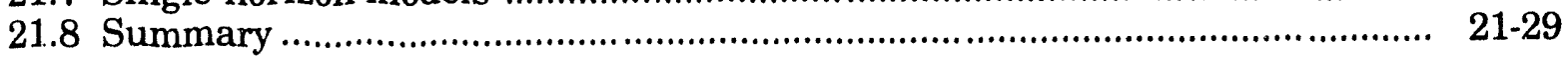

Chapter 22 Barometric Pumping of Moisture Through Unsaturated

Fractured Rock

$22-1$

$22-1$

22.1 Maximum moisture transport

22.2 Vertical background gradients

22.3 Problem formulation

$22-2$

$22-3$

22.3.1 Fracture model

22-5

22.3.2 Matrix model

22-6

22.3.3 Constitutive relations

$22-6$ 
22.3.4 Mixture relations and thermodynamics ......................................... $22-7$

22.3.5 The single-horizon approximation ............................................ $22-8$

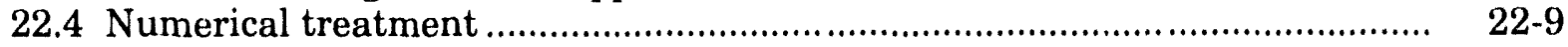

22.4.1 Test problems .............................................................................. 22-11

22.5 Barometric pumping of water vapor .................................................. $22-11$

22.5.1 Figures of merit and characteristic material functions ...................... 22-11

22.5.2 General features of the motion .................................................... 22-13

22.5.3 Factors controlling the net moisture respired .............................. 22-20

22.5.4 Effect of binary diffusion ........................................................ 22-21

22.5.5 Effect of matrix permeability ................................................... $22-24$

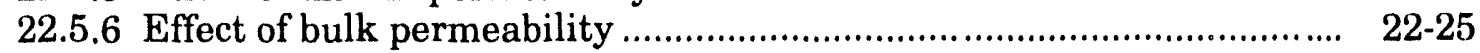

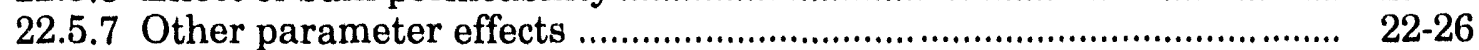

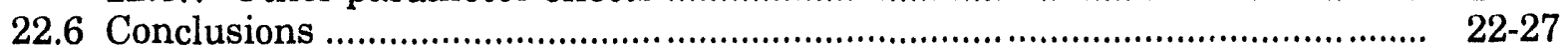

Chapter 23 Appropriateness of One-Dimensional Calculations ................................. 23-1

23.1 Effect of material heterogeneity ........................................................... $23-2$

23.1.1 Effect of low-conductivity obstructions on effective properties ........... 23-2

23.1.2 Effects of unsaturated fractures on effective material properties ................................................................................ 23-5

23.1.3 Effective conductivities for random material mixtures ....................... 23-6

23.2 Effect of boundary conditions on global-scale modeling ................................

23.2.1 Unit-gradient boundary conditions ................................................ $23-8$

23.3 Nonisotropic hydraulic conductivity effects ......................................... 23-12

23.3.1 Analytic model ........................................................................ 23-13

23.3.2 Numerical approach ................................................................ 23-13

23.3.3 Results of nonisotropic-hydraulic conductivity effects ..................... 23-15

23.4 Summary of one-dimensional appropriateness studies ............................. 23-16

Chapter 24 Effect of Fractures on Repository Dryout ......................................... 24-1

24.1 Problem description .......................................................................... $24-1$

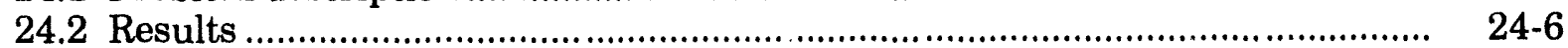

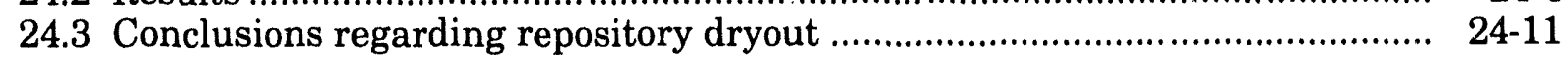

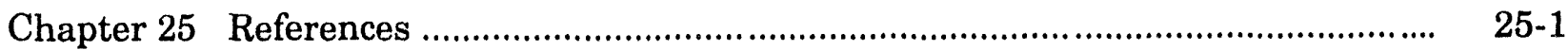

Appendix A TSPA-93 Column Stratigraphy …................................................ A-1

Appendix B Probability Distribution Functions for Solubility and Sorption .............. B-1

Appendix C Thermal Modeling Approaches ..................................................... C-1 


\section{Figures}

Page

1-1 Illustration of the purposes and users of iterative performance assessments

1-2 Elements of TSPA-93 analyses, showing chapters in report where they are discussed

2-1 Map showing location of Yucca Mountain region adjacent to the Nevada Test Site in southern Nevada.

2-2 Schematic cross section of the potential Yucca Mountain repository $\mathbf{r}^{-}$ion showing location of the repository horizon and static water table wit.s respest to the thermal/mechanical stratigraphic units defined by Ortiz et al. (1985)

Visualization of the potential Yucca Mountain repository and associated surface facilities

2-4 Release pathways arising from expected and unanticipated processes

2-5 Map of region surrounding the potential repository at Yucca Mountain; the area outside the shaded region is the accessible environment

3-3 Condensed FEP diagram for nominal flow in the presence

of a repository ....

Condensed FEP diagram for human intrusion

Flow chart showing computer programs used for calculation of nominal releases with the composite-porosity model

releases with the weeps model

Flow chart showing computer programs used for calculation of

Alternative repository layout based on tunnel-boring machine construction

Repository area for the $57-\mathrm{kW} /$ acre borehole emplacement case

6-1 Correlation between matrix porosity and matrix permeability for non-zeolitic welded and nonwelded tuffs from Yucca Mountain

6-2 Map showing locations of deep drillholes used in developing the simulated stratigraphic models and of the desired stratigraphic columns at Yucca Mountain 
6-3 Map showing the locations of the digitized cross sections used to develop the spatial continuity model of lithology

6-4 Sample variograms computed in the indicated directions from the digitized cross sections shown in Figure 6-3

6-5 Conceptual representation in two directions of the fitted, two-part nested variogram model: (a) plan view; (b) crosssectional view from west to east

6-6 Representative west-to-east cross section of Yucca Mountain illustrating the tendency of simulated welded and nonwelded lithologies to pinch and swell and to interfinger in a more complex fashion than is believed reasonable based on field observations .

6-7 Composite vertical profile of Yucca Mountain showing approximate correspondence of indicator lithologic categories used in TSPA-93 with the thermal/mechanical units of Ortiz et al. (1985) and formal geologic nomenclature as modified from Scott and Bonk (1984) Columns and associated areas for the 1139 -acre (57-kW/acre) repository model

6-9 Columns and associated areas for the 575-acre (114-kW/acre) repository model .....

6-10 Ten simplified stochastic realizations of stratigraphic column 1 extracted from the three-dimensional indicator simulations

6-11 Ten simplified stochastic realizations of stratigraphic column 2 extracted from the three-dimensional indicator simulations.

6-12 Ten simplified stochastic realizations of stratigraphic column 3 extracted from the three-dimensional indicator simulations

6-13 Ten simplified stochastic realizations of stratigraphic column 4 extracted from the three-dimensional indicator simulations

6-14 Ten simplified stochastic realizations of stratigraphic column 5 extracted from the three-dimensional indicator simulations

6-15 Ten simplified stochastic realizations of stratigraphic column 6 extracted from the three-dimensional indicator simulations

6-16 Ten simplified stochastic realizations of stratigraphic column 7 extracted from the three-dimensional indicator simulations....

6-17 Ten simplified stochastic realizations of stratigraphic column 8 extracted from the three-dimensional indicator simulations

6-18 Histograms summarizing the uncertainty associated with the upper contact of unit 5 at the location of (a) stratigraphic column 1 and (b) stratigraphic column 4

7-1 TSPA-93 unsaturated-zone hydrostratigraphy, from the top of the model domain to the water table.

Fit to limited data using the entropy-fit routine

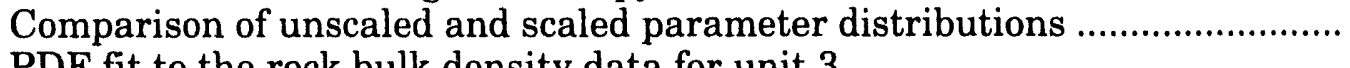

$7-12$

Log-transformed data and PDF for unit 2 ....

7-13

Distribution of fracture orientations for unit 5

7-26

PDF for fracture orientations for unit 5

$7-26$

Comparison of PDFs for matrix porosity in potential

repository horizon

7-34

Comparison of PDFs for matrix saturated hydraulic

conductivity in the potential repository horizon 
8-1 Overview of infiltration and percolation at Yucca Mountain, including definitions of terms used in Chapter 8

8-2 Oxygen isotope measurements made on two Indian Ocean cores by a CLIMAP research group showing size of the global ice sheets over the past half-million years

8-3 Oxygen isotope measurements made on ice core from central Greenland by a GRIP research group showing the average earth temperature over the past full glacial cycle

8-4 Distribution of northern-hemisphere ice sheets and modeled position of the jet stream.

8-5 Chronology of lake levels for Lake Lahontan, approximately $300 \mathrm{~km}$ northwest of Yucca Mountain

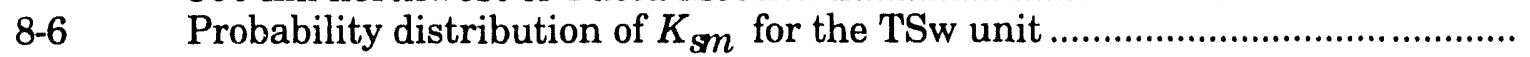

10-1 Possible thermally driven effects at a potential Yucca Mountain repository ....

10-3 Characteristics of double-blended waste stream for $21 / 40$ waste packages

10-5 Representation of unit cell to calculate LAPD; Heated drift length used to calculate design-basis areal power density

10-6 Isothermal plot for 5-m plane, 50 years following waste emplacement for the 114-kW/acre in-drift case.

10-7 Isothermal plot for 5-m plane, 50 years following waste emplacement for the $57-\mathrm{kW} /$ acre in-drift case

10-8 Isothermal plot for 5-m plane, 50 years following waste emplacement for the 114-kW/acre vertical-borehole case

10-9 Isothermal plot for 5-m plane, b0 years following waste emplacement for the $57-\mathrm{kW} / \mathrm{acre}$ vertical-borehole case ........................................................... Fraction dry calculated using V-TOUGH for 114-kW/acre case COYOTE and analytical waste-package surface temperatures for the 57-kW/acre, in-drift case

10-16 Composite container surface temperature for the 114-kW/acre, in-drift

10-17 Composite container surface temperature for the $57-\mathrm{kW} / \mathrm{acre}$, in-drift case

10-18 Composite container surface temperature for the 114-kW/acre, vertical-borehole case .

10-19 Composite container surface temperature for the 57-kW/acre, vertical-borehole case

Fuel-rod temperatures for the 114-kW/acre, vertical-borehole case 
11-1 Geologic units intercepted by the water table

11-2 A three-dimensional view of the Topopah Springs unit as constructed by translation

11-3 A schematic diagram showing the three-dimensional relationship among the potential repository, the stratigraphic units, and the major faults

11-4 The approximate location of the potential repository, Solitario Canyon Fault Zone, and Drill Hole Wash Fault Zone on the calculational grid of Figure 11-1 The revised potentiometric surface map from Ervin et al. (1993)

11-6 The potentiometric surface map based on calculated values of head for the case described in Table 11-2 ....

11-7 Approximate location of the 5-km fence at which breakthroughs are calculated

11-8 Locations of the three contaminant sources for transport calculations, shown as filled elements

11-9 Breakthrough curves along the 5- $\mathrm{km}$ fence for a source of unit concentration located at the water table in the Prow Pass

11-10 Breakthrough curves along the 5-km fence for a source of unit

11-11 Breakthrough curves along the 5- $\mathrm{km}$ fence for a source of unit concentration located at the water table in the Calico Hills .....

11-12 Concentration contours at the water table at 4,700 years for a continuous source of unit concentration, with retardation $=1$, located in the Prow Pass at the water table ....

11-13 Concentration contours at the water table at 4,700 years for a
continuous source of unit concentration, with retardation $=1$, located in the Bullfrog at the water table

Concentration contours at the water table at 4,700 years for a continuous source of unit concentration, with retardation $=1$, located in the Calico Hills at the water table

11-15 The potentiometric surface map based on calculated values of head for the case described in Table 11-4

11-16 Breakthrough curves along the 5-km fence for a source of unit concentration located at the water table in the Prow Pass

11-17 Breakthrough curves along the $5-\mathrm{km}$ fence for a source of unit concentration located at the water table in the Bullfrog

11-18 Breakthrough curves along the 5-km fence for a source of unit concentration located at the water table in the Calico Hills ....

11-19 Concentration contours at 4,700 years for a continuous source
of unit concentration, with retardation $=1$, located in the

Prow Pass at the water table

Distribution of effective velocities for Prow Pass source, no drain

Distribution of effective velocities for Bullfrog source, no drain

Distribution of effective velocities for Calico Hills source, no drain.................

Distribution of effective velocities for Prow Pass source, with drain ..............

Distribution of effective velocities for Bullfrog source, with drain ..................

Distribution of effective velocities for Calico Hills source, with drain ............

Comparison of SZ transport times for TSPA-91 and TSPA-93

$11-29$

$11-30$

$11-30$

$11-31$

$11-31$

$11-32$

11-34

12-1 Retardation factor as a function of temperature for the modeled units

Repository layout used for gas-flow calculations. 
12-4 Finite-difference mesh for cross section N765000

12-5a Retarded travel times of ${ }^{14} \mathrm{C}$ particles from the repository to the atmosphere for particles released at 1,000 years. Welded-tuff bulk permeability of $10^{-11} \mathrm{~m}^{2}$

12-5b Retarded travel times of ${ }^{14} \mathrm{C}$ particles from the repository to the atmosphere for particles released at 5,000 years. Welded-tuff bulk permeability of $10^{-11} \mathrm{~m}^{2}$.

12-5c Retarded travel times of ${ }^{14} \mathrm{C}$ particles from the repository to the atmosphere for particles released at 10,000 years. Welded-tuff bulk permeability of $10^{-11} \mathrm{~m}^{2}$.

12-5d Retarded travel times of ${ }^{14} \mathrm{C}$ particles from the repository to the atmosphere for particles released at 15,000 years. Welded-tuff bulk permeability of $10^{-11} \mathrm{~m}^{2}$

12-6a Calculated temperature field $\left({ }^{\circ} \mathrm{C}\right)$ at 1,000 years for cross section N765000. Welded-tuff bulk permeability of $10^{-11} \mathrm{~m}^{2}$.

12-6b Caiculated temperature field $\left({ }^{\circ} \mathrm{C}\right)$ at 5,000 years for cross section N765000. Welded-tuff bulk permeability of $10^{-11} \mathrm{~m}^{2}$

12-6c Calculated temperature field $\left({ }^{\circ} \mathrm{C}\right)$ at 10,000 years for cross section N765000. Welded-tuff bulk permeability of $10^{-11} \mathrm{~m}^{2}$

12-6d Calculated temperature field $\left({ }^{\circ} \mathrm{C}\right)$ at 15,000 years for cross section N765000. Welded-tuff bulk permeability of $10^{-11} \mathrm{~m}^{2}$ Calculated gas-flow field at 5,000 years for cross section N765000.

12-7a Calculated gas-flow field at 5,000 years for
Welded-tuff bulk permeability of $10^{-11} \mathrm{~m}^{2}$

12-7b Calculated gas-flow field at 10,000 years for cross section N765000. Welded-tuff bulk permeability of $10^{-11} \mathrm{~m}^{2}$

12-7c Calculated gas-flow field at 15,000 years for cross section N765000. Welded-tuff bulk permeability of $10^{-11} \mathrm{~m}^{2}$

12-8a Retarded travel times of ${ }^{14} \mathrm{C}$ particles from the repository to the atmosphere for particles released at 2,000 years. Welded-tuff bulk permeability of $10^{-12} \mathrm{~m}^{2}$.

12-8b Retarded travel times of ${ }^{14} \mathrm{C}$ particles from the repository to the atmosphere for particles released at 5,000 years. Welded-tuff bulk permeability of $10^{-12} \mathrm{~m}^{2}$.

12-8c Retarded travel times of ${ }^{14} \mathrm{C}$ particles from the repository to the atmosphere for particles released at 10,000 years. Welded-tuff bulk permeability of $10^{-12} \mathrm{~m}^{2}$.

12-9 ${ }^{14} \mathrm{C}$ travel times for welded-tuff permeability of $10^{-12} \mathrm{~m}^{2}$ compared to ${ }^{14} \mathrm{C}$ travel times for welded-tuff permeability of $10^{-11} \mathrm{~m}^{2}$

12-10 Comparison of retardation/permeability factor for TSPA-91 and TSPA-93

12-11 ${ }^{14} \mathrm{C}$ travel-time distributions for TSPA-91

12-12 $\quad{ }^{14} \mathrm{C}$ travel-time distributions for TSPA-93 $12-23$

${ }^{14} \mathrm{C}$ travel-time distributions for steady-state gas flow, with welded-tuff permeability of $10^{-11} \mathrm{~m}^{2}$ and nonwelded permeability of $10^{-12} \mathrm{~m}^{2}$

13-1 Functional structure of the YMIM model 
14-1 Distributions of UZ transport time for an unretarded tracer, for TSPA-91 and TSPA-93

Shedding-volume curves for $57 \mathrm{~kW} / \mathrm{acre}$, in-drift emplacement

Shedding-volume curves for $114 \mathrm{~kW} / \mathrm{acre}$, in-drift emplacement

14-26

Neptunium-solubility distributions for TSPA-91 and TSPA-93

14-29

CCDFs for individual columns, plus the combination CCDF ...

$14-42$

$14-18$

CCDFs of normalized cumulative aqueous release over 10,000 years

for the four cases and for TSPA-91

$14-43$

14-19 Comparison of normalized cumulative aqueous release over

10,000 years for TSPA-91, TSPA-93, and a test case in which

percolation flux is the same as for TSPA-91 but everything else

is the same as for TSPA-93

14-20 CCDFs of normalized cumulative aqueous release over 10,000 years, divided into two parts: one part with a climate change within the period and the other part with no climate change within the period

14-21 CCDFs of peak individual drinking-water dose rate over 1,000,000 years for the four cases.

14-22 Mean distributions of container-failure time for the four repository cases and for TSPA-91

Distributions of potential dilution factor for dry and wet climates

14-23

$14-24$

14-25 CCDFs of normalized cumulative aqueous release over 10,000 years with fluctuating water table and with fixed water table with fluctuating water table and with fixed water table

Distributions of time of peak individual drinking-water dose rate

for the four cases.

CCDFs for normalized cumulative aqueous release over 10,000 years

from the EBS, from the unsaturated zone, and to the accessible environment ( $57 \mathrm{~kW} /$ acre, vertical emplacement)

14-29b CCDFs for normalized cumulative aqueous release over 100,000 years

from the EBS, from the unsaturated zone, and to the accessible environment ( $57 \mathrm{~kW} /$ acre, vertical emplacement)

14-29c CCDFs for normalized cumulative aqueous release over $1,000,000$ years from the EBS, from the unsaturated zone, and to the accessible environment ( $57 \mathrm{~kW} /$ acre, vertical emplacement) 
14-30 CCDH's of normalized cumulative gaseous release over 10,000 years for the four cases and for TSPA-91....

14-31 CCDFs of normalized cumulative gaseous release from the EBS over 10,000 years for the four cases and for TSPA-91

14-32 CCDFs of normalized cumulative nominal release over 10,000 years for the four cases and for TSPA-91

14-33 Scatter plot of normalized cumulative aqueous release over 10,000 years vs. "dry" percolation flux

Scatter plot of normalized cumulative aqueous release over

14-34 Scatter plot of normalized cumulative aqu

14-35 Scatter plot of peak individual drinking-water dose rate over

Scatter plot of peak individual drinking-water dose rate over

$1,000,000$ years vs. "dry" percolation flux

14-37 Scatter plot of peak individual drinking-water dose rate over

$1,000,000$ years vs. TSw matrix saturated conductivity

$14-65$

$14-65$

14-38 Scatter plot of peak individual drinking-water dose rate over

$14-66$

14-39 Scatter plot of peak individual drinking-water dose rate over $1,000,000$ years vs. neptunium solubility

14-40 Scatter plot of normalized cumulative gaseous release over 10,000 years vs. TSw matrix saturated conductivity

14-41 Scatter plot of normalized cumulative gaseous release over 10,000 years vs. $100^{\circ} \mathrm{C}$ pitting increment

14-42 Scatter plot of normalized cumulative gaseous release over 10,000 years vs. "dry" percolation flux

14-43 Scatter plot of normalized cumulative gaseous release over 10,000 years vs. TSw bulk permeability

14-44 Mean distributions of container-failure time for some alternative two-walled containers

15-1 Overview of potential weep flow through the unsaturated zone at Yucca

Mountain.

15-2 Illustration of adjacent containers, one contacted by a weep and suffering degradation, the other not contacted and remaining intact

15-3 Overview of the method used by the weeps model to calculate probability of a weep contacting a container

15-4 Container numbering scheme used by the weeps model for determining container-wall and fuel-rod temperatures

15-5 Illustration of flow-pattern changes calculated by the weeps model when the dryout zone is expanding

15-6 Illustration of flow-pattern changes calculated by the weeps model when the dryout zone is contracting.

15-7 Calculation of the area in which a weep can intercept a container $\left(A_{\text {contact }}\right)$.

15-8 Layout of the one-dimensional flow tube used to describe the saturated zone for a weeps-model calculation

15-9 Overview of a typical realization of the weeps model for a 57-kW/acre repository with vertically emplaced containers

15-10 Distribution of containers contacted by weeps over a 1,000,000-year period

15-11 Distribution of containers that have aqueous releases of radionuclides over a 1,000,000-year period 
15-12 Distribution of initial times at which containers have aqueous releases of radionuclides

15-13 Distribution of containers that experience corrosion-induced failure over a $1,000,060$-year period

15-14 Distribution of juvenile failures specified as an input parameter .................

15-15 Distribution of the ratio of aqueous-releasing containers that experience corrosion-induced failures to all aqueous-releasing containers over a 1,000,000-year period

15-17 Distribution of the durations that weeps contact containers before corrosion-induced failure occurs Conditional CCDFs of cumulative aqueous releases to the accessible environment, normalized by the EPA limits

15-20 Conditional CCDFs of cumulative aqueous releases to the accessible environment, at 10,000 years, normalized by the EPA limits, for specified radionuclides and their combination

15-21 Conditional CCDFs of cumulative aqueous releases from the EBS, normalized by the EPA limits

15-22 Conditional CCDFs of cumulative aqueous releases from the EBS, at 10,000 years, normalized by the EPA limits, for specified radionuclides and their combination

Conditional CCDFs of peak radiation doses from drinking water to a maximally exposed individual

Conditional CCDFs of peak radiation doses from drinking water to a maximally exposed individual, for specified radionuclides and their combination

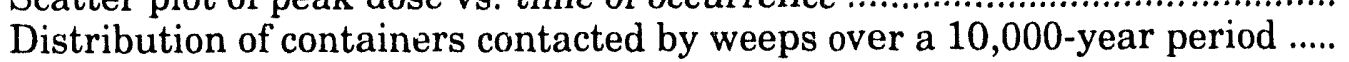

Distribution of containers that have gaseous releases of radionuclides over a 10,000-year period....

Distribution of initial times at which containers have gaseous releases of radionuclides

15-30 Distribution of containers that experience corrosion-induced failure over a 10,000-year period

Conditional CCDFs of cumulative gaseous releases to the accessible

15-32 Coleases to the accessible environment, at 10,000 years, normalized by the EPA limits

Comparison of the distributions of containers contacted by weeps over a 1,000,000-year period, for the four repository cases

15-34 Comparison of the distributions of containers that have aqueous releases of radionuclides over a 1,000,000-year period, for the four repository cases .15-44

15-35 Comparison of the distributions of initial times at which containers have aqueous releases of radionuclides, for the four repository cases

15-36 Comparison of the distributions of containers that experience corrosioninduced failure over a 1,000,000-year period, for the four repository cases .. 15-46

15-37 Comparison of the distributions of the times of corrosion-induced failures for the four repository cases

15-38 Comparison of the distributions of the durations that weeps contact containers before corrosion-induced failure occurs, for the rour repository cases 
15-39 Comparison of the distributions of the total durations that weeps

contact containers, for the four repository cases

$15-49$

15-40 Comparison of the conditional CCDFs of cumulative aqueous releases to the accessible environment, at 10,000 years, normalized by the

EPA limits, for the four repository cases

15-41 Comparison of the conditional CCDFs of cumulative aqueous releases from the EBS, at 10,000 years, normalized by the EPA limits, for the four repository cases

15-42 Comparison of the conditional CCDFs of peak radiation doses from drinking water to a maximally exposed individual, for the four repository cases

15-43 Comparison of the conditional CCDFs of the times of peak radiation doses for the four repository cases

15-44 Comparison of the distributions of containers contacted by weeps over a 10,000-year period, for the four repository cases

15-45 Comparison of the distributions of containers that have gaseous releases of radionuclides over a 10,000-year period, for the four repository cases ......

15-46 Comparison of the distributions of initial times at which containers have gaseous releases of radionuclides, for the four repository cases ...

15-47 Comparison of the distributions of containers that experience corrosionComparison of the conditional CCDFs of cumulative gaseous releases to the accessible environment, at 10,000 years, normalized by the EPA limits, for the four repository cases Comparison of the combined conditional CCDFs of cumulative aqueous and gaseous releases to the accessible environment, at 10,000 years, normalized by the EPA limits, for the four repository cases Comparison of the conditional CCDFs of cumulative aqueous releases to the accessible environment, at 10,000 years, normalized by the EPA limits, for the four repository cases

16-1 Possible orientations of drill and in-drift HLW containers

Standardized container-wetting conditions used

for lifetime studies.

Air-oxidation rates for alloy 825 and carbon steel

Container failure profile for $50 \%$ container wetting conditions

Container failure profile for $50 \%$ container wetting conditions

Container failure profile for $20 \%$ container wetting conditions

Range of container failures for $57-\mathrm{kW} / \mathrm{acre}$, borehole case

$16-8$

Range of container failures for $114-\mathrm{kW} /$ acre, borehole case

$16-9$

Range of container failures for $57-\mathrm{kW} / \mathrm{acre}$, in-drift case

$16-14$

$16-15$

Range of container failures for 114-kW/acre, in-drift case

$16-16$

Nonlinear entropy fit to histogram of releases ....

$16-16$

$16-11$

$16-12$

Mean values of release peaks for times to $1,000,000$ years

$16-17$

$16-18$

$16-13$

Contributions to releases from components of source term

for 57-kW/acre borehole case

$16-22$

16-14 Conditional CCDFs for 10,000-year cumulative releases after various

starting times for $57-\mathrm{kW} /$ acre borehole case ....

$16-23$

Conditional CCDFs for cumulative releases over $1,000,000$

16-15

years for $57-\mathrm{kW} /$ acre borehole case

$16-23$

16-16

$16-17$

Comparison of CCDFs for similar TSPA-91 and TSPA-93 analyses

$16-24$

Conditional CCDF for releases for 114-kW/acre, borehole case

$16-25$

16-18

Conditional CCDF for cumulative releases over 1,000,000

years for 114-kW/acre, borehole case 
16-19 Contributions to releases from components of source term

for 114-kW/acre, in-drift case

16-20 Conditional CCDF for 10,000-year releases for the two

in-drift cases

16-21 Conditional CCDFs for cumulative releases over 1,000,000

years for $57-\mathrm{kW} /$ acre, in-drift case

$16-27$

Conditional CCDF for cumulative releases over $1,000,000$

$16-22$

years for 114-kW/acre, in-drift case

$16-28$

Alternative distribution of waste released from in-drift waste package .........

$16-23$

$16-24$

Comparison of 10,000-year CCDFs for two assumptions for distributions

of waste-package releases

16-29

$16-30$

16-25 Comparison of 1,000,000-year CCDFs for two assumptions

for distributions of waste-package releases

$16-31$

$16-26$

16-27

Comparison of CCDFs for two drill-bit diameters

$16-31$

Comparison of CCDFs for different drill-bit diameters

$16-33$

$16-28$

Container lifetime profile for low corrosion rate assumption

$16-33$

$16-35$

17-1 Interaction between waste packages and magmatic intrusion

17-1

17-2 Time-temperature surface for rock temperatures adjacent

to a 0.75 -m (half-width) dike.

17-3 Time-temperature surface for rock temperatures adjacent

to a 2.25 -m (half-width) dike

17-6

$17-4$

Distribution of dike widths

$17-6$

$17-5$

Distribution of dike orientations

$17-8$

Examples of dikes crossing drifts for $57-\mathrm{kW} /$ acre repository area

$17-7$

Dike-induced temperature excursion for $57-\mathrm{kW} /$ acre repository ...

$17-8$

$17-9$

$17-8$

$17-9$

Dike-induced temperature excursion for $114-\mathrm{kW} /$ acre repository

Comparison of rock-temperature excursions for a dike in host rock

at $50^{\circ} \mathrm{C}$ and $500^{\circ} \mathrm{C}$ ambient temperatures

$17-10$

17-10 Cumulative releases to the accessible environment, with magmatic intrusion

$17-11$

Releases due to magmatic intrusion

17-10

$17-12$

Releases due to magmatic intrusion

$17-16$

$17-16$

$17-18$

$17-13$

Comparison of direct and indirect releases over 10,000 years ....

$17-19$

$17-14$

$17-15$

Releases due to magmatic intrusion scaled by probability of occurrence.....

$17-16$

Releases due to magmatic intrusion, scaled by probability of occurrence ......

Comparison of peak doses with and without magmatic intrusion

$17-19$

$17-20$

$17-21$

18-1 CCDFs of normalized cumulative release over 10,000 years for nominal aqueous releases

18-2 CCDFs of normalized cumulative release over 10,000 years for nominal

gaseous releases

$18-3$

aqueous releases

$18-4$

CCDFs of peak individual drinking-water dose over $1,000,000$ years for nominal aqueous releases

$18-5$

Distribution of time of peak dose for nominal aqueous releases

18-6 Combination of nominal and human-intrusion CCDFs.

Composite-porosity model used for UZ flow and transport

18-7 Combination of nominal and human-intrusion CCDFs.

Weeps model used for UZ flow and transport

18-8 Combination of nominal and human-intrusion CCDFs.

Weeps model used for UZ flow and transport

$18-10$

$18-10$

18-11

18-12

$18-14$

18-14

18-15 
18-9 Combination of nominal and human-intrusion CCDFs.

Composite-porosity model used for UZ flow and transport

$18-16$

18-10 Combination of nominal and human-intrusion CCDFs.

Weeps model used for UZ flow and transport ....

$18-16$

18-11 CCDFs of normalized cumulative release over 10,000 years.

Composite-porosity model used for UZ flow and transport ......

18-12 CCDFs of normalized cumulative release over 10,000 years.

Weeps model used for UZ flow and transport

$18-17$

21-1

21-2

21-3

$21-4$

21-5

21-6

21-7

Schematic of barometric pumping in a fractured permeable medium

21-2

Schematic of proposed Yucca Mountain repository

21-4

Concentration profiles for typical Yucca Mountain parameters

$21-11$

Normalized outflows for typical Yucca Mountain parameters

21-12

Concentration profiles for typical Nevada Test Site parameters

21-15

Normalized outflows for typical Nevada Test Site parameters

$21-15$

Concentration profiles for typical Nevada Test Site parameters

with retardation

$21-17$

21-8 Normalized outflows for typical Nevada Test Site parameters

with retardation

21-9 Concentration profiles for quasi-steady analysis with typical

Yucca Mountain parameters

21-10 Normalized outflows for quasi-steady analysis with typical

Yucca Mountain parameters

Influence of retardation factor on quasi-steady outflow

of contaminant

21-12

Influence of matrix permeability on quasi-steady outflow

of contaminant

$21-13$

21-14

Influence of fracture spacing on quasi-steady contaminant outflow

21-17

Influence of diffusion strength of quasi-steady contaminant outflow

21-15

21-16

Comparison of analytical and numerical solutions for

quasi-steady contaminant transport through a uniform

gradient in a semi-infinite medium

$21-25$

Comparison of single-horizon model with numerical calculations

which take account of finite height and nonuniform gradients

21-17 Concentration histories at three elevations for $\Delta \mathrm{L} / \mathrm{L}=1 / 2$

21-18 Concentration profiles at various times during typical cycle

with $\Delta \mathrm{L} / \mathrm{L}=1 / 2$

21-19

Concentration histories at three elevations for $\Delta \mathrm{L} / \mathrm{L}=2$

$21-20$

Concentration profiles at various times during typical cycle

with $\Delta \mathrm{L} / \mathrm{L}=2$

22-1 Conceptual model of the fractured permeable medium

Profiles of capillary pressure in the matrix during a 5-day

barometric cycle

22-4 Profiles of vapor mass fraction in the matrix during a 5-day

barometric cycle

Profiles of gas mass flux in the matrix during a 5-day

barometric cycle

$22-15$

$22-5$

$22-6$

Profiles of liquid mass flux in the matrix during a 5-day

barometric cycle

22-7 Profiles of vapor mass flux in the matrix during a 5-day barometric cycle 
22-8 Profiles of moisture (liquid and vapor) mass flux in the matrix during a 5-day barometric cycle

22-9 Gas displacement in the fracture as a function of diffusive strength and matrix permeability

Net annual outflow of moisture as a function of diffusive strength and matrix permeability

Illustration of time-phase shifts and

with respect to diffusive strength

22-12 Gas displacement and net annual outflow as function of matrix permeability

22-13 Gas displacement and annual net outflow as a function of fracture spacing

23-1 (a) Nonhomogeneous material concept, (b) assumed idealized symmetric array, and (c) numerical mesh

23-2 Material hydraulic conductivity

23-3 Nondimensional fluxes for three geometric configurations

23-4 (a) Schematic of the periodic global fracture/matrix system,

(b) repi esentative unit cell of the periodic fracture model

23-5 Flow path lines for material mixes: (a) $25 \%$, (i) $50 \%$, and (c) $75 \%$

23-6 Two-dimensional computational domain

23-7 Darcy velocity vectors, using unit-gradient boundary conditions, $q=0.01 \mathrm{~mm} / \mathrm{yr}$

23-8 Darcy velocity vectors, using no-flow boundary conditions, $\mathrm{q}=0.01 \mathrm{~mm} / \mathrm{yr}$....

23-9 Particle path lines, $0.01 \mathrm{~mm} / \mathrm{yr}$.

$23-3$

23-4

23-6

23-7

23-9

23-10

Problem geometry and numerical boundary conditions

23-11 Hydraulic conductivity ratio as a function of boundary capillary pressure for an average of eleven realizations, downdip $=10$ degrees

23-12 Hydraulic conductivity ratio as a function of capillary pressure for an average of eleven realizations, $\operatorname{dip}=70$ degrees

24-1 Two-dimensional axisymmetric geometry of repository and surrounding geologic media for 114-kW/acre, 30-yr-old fuel, Buscheck and Nitao (1993)

24-2 (a) One-dimensional approximation to repository and surrounding layered geologic media (b) Initial temperature and saturation profiles .........

24-3 Vertical liquid saturation profiles along the repository centerline, 30-yr-old SNF, $114 \mathrm{~kW} /$ acre

24-4 Vertical temperature profiles along the repository centerline, 30-yr-old SNF, $114 \mathrm{~kW} /$ acre

24-5 Vertical liquid saturation profiles along the repository centerline for 30-yr-old SNF, $114 \mathrm{~kW} / \mathrm{acre}, \mathrm{t}=0,100,600$, and $10,000 \mathrm{yr}$

24-6 Vertical liquid saturation profiles along the repository centerline for 30 -yr-old SNF, $114 \mathrm{~kW} / \mathrm{t}=0,100,600$, and 10,000 yr

$24-4$

24-7

24-8

$24-7$

Vertical extent of dryout as a function of fracture permeability

$24-9$

24-8 Vertical extent of perched water above the repository as a function of permeability ....

24-9 Permeability as a function of capillary pressure, TSw2 


\section{Tables}

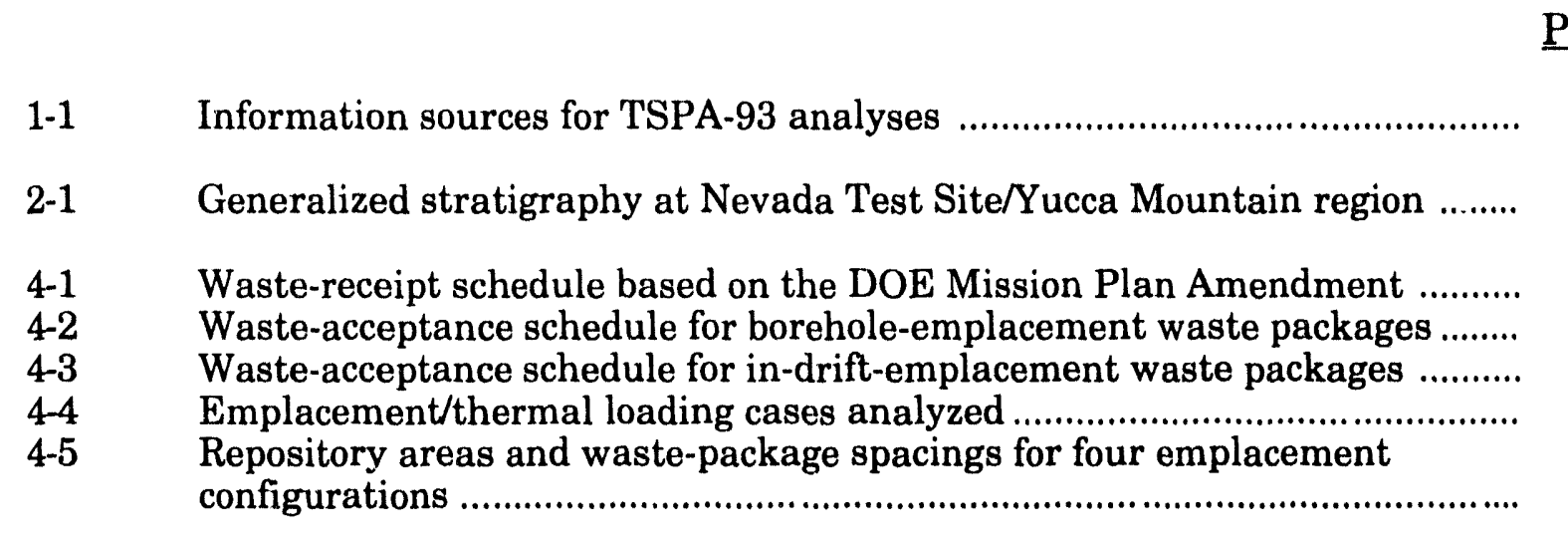

Page

5-1

5-2

5-3

$5-4$

$5-5$

Weighted-average age and burnup of spent fuel Spent-fuel inventory and characteristics Description of reactor fuel assemblies Numbers of fuel rods per package Fuel rod parameters Sources of high-level waste HLW waste stream used for TSPA analyses Comparison of HLW inventories at two burnups High-level waste radionuclides with EPA limits not included in TSPA inventory

Combined (spent-fuel and high-level waste) inventory

Radionuclides and modified inventories used for aqueous and gaseous analyses Rock bulk density statistics, and beta and scaled beta distribution parameters and scaled beta probability distribution parameters

Matrix air-entry parameter entropy fit parameters, and scaled beta-distribution parameters 
7-7b Matrix saturation/desaturation entropy fit, and scaled

beta-distribution parameters

7-8 Matrix residual degree of saturation statistics, and beta

and scaled beta distribution parameters

7-9a Bulk saturated hydraulic conductivity basic statistics and $\log _{10}$ statistics .. 7-18

$7-9 b$

Bulk saturated hydraulic conductivity probability-distribution

parameters from an entropy fit

7-10a Barometric pumping statistics expressed as bulk conductivities for units 2 and 3

7-10b Barometric pumping beta probability distribution parameters from an entropy fit.

7-11 Hydrogeologic unit matrix, bulk-hydraulic, and fracture parameters comparison for analog bulk saturated hydraulic conductivity

Bulk saturated hydraulic conductivity parameters for units 1,4 , and 5

Summary of $K_{b s}$ parameters

Fracture frequency statistics and beta distribution approximation of the exponential

Analog units used for fracture orientation missing units

Fracture angle/orientation statistics and beta-distribution parameters

Hydraulic aperture statistics and beta-distribution parameters ...

7-20 Fracture hydraulic conductivity statistics, $\log _{10}$ statistics, and beta distribution parameters ....

Fracture air-entry parameter basic statistics and beta-

7-23 Corresponding hydrogeologic units in TSPA-91 and TSPA-93....

7-24 Comparison of expected values for matrix-porosity between

TSPA-91 and TSPA-93

Comparison of expected values for matrix saturated hydraulic

Comparison of expected values for matrix air-entry between

7-26 Comparison of expected
TSPA-93 and TSPA-91

7-27 Comparison of expected values for matrix saturation/desaturation between TSPA-93 and TSPA-91

7-28 Comparison of matrix residual saturation expected values between TSPA-93 and TSPA-91

Comparison of expected values for fracture parameters between

8-1. Distributions used for climate/percolation parameters 
10-1 Summary of thermal loading cases examined in TSPA-93 .

11-1 Parameters and boundary conditions used for calibration, non-diversionary model

11-2 Comparison of calculated heads to data for heads measured in various wells

11-3 The fit of calculated heads to data for the diversionary model without Solitario Canyon and Drill Hole Wash faults

The fit of calculated heads to data for the diversionary model with Solitario Canyon and Drill Hole Wash faults

Parameters and boundary conditions used for calibration

diversionary model

Total-body dose-conversion factors for ingestion

Number of containers in each column....

Summary of radionuclide properties

Summary of physical dimensions and geochemistry....

Summary of parameters for container and fuel-rod failure 
15-3 Parameters used by the weeps model for calculating saturatedzone flow

15-4 Weeps-model mean releases and doses in relation to total

$15-16$

$15-5$

Parameters important to weeps-model aqueous EPA releases

15-6 Parameters important to weeps-model aqueous peak doses

15-7 Parameters important to weeps-model gaseous EPA releases

$15-36$

$15-61$

$15-63$

16-1 Drilling analysis probabilities and parameters .

$16-3$

$16-2$

Repository-related parameters for drilling analyses .

$16-4$

Source-term parameters for drilling analyses ....

16-5

Times to cool to $100^{\circ} \mathrm{C}$ and $70^{\circ} \mathrm{C}$ for various analysis cases ......................... 16-9

$16-4$

Range of container failure times

$16-15$

$16-6$

Scaling factors for 1,000,000-year releases

$16-19$

$16-7$

Probabilities of hits for 0.21 -m drill bit diameter

$16-32$

$16-8$

Waste-package failure times for various analysis cases

$16-34$

17-1 Probabilities of occurrence for magmatic events ...................................... 17-3

17-2 Thermal properties of tuff and dike ..................................................... 17-7

17-3 Container half-spacings and range of distances from dikes ........................... 17-11

17-4 Magma-induced sulfidation rates used for TSPA-93...

$\begin{array}{ll}\text { 17-5 } & \text { Fractions of undistributed releases at various probability levels } \\ 17-6 & \text { Fractions of undistributed releases at various probability levels }\end{array}$

$17-13$

$17-6$

$17-17$

$17-17$

21-1 Parameters used in base case calculation of contaminant

transport at Yucca Mountain

22-1 Standard problem parameters, $k_{b}=10 \mathrm{D}$

$22-13$

23-1 Material properties

23-10

24-1

24-2

Material matrix properties

24-5

24-3

Fracture properties for all units

24-5

Parametric variation in material properties

24-6 
(This page left intentionally blank)

xxviii 


\section{Executive Summary}

\section{Introduction}

Yucca Mountain is being investigated by the U.S. Department of Energy (DOE) as the potential site for the permanent disposal of spent fuel from nuclear reactors and highlevel radioactive waste generated by the U.S. Department of Defense. Yucca Mountain is located in a sparsely populated, arid region of the U.S., approximately $120 \mathrm{~km}$ northwest of Las Vegas, Nevada, on the border of the DOE's Nevada Test Site. To take advantage of less groundwater, a potential repository at the site would be mined in the unsaturated zone of the mountain, about $300 \mathrm{~m}$ below the surface, but over $200 \mathrm{~m}$ above the water table (Figure ES-1).

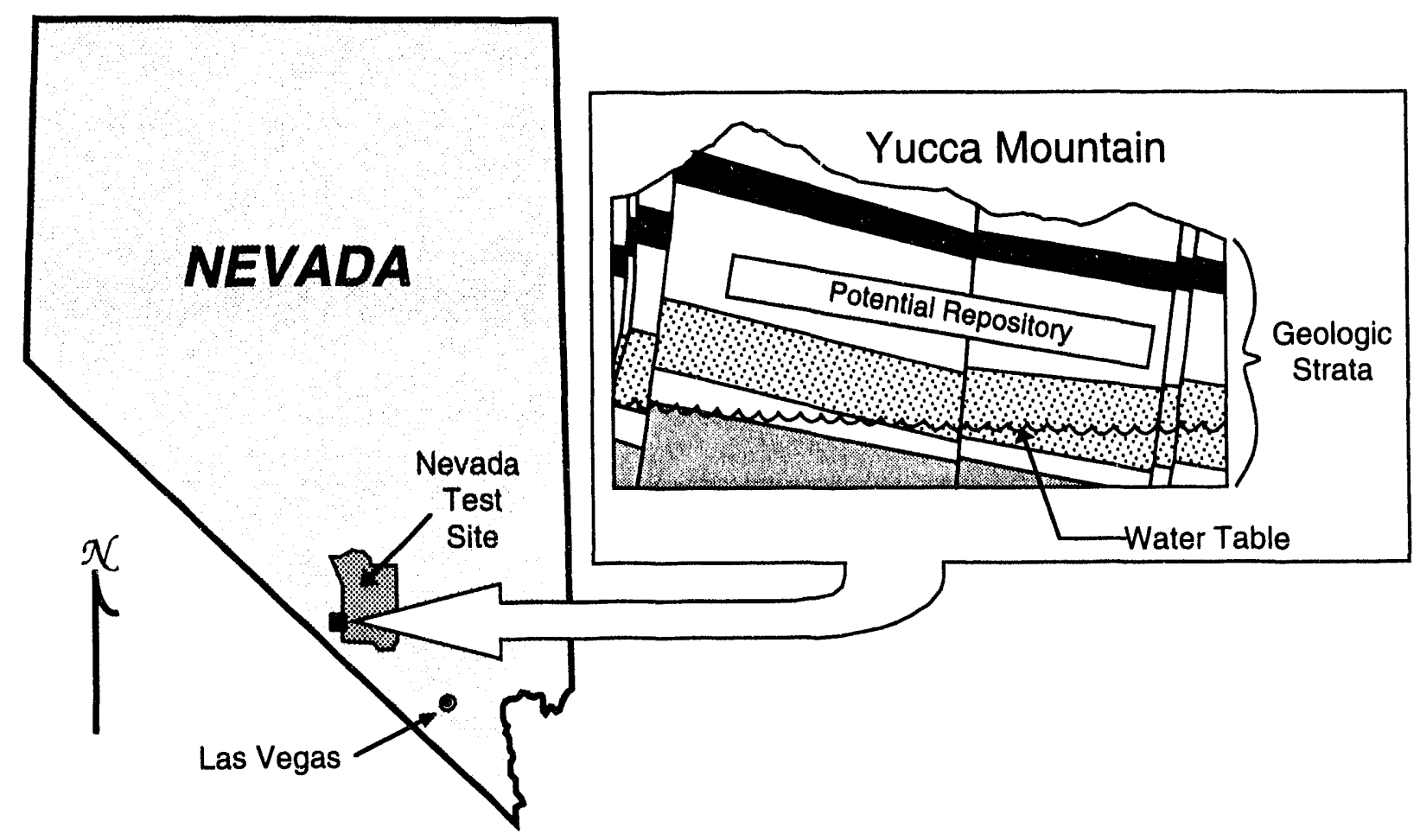

Figure ES-1. Location of Yucca Mountain and a potential high-level radioactive-waste repository.

A repository at Yucca Mountain will have to meet a number of Federal regulations, including regulations concerning long-term waste isolation promulgated by the U.S. Environmental Protection Agency (EPA) and the U.S. Nuclear Regulatory Commission. To determine long-term waste isolation, the Yucca Mountain Site Characterization Project (YMP) of DOE has begun a series of total-system performance assessments (TSPAs). The work described in this report-TSPA-93-is part of the second full iteration in the series (Figure ES-2). 


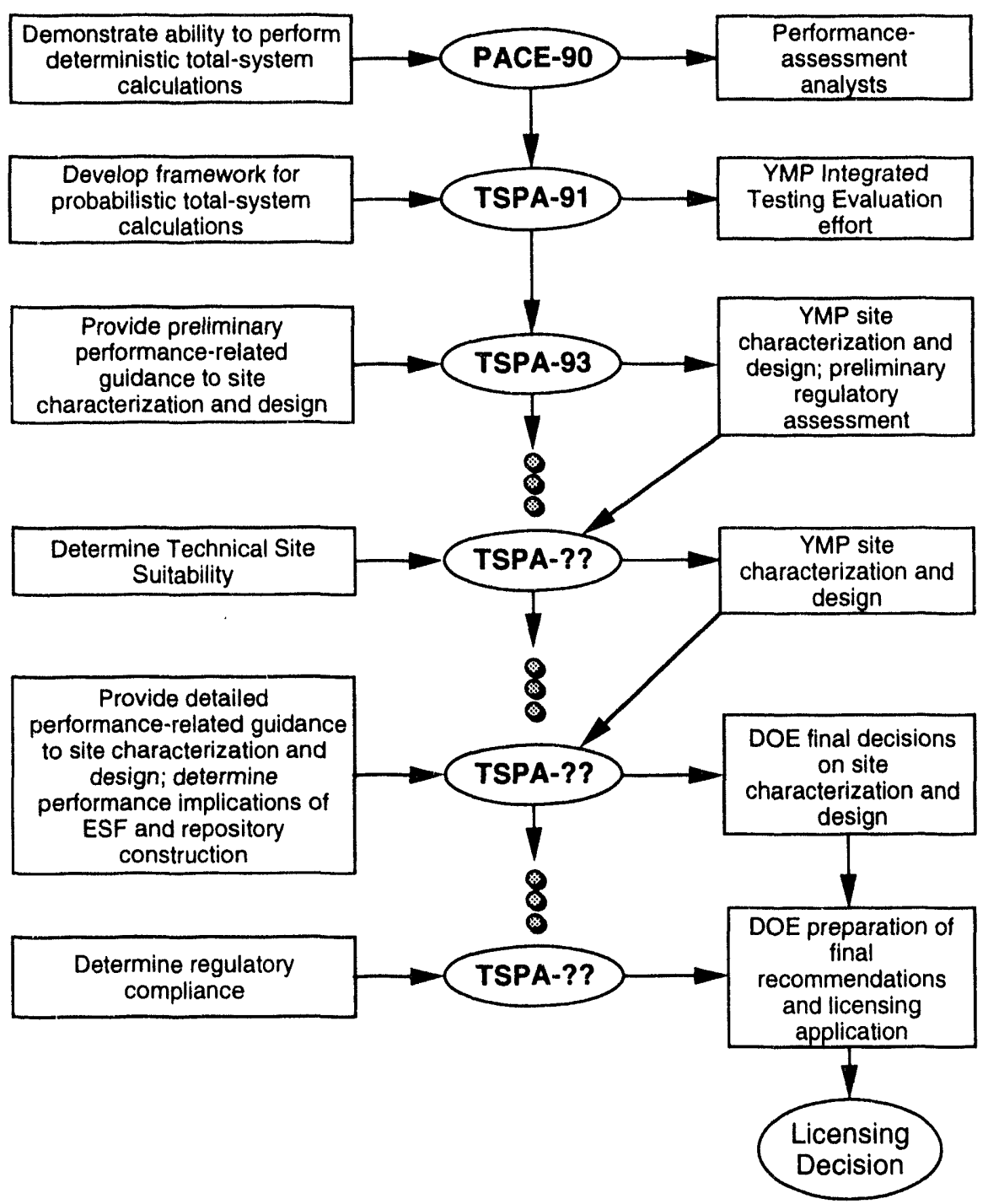

Figure ES-2. Progression of TSPA analyses.

TSPA-93 differs from previous analyses in several important respects. Significant new detailed modeling is undertaken, including three-dimensional geostatistical modeling of the stratigraphy, three-dimensional modeling of the saturated zone, and modeling of repository thermal effects. A phenomenological source term developed by Lawrence Livermore National Laboratory (LLNL) and climate change extrapolated from the paleoclimatic record are included in the probabilistic models. Several different repository designs with different containers and different thermal loadings are evaluated.

Two performance measures are considered in this TSPA iteration: normalized cumulative release, as defined by the EPA in 40 CFR 191.13, and radiation dose to a maximally exposed individual. The Energy Policy Act of 1992 dictates that 40 CFR Part 191 no longer 
applies to Yucca Mountain, and sets a course of action for specifying a new standard. Individual dose is examined in TSPA-93 to determine the potential impact of such a standard on the performance assessment. To study the impact of longer time periods on repository performance, both cumulative-releases and dose results were calculated for a million-year time period in addition to the typical 10,000-year period.

In one respect, the results of TSPA-93 tend to confirm previous work: cumulative releases from all investigated sources are generally below the EPA standard (40 CFR 191.13), except for gaseous releases of ${ }^{14} \mathrm{C}$. However, a significant new result is that future peak doses from drinking water in the area could be substantially above background radiation levels. Also, some of the models indicate that larger containers (e.g., the multipurpose container) and hotter repository configurations could lead to worse long-term performance, although a great deal of uncertainty is associated with these results.

\subsection{TSPA-93 purpose}

The ultimate goal of the TSPA process is to determine compliance of a repository with applicable regulations and to support a license application for construction and operation of a repository. However, at this point in the process, the primary goal of TSPA-93 is to provide feedback to YMP particpants on the significance of design and site-characterization information to regulatory compliance. Secondary goals of TSPA-93 involve progress toward performance assessments that are scientifically justified and acceptable for a license application, including refinement of mathematical models of physical processes, features, and events that could influence repository performance; consideration of an individual-dose performance measure; and calculation of conditional estimates of compliance with performance measures for scientific review. A final goal of TSPA-93 is to involve several different organizations within the project in production of a TSPA for Yucca Mountain. Table ES-1 shows the participants who provided input to TSPA-93. In addition, researchers from the Waste Isolation Pilot Project (WIPP) contributed to an independent review of this work.

\subsection{Scenarios}

A TSPA is based on a risk-assessment methodology that contains the following major steps: (1) develop and screen scenarios, (2) develop models of important features, events, and processes, (3) estimate parameter values and uncertainties, (4) make calculations using the models and parameter values, and (5) interpret results. A summary of models, parameters, and results is contained in the following sections. Development and screening of scenarios are independent efforts and are described in separate documents; a brief disscussion follows. 
Table ES-1. Information sources for TSPA-93 analyses.

\begin{tabular}{|c|c|}
\hline Component & Contributors \\
\hline $\begin{array}{c}\text { Stratigraphy and Hydrogeologic } \\
\text { Parameters }\end{array}$ & $\begin{array}{l}\text { LBL (C. Wittwer, G. Bodvarsson) } \\
\text { USGS (A. Flint, L. Flint, R. Spengler, } \\
\text { E. Weeks, R. Luckey, A. Geldon, } \\
\text { D. Appel, D. Hoxie) } \\
\text { SNL (A. Schenker, T. Robey, C. Rautman, } \\
\text { D. Guerin) }\end{array}$ \\
\hline Climate Change & $\begin{array}{l}\text { USGS (A. Flint, L. Flint, D. Hobson, } \\
\text { R. Forester, Z. Peterman) } \\
\text { WIPP (P. Swift) } \\
\text { SNL (J. Gauthier, M. Wilson) }\end{array}$ \\
\hline Geochemistry & $\begin{array}{l}\text { LANL (I. Triay, D. Morris, A. Meijer, } \\
\text { M. Ebinger) } \\
\text { SNL (M. Siegel) }\end{array}$ \\
\hline Thermal Effects & $\begin{array}{l}\text { LLNL (G. Johnson, T. Buscheck, L. Lewis) } \\
\text { TRW (J. King) } \\
\text { B\&W Fuel (T. Doering, R. Bahney, } \\
\text { A. Thompson) } \\
\text { SNL (E. Ryder, E. Dunn, J. Holland) }\end{array}$ \\
\hline Saturated Zone & $\begin{array}{l}\text { USGS (R. Luckey) } \\
\text { SNL (G. Barr) }\end{array}$ \\
\hline Gas Flow & $\begin{array}{l}D S I(\text { B. Ross, N. Lu) } \\
\text { SNL (M. Wilson) }\end{array}$ \\
\hline $\begin{array}{l}\text { Source Term and } \\
\text { EBS Processes }\end{array}$ & $\begin{array}{l}\text { LLNL (A. Lamont, J. Gansemer, } \\
\text { W. Halsey, L. Lewis, R. Stout, } \\
\text { D. McCright) } \\
\text { Iowa State University (D. Bullen) } \\
\text { ORNL (A. Croff) } \\
\text { SNL (R. Barnard, J. Gauthier, M. Wilson) }\end{array}$ \\
\hline
\end{tabular}

A scenario consists of an organized list of features, events, and processes (FEPs) that could lead to releases of radionuclides to the accessible environment-either the ground surface or a subsurface boundary $5 \mathrm{~km}$ from the repository. Scenario categories consist of groupings of similar scenarios. The general scenario categories considered in TSPA-93 include cases with an undisturbed repository (the "nominal" case), and with a disrupted repository (the "disturbed" cases).

For TSPA-93, the nominal case consists of a heat-generating repository that is subjected to climate-dependent groundwater flow. Two alternative conceptual models of groundwater flow in the unsaturated zone are considered. Waste containers within the repository degrade by a variety of mechanisms, but the most important mechanism is aqueous-induced corrosion. If and when containers fail, radionuclides are available for gaseous or aqueous transport to the accessible environment. For gaseous transport, radionuclides move upward through the unsaturated zone to the ground surface. For aqueous transport, radionuclides 
move downward through the unsaturated zone, then laterally through the saturated zone past the $5-\mathrm{km}$ subsurface boundary. Radionuclides are tracked in terms of (1) cumulative releases to the accessible environment and (2) the dose an individual might recieve by drinking contaminated water pumped from the saturated zone at the accessible environment.

For TSPA-93, two disturbed cases are investigated: (1) inadvertant human intrusion by exploratory drilling, and (2) volcanic activity that introduces corrosion-enhancing heat and volatiles into the repository. For human intrusion, radionuclides exhumed with the drill core and the drilling fluids contribute to releases. For indirect volcanic effects, magmaticinduced corrosion of containers allows earlier releases of radionuclides that are transported in groundwater flowing as described in the nominal case. (Direct volcanic releases were evaluated in TSPA-91.)

\section{Data development}

\subsection{Repository}

The design limit for a repository at Yucca Mountain is 70,000 metric tons of radioactive waste. The approximately 63,000 metric tons of spent fuel emplaced in the repository is considered to be aged 25 years, with burnups of $30,000 \mathrm{MWd} / \mathrm{MTU}$ for boiling-water-reactor fuel and 40,000 MWd/MTU for pressurized-water-reactor fuel. The approximately 7,000 metric tons of defense high-level waste is considered to have many of the heavy metal products removed and to be encased in a vitrified waste form. A study performed in conjuction with TSPA-93 examined the significance of each radionuclide contained in the wastes in terms of its potential for contributing to contamination at the accessible environment. Based on this study, the human-intrusion analyses in TSPA-93 consider a broad suite of 43 radionuclides. Nominal case and indirect volcanic effects consider 8 radionuclides, chosen for their transport characteristics (low retardation) or their potential contribution to individual dose.

The waste forms are enclosed in containers; container designs have not been finalized, but those investigated to date consist of cylindrical metal containers with gas-tight closures. Two container types are considered in TSPA-93 (Figure ES-3): (1) a smaller, "vertically emplaced" container proposed in the Site Characterization Plan (SCP) Conceptual Design of 1987, and (2) a larger, "in-drift" container which approximates the multipurpose container (MPC) presently being considered by the Yucca Mountain Project. Vertically emplaced containers are modeled with a surrounding air gap that is sometimes filled with rubble. In-drift containers are modeled with a surrounding backfill, provided to prevent drift collapse. (Consequences of adding a backfill are an increased potential for water pathways to the waste container, and higher container temperatures caused by the backfill acting as a thermal 
Thin-wall, SCP-type

container

vertically emplaced

in borehole

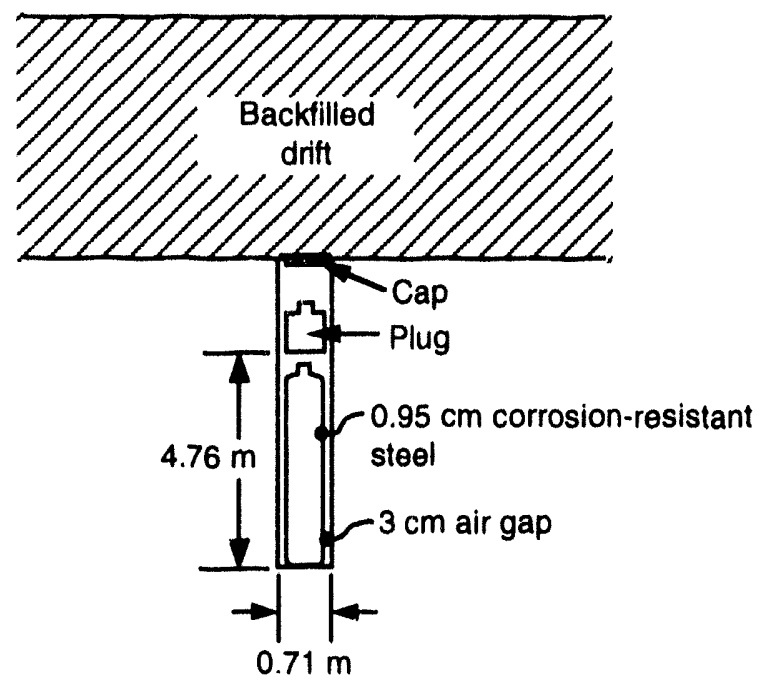

Robust container horizontally emplaced

In drift

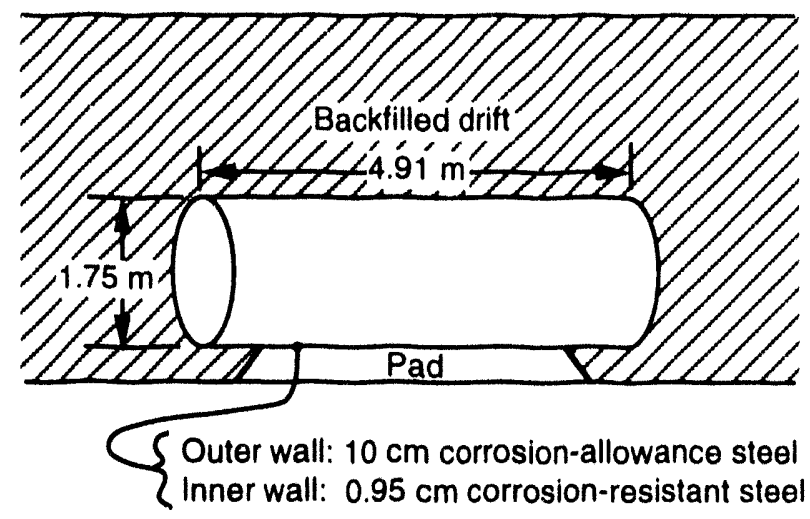

Figure ES-3. The two container types and emplacement strategies considered in TSPA-93.

insulator.) A 70,000-metric-ton repository requires the use of about 35,000 of the vertically emplaced containers or about 8,500 of the in-drift containers.

The repository layout incorporated in TSPA-93 consists of a series of emplacement drifts that run perpendicular to a main access drift. Length and proximity of the drifts to one another depend on the rock mass and the thermal characteristics of the repository. Decay of the radioactive waste produces heat: approximately $1 \mathrm{~kW}$ of heat for every metric ton (at emplacement-heat generation decreases over time). While the heat output depends primarily on the spent-fuel burnup and on the waste-acceptance schedule, the temperatures within the repository depend on the local areal power density (LAPD, expressed in terms of $\mathrm{kW}$ /acre), which is primarily a function of the waste-container spacing. It has been proposed that temperatures above boiling could produce a dry environment that would enhance the long-term performance of the repository. The SCP Conceptual Design specified an LAPD of $57 \mathrm{~kW} /$ acre (Figure ES-4). More recently, LAPDs up to $114 \mathrm{~kW} /$ acre have been considered by the YMP in order to attempt to induce a larger dryout zone.

Four combinations of container/thermal loadings are examined in TSPA-93. A 57$\mathrm{kW} /$ acre repository with vertically emplaced containers is the baseline analysis case for TSPA-93, and most like the design described in the SCP and evaluated in TSPA-91. Also 

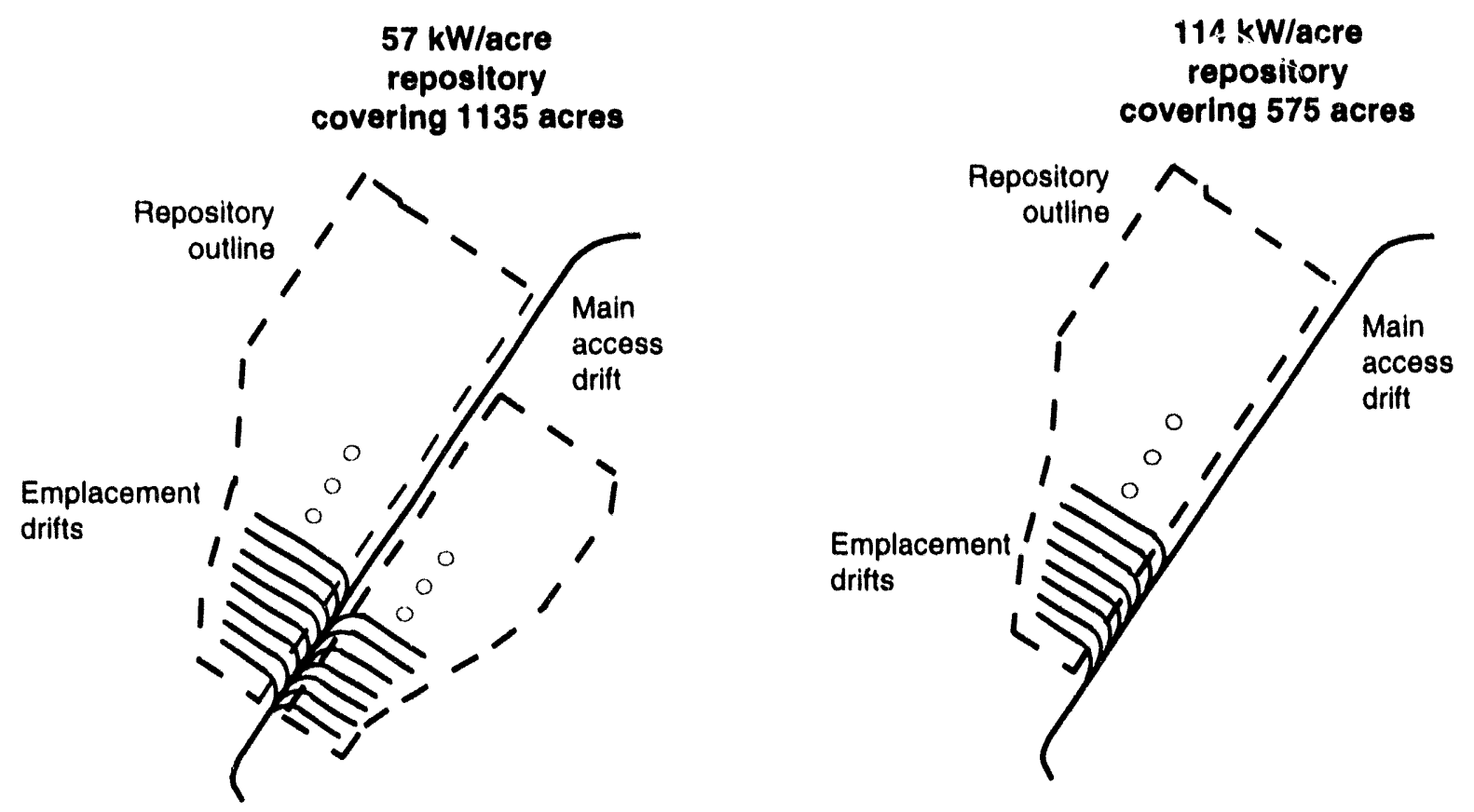

Figure ES-4. Repository layouts for the two thermal loadings considered in TSPA-93.

examined are a $114-\mathrm{kW} /$ acre repository with vertically emplaced containers, a $57-\mathrm{kW} / \mathrm{acre}$ repository with in-drift containers, and a $114-\mathrm{kW} /$ acre repository with in-drift containers.

\subsection{Stratigraphy}

A fully three-dimensional stratigraphic model of the potential repository region is developed for TSPA-93. The model uses geostatistics to reduce dependence on qualitative approaches by incorporating as much site-specific information as possible. The model was developed with the long-term goal of determining whether the thicknesses of the strata at the site are important to the modeled performance. For TSPA-93, probabilistic calculations (see below) are conducted using a reference stratigraphy selected from 10 geostatistical simulations performed with this approach.

The model incorporates lithologic data from 22 deep drillholes within or near the potential repository region in an indicator simulation to determine boundaries between welded and nonwelded layers of tuff. More regular structures - the Topopah Spring vitrophyre and the boundary between the vitric and zeolitized Calico Hills layers-are added separately.

Despite the welded/nonwelded indicator having horizontal correlation lengths on the order of kilometers, significant variation is seen in the strata contacts within the repository block for the 10 geostatistical outcomes. The implication is that the lithologic-data drillholes are not spaced closely enough for accurate predictions. 


\subsection{Hydrogeologic parameters}

A performance-assessment data base is produced for TSPA-93 for the purpose of standardizing available data and generating probability distributions of parameters used in both the detailed and the probabilistic models. Data are categorized for 15 hydrologic properties (e.g., porosity, hydraulic conductivity, etc.) in 10 strata, both in the unsaturated and saturated formations. Each of the 10 modeled strata is considered homogeneous, and one probability density function (PDF) is deveıped for each hydrologic property in each layer. Each PDF is either derived directly from available data (where data are abundant), or is derived based on maintaining maximum informational entropy (where data are sparse), in order to minimize tise chance of biasing the results. PDFs are also adjusted from lab scale to site scale to mals them more representative.

A new accomplishment with this effort is the development of a method for determining fracture characteristics that are consistent with site data. Distributions of bulkpermeability, fracture-frequency, and fracture-dip data from drillholes are used as input to a parallel-plate model, allowing calculation of fracture apertures, hydraulic conductivities, porosities, etc.

\subsection{Climate change}

Groundwater flow could be the most important process affecting the performance of a repository at Yucca Mountain (analysis of TSPA-91 and TSPA-93 results show a significant sensitivity to the groundwater-flux parameter). Although the present groundwater flow through Yucca Mountain is thought to be relatively insignificant, few quantitative data are available. The strategy for TSPA-93 is to examine the paleoclimatic record and data from analog sites, then extrapolate future infiltration and percolation at Yucca Mountain. The paleoclimatic record shows that an ice-age cycle of 100,000 years has existed during the recent Pleistocene, and researchers have noted that Yucca Mountain experienced probably $40 \%$ but perhaps up to $200 \%$ more annual precipitation during the last ice age. Recent data

from the U. S. Geological Survey (USGS) has also indicated that the water table under Yucca Mountain was higher by $85 \mathrm{~m}$ or more during the last ice age.

For TSPA-93, a series of "wet" (ice-age) and "dry" (interglacial) climates are specified, with a cycle of 100,000 years, but with the dividing time between wet and dry selected at random. Flow is modeled as a sequence of steady states. Infiltration rates average $10 \mathrm{~mm} / \mathrm{yr}$ for wet climates, and $0.5 \mathrm{~mm} / \mathrm{yr}$ for dry climates. The water table is allowed to rise up to 120 $m$ during wet climates. These values are greater than what often is believed for the region. Percolation from meteoric sources is assumed to equal infiltration in the TSPA model that describes groundwater flow in fractures (the weeps model) but, for the model that describes 
flow in both matrix and fractures (the composite-porosity model), percolation is reduced to account for lateral diversion of flow above the repository. For TSPA-93, groundwater mobilized by a repository thermal pulse (see below) is added onto the direct meteoric influx and both are diverted around the dried region where temperatures are above boiling.

\subsection{Solubility and sorption parameters}

Distributions of solubility and sorption parameters for TSPA-93 were obtained through elicitation of experts from Los Alamos National Laboratory (LANL) and Sandia National Laboratories (SNL). Their decisions are based primarily on laboratory data, while keeping in mind that solubility and sorption characteristics of radionuclides are especially dependent on site-specific groundwater chemistry and somewhat dependent on temperature. The experts reaffirmed that most of the actinides are relatively insoluble and highly sorbing in conditions typical of Yucca Mountain. However, neptunium does not adsorb well to tuffs and under oxidizing conditions is relatively soluble. The solubility and sorption values offered by the experts resulted in neptunium often beirig a major contributor to aqueous releases and doses for the nominal-case scenarios.

\section{Detailed calculations}

\subsection{Thermal effects}

It has become increasingly apparent over the last few years that heat generated by radioactive decay within a repository will influence the environment around it. For TSPA93, thermal effects related to the thermal dryout, perturbation of the flow field, container corrosion, and spent-fuel alteration are considered.

For TSPA-93, three-dimensional heat-flow calculations were performed to determine parameters thought to be the most critical in defining the impact of the repository thermal pulse. Only heat conduction was considered in the calculations; hydrologic and mechanical effects were not explicitly modeled. All four repository configurations were explicitly modeled, however, accounting for each container location, container thermal output, and container emplacement time. In addition, LLNL supplied TSPA-93 with results of twodimensional hydrothermal calculations with a smeared heat source for comparison (see below).

Critical parameters that are produced relate to the extent that the thermal pulse protects the repository from groundwater by forming a region above boiling temperature (called the protected, or "dryout fraction," of the repository), as well as the extent that it perturbs the environment by displacing vaporized water (water is displaced from the "dryout volume") and diverting meteoric water. In addition, container-wall temperatures and internal waste 
tempertures are produced. The parameters are used in the probabilistic calculations to redistribute groundwater flow and to adjust the source term. For example, the source term used in the probabilistic calculations allows aqueous corrosion of a container only when liquid water is contacting the container and the container-wall temperature is below $100 \mathrm{C}$.

Some major results of the thermal modeling are as follows. The boiling isotherm, and therefore the perturbation in the environment, reaches substantial proportions around both the $57-\mathrm{kW} /$ acre repositories and the $114-\mathrm{kW} /$ acre repositories, although more so for the higher thermal loading (Figure ES-5). (For a period, at 114-kW/acre, the entire repository is dried out.) Comparison of the SNL and LLNL thermal modeling shows that repository geometry and the discrete nature of the heat sources are important: the center of $114-\mathrm{kW} / \mathrm{acre}$ repositories drops below boiling at around 5000 years with a discretely modeled repository, but at around 9000 years when the repository is modeled as a smeared heat source. Also, the in-drift containers are large discrete heat sources that produce a nonuniform dryout zone at early times. Thermal loading, backfill, and container size have a significant effect on container temperatures: the in-drift containers could see temperatures well above 500 C under certain conditions in a $114 \mathrm{~kW} /$ acre repository; the vertically emplaced containers reach temperatures slightly above $200^{\prime} \mathrm{C}$ in a $57 \mathrm{~kW} /$ acre repository.

\section{7 kW/acre repository}

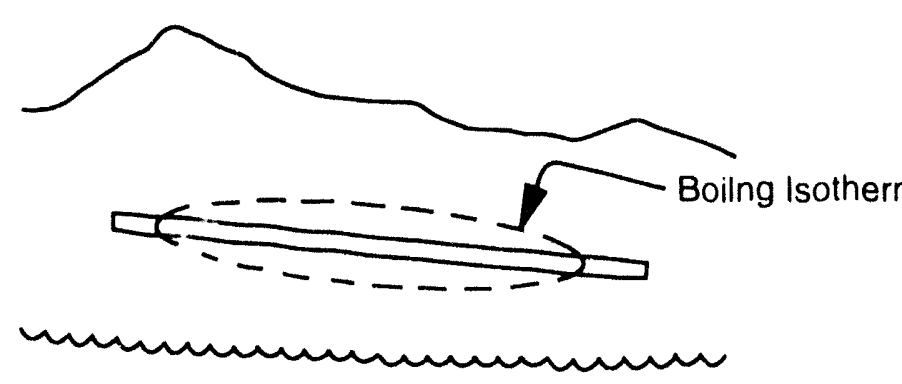

Max dryout volume $1.5 \times 10^{8}\left(2 \times 10^{8}\right) \mathrm{m}^{3}$ at 300 (1000) yr. Total collapse by $1300(2500) \mathrm{yr}$.

\section{$114 \mathrm{~kW} / \mathrm{acre}$ repository}

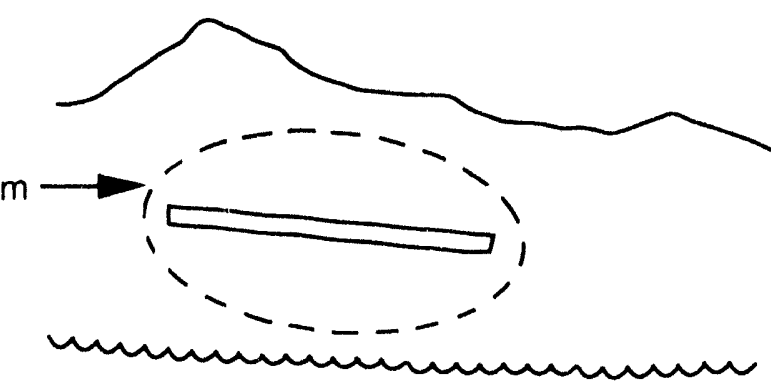

Max dryout volume $6 \times 10^{8} \mathrm{~m}^{3}$ at $800 \mathrm{yr}$. Total collapse by $5000(9000) \mathrm{yr}$.

Figure ES-5. Extent and duration of the volume encompassed by the boiling isotherm (the dryout volume). Where different, the values calculated with a smeared heat source are shown in parentheses.

\subsection{Saturated zone}

A three-dimensional model of steady-state groundwater flow in the saturated zone is constructed for TSPA-93. Geometry for the model consists of an approximately 8-km square 
section extending from the water table down $200 \mathrm{~m}$. Five strata are included, which because of the tilt of the units intersect the water table at an angle. Two different flow models are superimposed on this geometry: nondiversionary flow, where all fluid entering the "highgradient region" (to the northeast of the repository block) in the tuff aquifers continues to move through the tuff aquifers; and diversionary flow, where part of the fluid entering the high-gradient region is diverted from the saturated tuff downward to continue its flow path in the carbonate aquifers. Flow boundary conditions are taken from a regional saturatedzone flow model. Both the nondiversionary and the diversionary models calibrate to within a meter of water-table elevation at almost all drillholes.

Tracer transport times through the complicated three-dimensional structure are estimated for both models by transport calculations. The calculations involve a nonsorbing tracer released at various points under the repository block. Transport-time distributions are changed to velocity distributions for use in the probabilistic models.

Model calculations indicate that tracer transport times over the $5 \mathrm{~km}$ to the accessible environment tend to be less than 1000 years, and they tend to be shorter for the diversionary flow model than for the nondiversionary model. The short transport times, as well as the structure exhibited by the tracer concentrations during transport, indicate that threedimensional modeling is important in the saturated zone. Accurate calibration of the flow systems required that reduced hydraulic conductivities be assigned to the Solitario Canyon fault and the Drill Hole Wash fault; these faults should be investigated for these properties.

\subsection{Gas flow}

A two-dimensional, nonisothermal, transient model of gas flow and ${ }^{14} \mathrm{CO}_{2}$ transport provide gaseous-transport-time distributions for use in the TSPA-93 probabilitic models. Geometry for the model is taken from three parallel east-west cross sections that incorporate the latest information about site topography and stratigraphy. Only a 57-kW/acre repository is considered. For each calculation, transport times are determined for gas particles traveling from points distributed throughout the repository area to the ground surface. Transport-time distributions for ${ }^{14} \mathrm{CO}_{2}$ particles are output at 1000-year intervals.

Major results of the gas-flow calculations indicate that ${ }^{14} \mathrm{CO}_{2}$ transport times are short enough to have only marginal effect on cumulative releases. Gas flow depends primarily on temperature and the bulk-permeability distribution within the mountain. Retardation by exchange of ${ }^{14} \mathrm{CO}_{2}$ with bicarbonate in the groundwater is included in the model, and significantly slows transport-typically by an order of magnitude or more. Adsorption onto minerals in the rock is not included, but is potentially important.

ES-11 


\section{Probabilistic modeling}

The models for probabilistic analyses are abstractions of process models. The input parameters for these models come primarily from the data development and detailed modeling activities discussed above. To address uncertainty in parameters, the probabilistic models are used to perform thousands of calculations with parameters picked from probability distributions (the Monte Carlo method). To address uncertainty in models, two alternative conceptual models of groundwater flow in the unsaturated zone are analyzed. To simplify the process, aqueous, gaseous, human-intrusion, and basaltic-volcanism releases are modeled separately.

\subsection{Nominal-case models}

Two alternative conceptual models of flow in the unsaturated zone form the foundation of the nominal-case calculations. These two models were used in TSPA-91, but are refined for TSPA-93 to include an abstracted thermal-effects model (based on the results of the detailed thermal-effects calculations discussed above) and climate change. To calculate aqueous releases and doses, each of these models incorporates: (1) a phemonenological source-term model to calculate radionuclide releases from containers, (2) a transport model to calculate spread of radionuclides through the groundwater, (3) a simplified saturated-zone model (using parameters from the detailed saturated-zone calculations discussed above), (4) a simple drinking-water-dose model, and (5) a simplified gas-flow model (based on the detailed gas-flow modeling discussed above).

\subsubsection{The composite-porosity model}

The composite-porosity model (also known as the equivalent-continuum model) describes flow through an equivalent porous medium of matrix and fractures using Darcy's law. The major assumption in the model is that a local pressure equilibrium tightly couples flow in the matrix and flow in the fractures; thus, groundwater flow is dominated by capillary forces and only occurs in the fractures when the matrix is saturated. The result is a relatively uniform flow (Figure ES-6). Radionuclide transport also is modeled assuming tight coupling between matrix and fracture transport; thus, when fracture flow does occur in the calculations, diffusion of radionuclides into the matrix slows the transport considerably. At the onset of a climate change, the water table is modeled to rise abruptly, and all radionuclides in the inundated part of the unsaturated zone are transfered immediately to the saturated zone, shortly thereafter forming a spike in the releases at the accessible environment. 


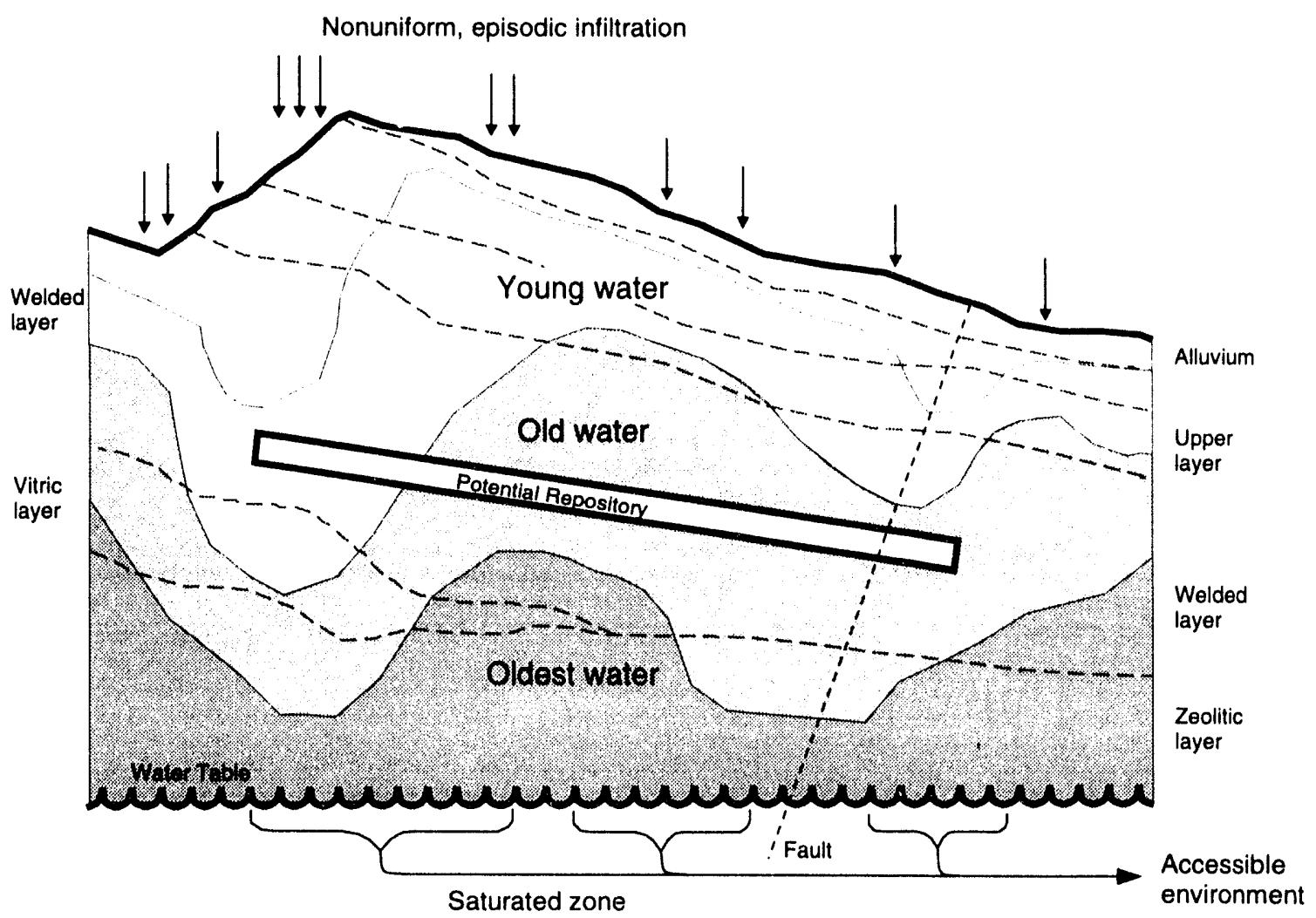

Figure ES-6. The composite-porosity model (large-scale regular percolation).

For TSPA-93, flow and transport through the unsaturated zone is modeled in 8 (for the $57-\mathrm{kW} /$ acre repositories) or 5 (for the $114-\mathrm{kW} /$ acre repositories) vertical flow tubes. Each unsaturated-zone flow tube is matched with a horizontal flow tube in the saturated zone.

Calculations using the composite-porosity model indicate that a relatively uniform flow pattern causes a large number of containers to be in a moist or a wet environment. Subsequent aqueous corrosion of these containers leads to widespread failure. (With the sourceterm being used, most aqueous corrosion occurs during the collapse of the repository thermal pulse, when water contacts containers that are near $100^{\circ} \mathrm{C}$ - see below.) Slow, constant percolation causes slow, constant leaching of waste from the failed waste containers. Long travel times afforded by the slowly percolating water in the unsaturated zone limit cumulative releases over 10,000 years, but are not sufficient to significantly limit peak doses that could occur in a 1,000,000-year period.

The parameters most important to performance depend on the performance measure applied, i.e., cumulative releases or individual dose. For the EPA measure from 40 CFR 191.13, percolation flux is the dominant parameter; when cumulative releases are measured at 10,000 years, the leading edge of a long-term pulse of releases is being measured, and the percolation flux determines how much of that leading edge crosses the boundary to 
the accessible environment within 10,000 years. For the individual-dose measure, without any time limit, dilution in the environment is most important, but parameters relating to releases from containers are also important. For example, backfill allows more water contact with in-drift containers, causing a substantial number of failures and subsequent radioactive releases.

\subsubsection{The weeps model}

The weeps model describes groundwater flow restricted to locally saturated fractures, which only contact the repository at discrete points (Figure ES-7). Weep location in time and space depends on thermal effects and climate change, and is treated as an inherently probabilistic process. Degradation of containers and releases of radionuclides are limited to the intersections of weeps and containers. Transport of radionuclides through the unsaturated zone is assumed to be instantaneous. The saturated zone is modeled with a single flow tube.

Weeps-model calculations indicate that flowing fractures contacting containers are relatively rare occurrences, and that many containers within a repository remain relatively dry

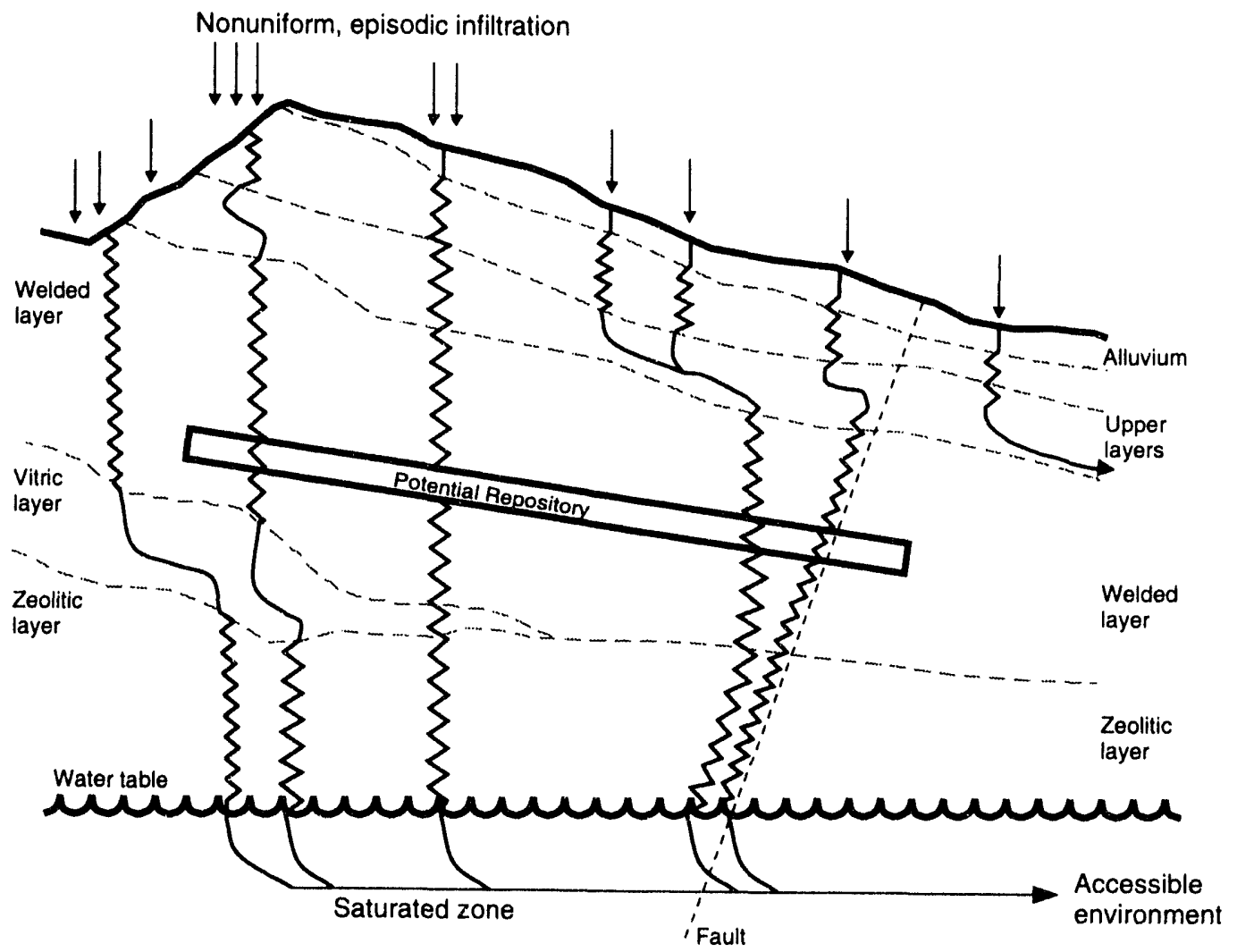

Figure ES-7. The weeps model (episodic pulses of flow in locally saturated zones, e.g. fractures). 
and intact. In-drift containers present a larger cross section to vertical weeps than vertically emplaced containers, and are more readily contacted. Most contacts occur because of the flow perturbation from repository thermal effects or during a wet climate. Although it is typically of shorter duration, the flow perturbation caused by thermal effects is more significant in terms of releases than the increased flow caused by a wet climate. The reason is because the waste containers are susceptible to corrosion primarily when their temperature is above ambient (about $25^{\circ} \mathrm{C}$ ), and especially when near $100^{\circ} \mathrm{C}$, which occurs during the collapse of the thermal pulse. At later times when climate change is most often modeled to occur, container temperatures have fallen to levels where the corrosion rates are insignificant. Releases during wet climates typically only occur from a few previously failed containers. Consequently, peak doses occur most often within the first 20,000 years of repository life, and cumulative releases do not increase much after this time.

\subsubsection{Radionuclide source-term model}

For TSPA-93, the YMIM source-term model, developed at LLNL, is directly incorporated into the nominal-case probabilistic models. YMIM is a phenomenological model that calculates container corrosion (including oxidation, general aqueous corrosion, and localized corrosion-pitting), oxidation alteration of spent fuel, and dissolution of radionuclides within spent fuel. Temperature dependence of these processes is included in the model, although the temperature dependence of solubility is not considered in TSPA-93. Inputs include near-field hydrology, container and fuel-rod temperature, and water chemistry. Defective or mechanically failed containers (known as juvenile failures) are consider probabilistically. Several important processes (e.g., steam corrosion and cathodic protection of containers) are not yet included in YMIM.

Use of YMIM within the composite-porosity and weeps models provides two important results: (1) dry oxidation destroys the corrosion-allowance steel outer wall of the in-drift containers during the high-temperature period following backfill, and (2) aqueous corrosion is only significant while container temperatures are above ambient (about $25^{\circ} \mathrm{C}$ ), and it can be especially rapid while temperatures are near $100^{\circ} \mathrm{C}$.

\subsection{Disturbed-case models}

\subsubsection{Human intrusion}

The human-intrusion analysis is based on a FEP sequence involving exploratory drilling, waste container breakage, and radionuclide release via extracted drill core and entrainment in the drilling fluid. Extraction of contaminated rock from a near miss of a failed container is also considered. Present-day drilling technology is assumed. Drilling 
frequency is based on guidance given in 40 CFR Part 191. A more comprehensive source term that distinguishes between spent-fuel and defense-high-level-waste containers is used in TSPA-93 than was used in TSPA-91. The only performance measure calculated is normalized cumulative release-individual doses are not considered.

Because of the more detailed source term, more variation is seen in the results when compared with the results for TSPA-91. As with TSPA-91, drilling frequency is the most important parameter (and one of the most difficult to predict). The in-drift containers, being larger, are more often hit by drilling and lead to greater releases; however, if it is assumed that only part of the container is exhumed commensurate with the size of the drill, then releases from in-drift containers are similar to releases from vertically emplaced containers.

\subsubsection{Indirect volcanic effects}

For TSPA-91, direct releases of radionuclides caused by intrusion of a basaltic dike into the repository were investigated; for TSPA-93, indirect releases are investigated. The FEP sequence modeled addresses magma intruding rock units near the repository and accelerating waste-container degradation because of the effects of heat and aggressive volatiles. These effects result in changes to the aqueous-transport source term. Dike length, location, and thickness are calculated probabilistically. The temperature of rock adjacent to a magmatic intrusion is calculated as a function of basaltic dike temperature and thickness, distance into the rock, and time. Waste-container corrosion rates are adjusted $10^{4}$ higher to account for aggressive magmatic volatiles. This value is consistent with sulfidization rates.

Analysis results show penetration of heat from a dike only on the order of a few meters. Magmatic volatiles are assumed to intrude only the same distance. Also, the probability of magmatic intrusion, based on geologically realistic values for the volcanic recurrence rate in the Yucca Mountain region and scaled for the two possible areas of the repository, is extremely low over 10,000 years $\left(\sim 10^{-4}\right.$ probability of occurrence), and even when extrapolated to $1,000,000$ years $\left(\sim 10^{-2}\right.$ probability of occurrence). Thus, little contribution from indirect volcanic effects to the nominal-case aqueous releases is observed.

\section{Results}

Results of the TSPA-93 probabilistic modeling are in the form of conditional complementary cumulative distribution functions (CCDFs). The CCDFs show the probability of exceeding a given value of either the EPA sum (i.e., the cumulative release normalized as specified in 40 CFR 191.13) or peak individual dose for a given realization of a probabilistic model. The distributions are conditional because they do not as yet include all possible scenarios. 
Figure ES-8 shows calculated CCDFs of 10,000-year normalized cumulative release using the composite-porosity model, for all modeled release mechanisms. Only results for a 57-kW/acre repository with vertically emplaced containers are shown; however, with the composite-porosity model, all repository configurations produce similar results (see below). Gaseous releases are predicted to be the most significant, exceeding the EPA standard. Several factors contribute to the large gaseous releases: relatively uniform flow causes a large number of containers to be contacted by water when they are warm (near $100^{\circ} \mathrm{C}$ ) and susceptible to corrosion; upon container failure, ${ }^{14} \mathrm{CO}_{2}$ is readily released (there is a sizable prompt fraction of ${ }^{14} \mathrm{C}$, but also, when temperatures are elevated, oxidation alteration of spent fuel proceeds rapidly and allows ${ }^{14} \mathrm{C}$ to escape); and ${ }^{14} \mathrm{CO}_{2}$ has a short transport time to the ground surface. Releases caused by human intrusion and nominal-case aqueous releases are important, but do not violate the standard. Indirect releases caused by volcanism are both few and low; direct releases caused by volcanism (a TSPA-91 result) are low primarily because the probability of a basaltic dike intruding in the repository in 10,000 years is very low.

As mentioned, the composite-porosity model predicts little influence of the four repository designs on performance. Container size is immaterial because slow, uniform percolation

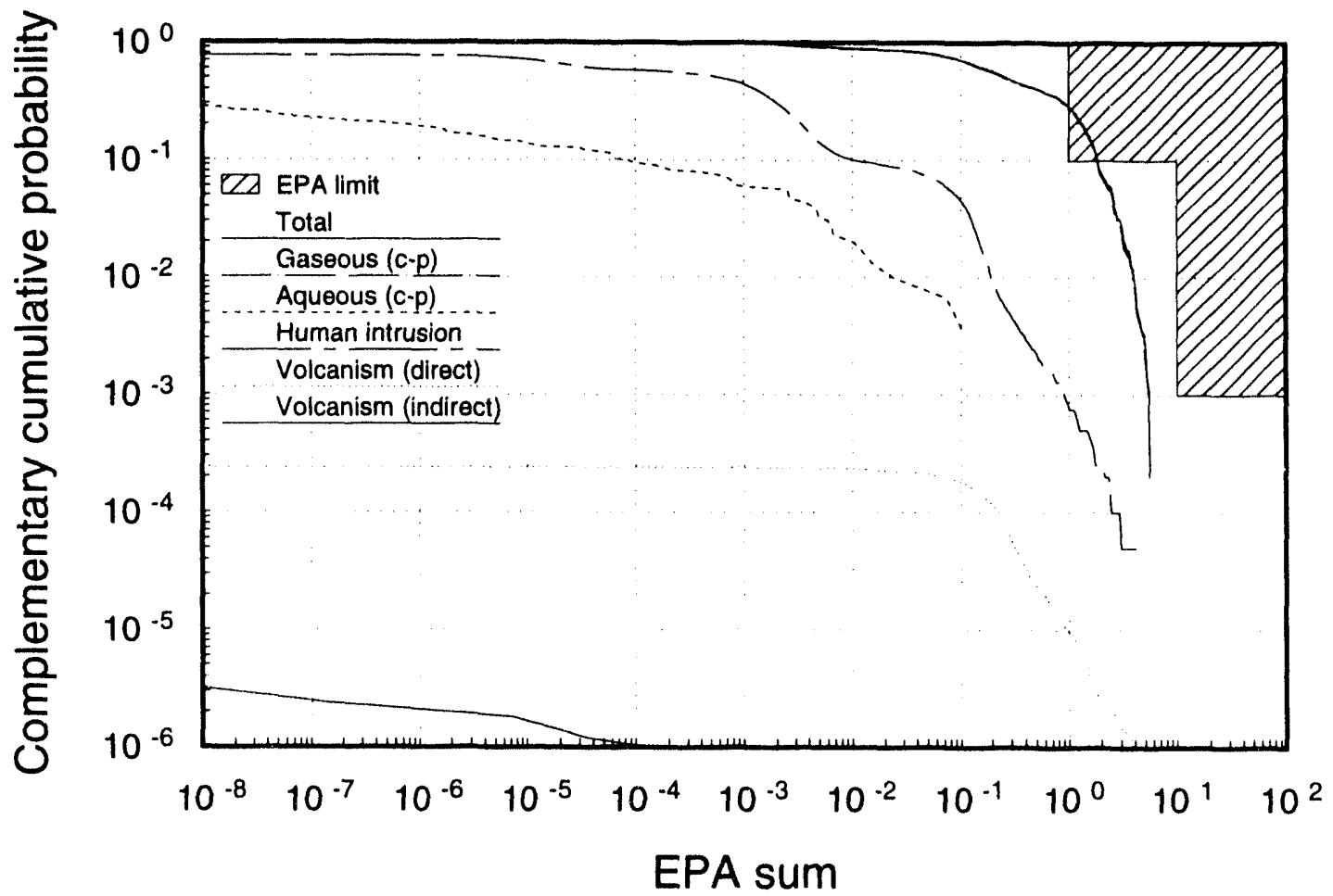

Figure ES-8. Base-case normalized cumulative release predicted by the composite-porosity model. 
of groundwater leads to widescale contact irrespective of size. A slight effect is seen in the normalized cumulative releases over 10,000 years, where the dryout zone created by the hotter repositories results in a several thousand year increase in container lifetime. But for dose calculations over 1,000,000 years, container lifetime and thermal perturbations are too short to make much difference.

The CCDFs of 10,000-year normalized cumulative release calculated using the weeps model are shown in Figure ES-9. Normalized cumulative releases are predicted to be lower for the weeps model than for the composite-porosity model (compare total releases in Figure ES-8 with those shown in Figure ES-9). Releases caused by human intrusion are often predicted to be greater than the nominal-case releases predicted by the weeps model. The reason is that weeps rarely contact waste containers. And within 10,000 years, most weep contacts are caused by groundwater shed around the dryout volume onto unprotected parts of the repository (although many of the resulting contacts are for short periods of time). Gaseous releases are greater than aqueous releases at the highest probabilities because of juvenile failures that release ${ }^{14} \mathrm{CO}_{2}$ without weep contact. Indirect releases caused by volcanism are not calculated for the weeps model and do not appear in the figure. (This figure only represents the base-case design; repository design does influence releases predicted by the weeps model, as discussed below.)

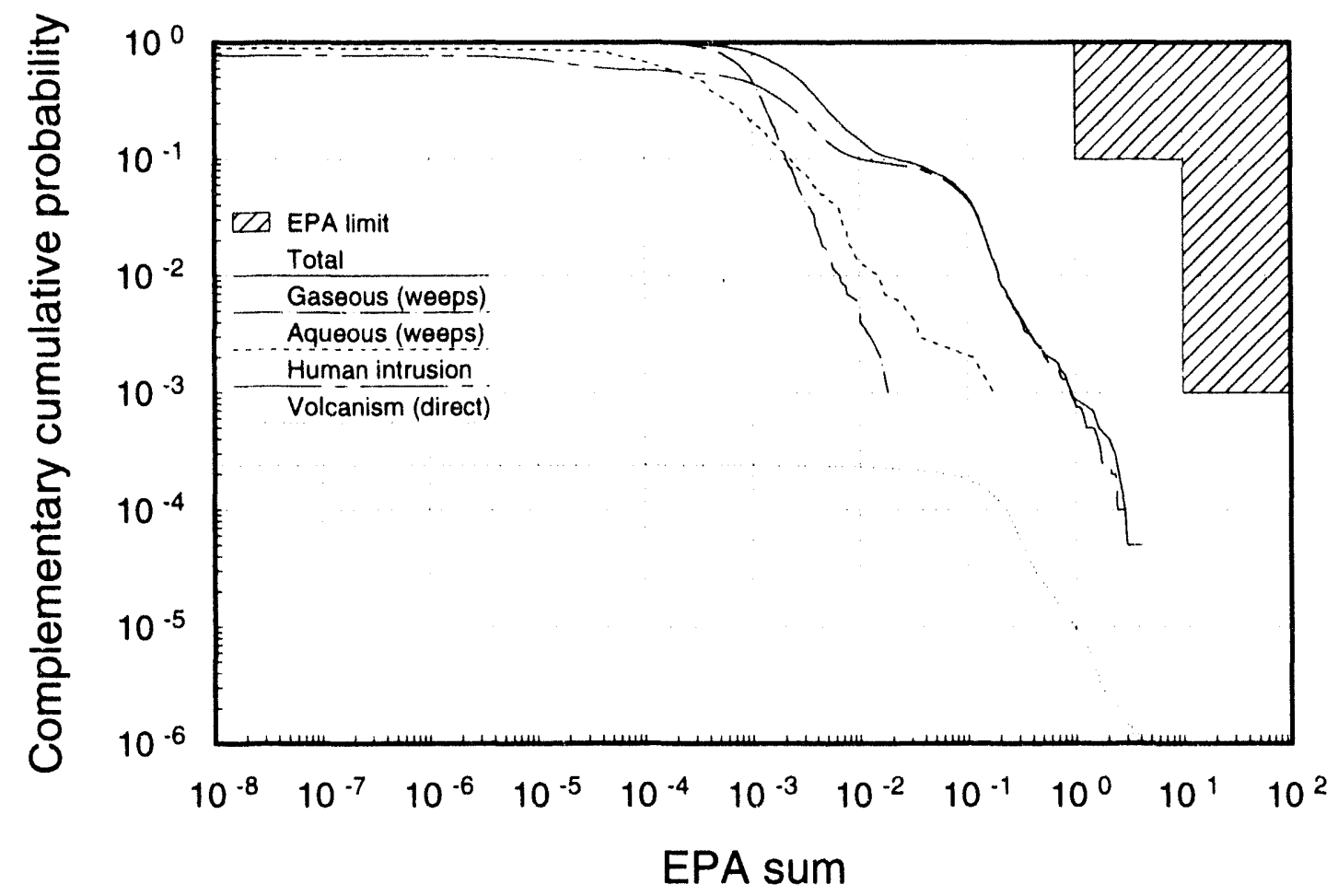

Figure ES-9. Base-case normalized cumulative release predicted by the weeps model. 
A comparison of peak individual doses for the two unsaturated-zone flow models is shown in Figure ES-10. The doses shown are for drinking water only and are the peak doses realized within a $1,000,000-y r$ period. The figure shows that both models predict doses from the repository at levels above background dose (approximately $300 \mathrm{mrem} / \mathrm{yr}$ ): over $90 \%$ of the composite-porosity realizations and about $1 \%$ of the weeps model realizations exceed background. These doses are primarily caused by neptunium. Peak doses predicted by the composite-porosity model typically occur because of high percolation rates and watertable rise of a wet climate; those predicted by the weeps model typically occur because of water shed on easily corroded containers (the number of containers contacted by water is a probabilistic result) as the repository thermal perturbation dissipates.

Because transport time is not an issue (except that some actinides decay away before they reach the accessible environment), peak doses are primarily a function of radionuclide release rate from the repository and dilution in the environment. Arid environments typically have little dilution. The release rate is greater, and thus the doses are greater, for the composite-porosity model than for the weeps model because of the larger number of containers that are contacted by water and fail.

Figure ES-11 presents weeps-model peak doses calculated for the four repository designs. The weeps model predicts that larger containers, because of the larger cross section

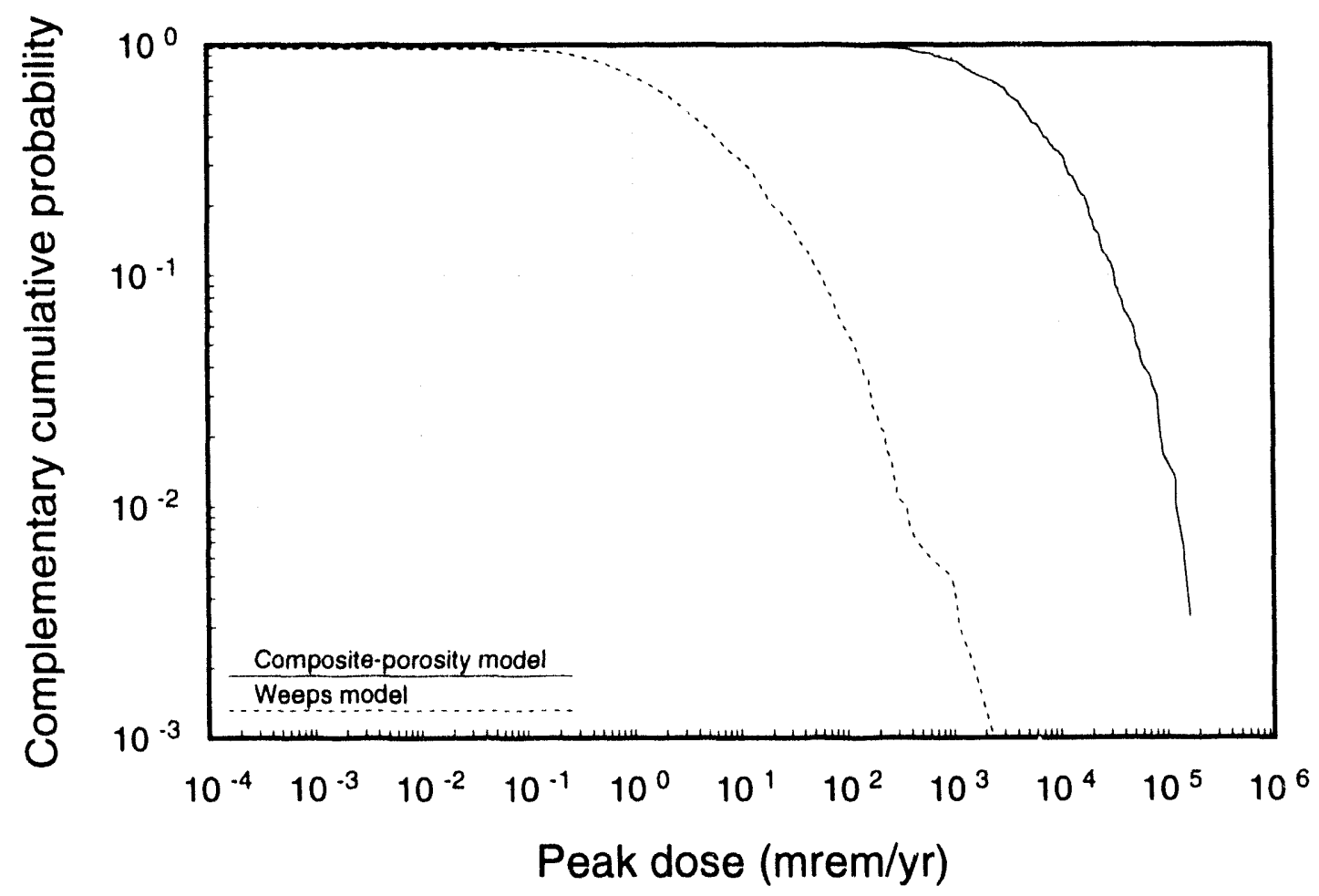

Figure ES-10. Peak drinking-water dose within 1,000,000 years. 
they offer for vertical weeps, have worse performance. A secondary effect is that hotter repositories cause worse performance, because hotter repositories cause a greater perturbation in groundwater flow and an increased probability of containers being contacted by weeps. (These findings are predicated on a number of factors, including that the repository drifts do not divert or concentrate weep flow, that flow returns to the dryout volume coincident with its collapse, etc.) The weeps model predicts similar behavior with the EPA performance measure, although none of the repository designs violate this standard.

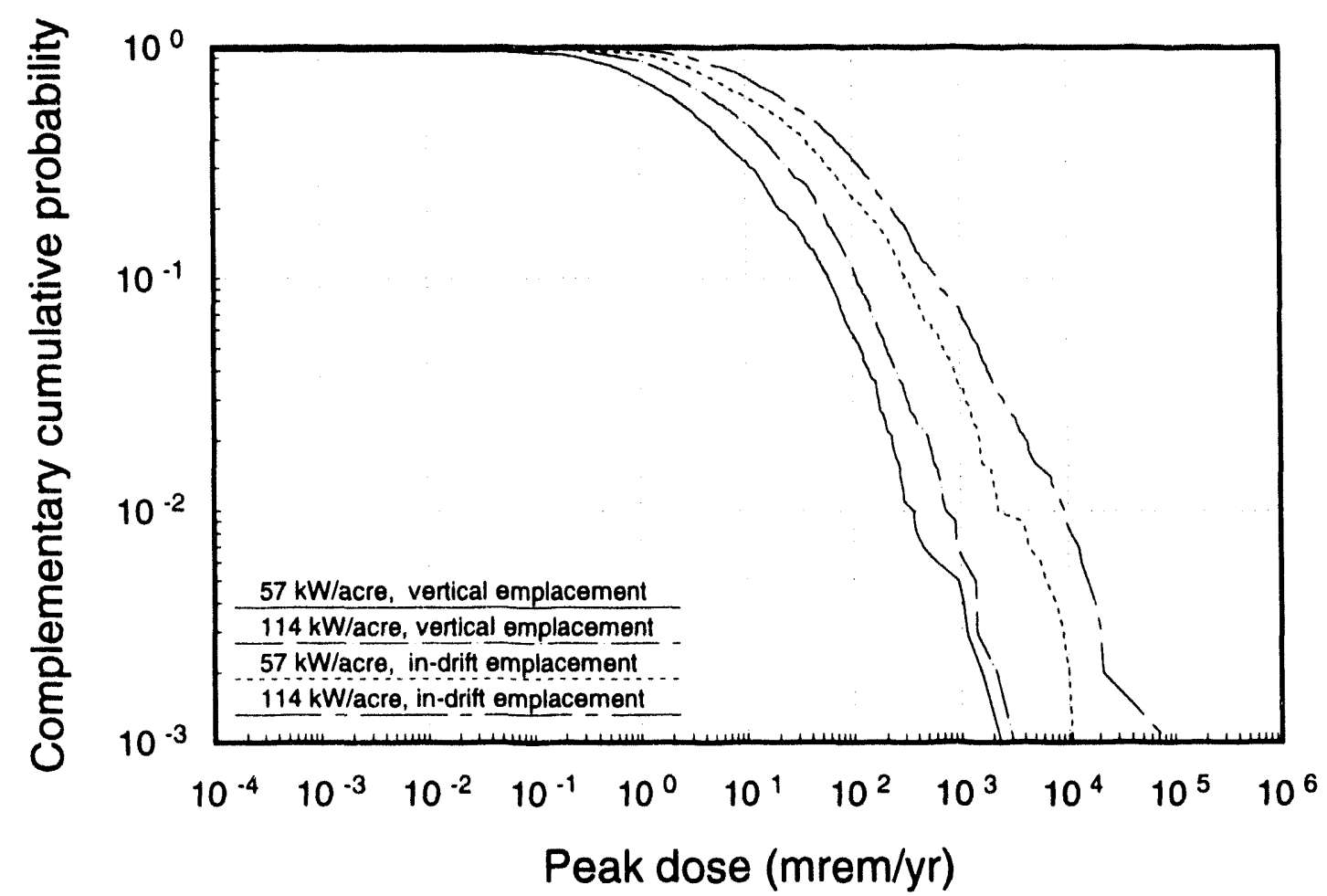

Figure ES-11. Peak doses for four repository configurations as predicted by the weeps model.

\section{Conclusions and recommendations}

The large difference in the results of the alternative conceptual models leads to questions about what model best approximates the behavior of the groundwater flow system. Calculations of peak individual drinking-water dose over 1,000,000 years indicate that radionuclides released from a Yucca Mountain repository could experience little dilution, and extremely low release rates from the repository-either from a highly engineered waste container or a system for reducing water contact with containers-might be needed to achieve low individual dose rates. Two possible impacts of repository design on long-term performance are also identified: (1) larger containers could be more readily contacted by weeps and drilling; (2) hotter repositories could cause a greater perturbation in the flow field, resulting in more containers being contacted by weeps. Results from the composite-porosity model 
indicate that normalized cumulative releases and doses are relatively insensitive to thermal loading and container size and emplacement. The YMIM corrosion models used by both the composite-porosity model and the weeps model predict that most container failures significant to performance occur during decay of the repository thermal pulse-within the first few thousand years. A $10-\mathrm{cm}$ corrosion-allowance overpack for in-drift containers is prerticted to be oxidized away within a few hundred years, with no contribution to performance. ('The overpack could be more important than indicated because of processes not included in the models currently being used.) Indirect releases from volcanic activity are not found to be significant contributors to overall releases.

Recommendations regarding site-data needs derive primarily from nominal-condition results because human-intrusion results are largely site-independent and volcanism results are comparatively insignificant. The following recommendations are made acknowledging limitations and assumptions in the present models, as well as uncertainities in our knowledge of physical conditions within Yucca Mountain and future events. It should also be mentioned that data are being collected in a number of these areas and an effort is being made to ascertain that the data are useful to determining long-term performance.

- Because of the substantial difference between the results of the two groundwater flow models, the first priority should be the determination of the dominant flow mechanisms (in both time and space) operating in the unsaturated zone at Yucca Mountain.

- Concerning gaseous releases, more data are needed on the spatial distribution of bulk permeability throughout Yucca Mountain and on adsorption of $\mathrm{CO}_{2}$ to tuff.

- Concerning aqueous releases, characterization at the repository horizon of percolationflux magnitude and distribution (in both time and space) is a high priority.

- Concerning individual doses, a high priority is characterization of the amount of horizontal and vertical dispersion (factors in dilution) in the saturated zone.

- Additional hydrogeologic data from new drillholes are also needed, as is research on scaling of properties and hydraulic characterization of unsaturated fractures in the rock matrix.

- Additional information is needed on heterogeneity and spatial correlations for geostatistical modeling and on cross-correlations among parameters.

- Thermal and hydraulic properties of proposed backfill materials should be determined, and fault-zone hydrogeologic properties should be characterized.

- To develop reliable models of near-field interactions, integrated testing is needed in the areas of waste-container/groundwater contact, radionuclide transport from degraded 
containers, coupled thermal-mechanical-hydrologic-chemical processes, and the interactions between natural and man-made system components.

- Further work is also recommended on waste-form alteration and container corrosion under realistic conditions.

Repository design must meet a number of requirements, with long-term performance being but one. Recommendations concerning long-term performance typically come from models that contain a number of limitations. Acknowledging this situation, the following design-related recommendations are made based on the TSPA-93 results.

- Calculated waste-container temperatures are very high for the in-drift cases, well above the thermal goals defined in the SCP. To approach the thermal goals, any backfill used with in-drift emplacement needs to be designed to allow for heat transfer.

- The biggest difference in the performance measures for the four repository configurations that are considered is a result of the difference in container "target size." Reduction in target size or engineered measures to reduce contact between containers and weeps or drilling paths is recommended.

- Container emplacement should be designed to reduce moisture contact with containers (both weeps and uniformly percolating water). Borehole emplacement attempts to achieve this reduction by specifying an air gap surrounding the container. For in-drift emplacement, backfill or a system within the backfill could possibly be engineered to control water contact.

Regulatory change could affect performance assessment for radioactive-waste disposal. If the radioactive-release standard changes to a measure based on individual dose rates over a time period much longer than 10,000 years, significant changes in site-characterization program priorities might be needed, with more emphasis on determining radionuclide release rates. If the standard is changed to an individual-dose standard but the regulated time period remains at 10,000 years, impact on the site-characterization needs would be lessened. Dose calculations require more information than cumulative-release calculations and would require additional characterization of the biosphere in the vicinity of Yucca Mountain. Information extrapolated into the distant future will introduce additional uncertainty into the calculations. 


\section{YUCCA MOUNTAIN SITE CHARACTERIZATION PROJECT DISTRIBUTION LIST}

D.A. Dreyfus (RW-1)

Director

OCRWM

US Department of Energy

1000 Independence Avenue SW

Washington, DC 20585

$1 \quad$ L.H. Barrett (RW-2)

Acting Deputy Director

OCRWM

US Department of Energy

1000 Independence Avenue SW

Washington, DC 20585

1 J.D. Saltzman (RW-4)

Office of Strategic Planning and International Programs

OCRWM

US Department of Energy

1000 Independence Avenue SW

Washington, DC 20585

1 J.D. Saltzman (RW-5)

Office of External Relations

OCRWM

US Department of Energy

1000 Independence Avenue SW

Washington, DC 20585

1 Samuel Rousso (RW-10)

Office of Program and Resource Mgt.

OCRWM

US Department of Energy

1000 Independence Avenue SW Washington, DC 20585

1 J. C. Bresee (RW-10)

OCRWM

US Department of Energy

1000 Independence Avenue SW

Washington, DC 20585

1 R.M. Nelson (RW-20)

Office of Geologic Disposal

OCRWM

US Department of Energy

1000 Independence Avenue, SW

Washington, DC 20585
1 S. J. Brocoum (RW-22)

Analysis and Verification

Division

OCRWM

US Department of Energy

1000 Independence Avenue SW

Washington, DC 2585

1 D. Shelor (RW-30)

Office of Systems and Compliance

OCRWM

US Department of Energy

1000 Independence Avenue, SW

Washington, DC 20585

1 J. Roberts (RW-33)

Director, Regulatory Compliance

Division

OCRWM

US Department of Energy

1000 Independence Avenue, SW

Washington, DC 20585

1 G. J. Parker (RW-332)

Reg. Policy/Requirements Branch OCRWM

US Department of Energy

1000 Independence Avenue, SW

Washington, DC 20585

1 R. A. Milner (RW-40)

Office of Storage and

Transporation

OCRWM

US Department of Energy

1000 Independence Avenue, SW

Washington, DC 20585

1

S. Rousso (RW-50)

Office of Contract Business

Management

OCRWM

US Department of Energy

1000 Independence Avenue, SW

Washington, DC 20585

1 T. Wood (RW-52)

Director, M\&O Management

Division

OCRWM

US Department of Energy

1000 Independence Avenue, SW

Washington, DC 20585 
Victoria F. Reich, Librarian

Nuclear Waste Technical Review Board

1100 Wilson Blvd, Suite 910

Arlington, VA 22209

5

R.M. Nelson Jr, Acting Project

Manager

Yucca Mountain Site

Characterization Office

US Department of Energy

P.O. Box 98608--MS 523

Las Vegas, NV 89193-8608

1 C. L. West, Director

Office of External Affairs

DOE Nevada Field Office

US Department of Energy

P.O. Box 98518

Las Vegas, NV 89193-8518

8 Technical Information Officer

DOE Nevada Field Office

US Department of Energy

P.O. Box 98518

Las Vegas, NV 89193-8518

1 P. K. Fitzsimmons, Technical

Advisor

Office of Assistant Manager for

Environmental Safety and

Health

DOE Nevada Field Office

US Department of Energy

P.O. Box 98518

Las Vegas, NV 89193-8518

1 D. R. Elle, Director

Environmental Protection and

Division

DOE Nevada Field Office

US Department of Energy

P.O. Box 98518

Las Vegas, NV 89193-8518

1 Repository Licensing \& Quality

Assurance

Project Directorate

Division of Waste Management

US NRC

Washington, DC 20555

1 Senior Project Manager for Yucca

Mountain

Repository Project Branch

Division of Waste Management

US NRC

Washington, DC 20555
$1 \quad$ NRC Document Control Desk

Division of Waste Management

US NRC

Washington, DC 20555

$1 \quad$ Philip S. Justus

NRC Site Representive

301 E Stewart Avenue, Room 203

Las Vegas, NV 89101

$1 \quad$ E. P. Binnall

Field Systems Group Leader

Building 50B/4235

Lawrence Berkeley Laboratory

Berkeley, CA 94720

1 Center for Nuclear Waste

Regulatory Analyses

6220 Culebra Road

Drawer 28510

San Antonio, TX 78284

3 W. L. Clarke

Technical Project Officer - YMP

Attn: YMP/LRC

Lawrence Livermore National

Laboratory

P.O. Box 5514

Livermore, CA 94551

$1 \quad$ J. A. Blink

Deputy Project Leader

Lawrence Livermore National

Laboratory

101 Convention Center Drive

Suite 820, MS 527

Las Vegas, NV 89109

4

J. A. Canepa

Technical Project Officer - YMP

N-5, Mail Stop J521

Los Alamos National Laboratory

P.O. Box 1663

Los Alamos, NM 87545

$1 \quad$ H. N. Kalia

Exploratory Shaft Test Manager Los Alamos National Laboratory Mail Stop 527

101 Convention Center Dr., \#820

Las Vegas, NV 89101

$1 \quad$ N. Z. Elkins

Deputy Technical Project Officer Los Alamos National Laboratory Mail Stop 527

101 Convention Center Dr., \#820

Las Vegas, NV 89101 
L. E. Shephard

Technical Project Officer - YMP

Sandia National Laboratories

Organization 6302, M/S 1333

P.O. Box 5800

Albuquerque, NM 87185

1 J. F. Devine

Asst Director of Engineering

Geology

US Geological Survey

106 National Center

12201 Sunrise Valley Drive

Reston, VA 22092

1 L. R. Hayes

Technical Project Officer

Yucca Mountain Project Branch

MS 425

US Geological Survey

P.O. Box 25046

Denver, CO 80225

1 V. R. Schneider

Asst. Chief Hydrologist--MS 414

Office of Program Coordination and Technical Support

US Geological Survey

12201 Sunrise Valley Drive

Reston, VA 22092

1 J. S. Stuckless

Geologic Division Coordinator

MS 913

Yucca Mountain Project

US Geological Survey

P.O. Box 25046

Denver, CO 80225

1 D. H. Appel, Chief

Hydrologic Investigations

Program

MS 421

US Geological Survey

P.O. Box 25046

Denver, CO 80225

1 E. J. Helley

Branch of Western Regional Geology

MS 427

US Geological Survey

345 Middlefield Road

Menlo Park, CA 94025
1 R. W. Craig, Chief

Nevada Operations Office

US Geological Survey

101 Convention Center Drive

Suite 860, MS 509

Las Vegas, NV 89109

1 D. Zesiger

US Geological Survey

101 Conventional Center Drive

Suite 860, MS 509

Las Vegas, NV 89109

1 G. L. Ducret, Associate Chief Yucca Mountain Project Division US Geological Survey

P.O. Box 25046

421 Federal Center

Denver, CO 80225

1 A. L. Flint

US Geological Survey

MS 721

P.O. Box 327

Mercury, NV 89023

1 D. A. Beck

Water Resources Division, USGS 6770 S Paradise Road

Las Vegas, NV 89119

$1 \quad$ P. A. Glancy

US Geological Survey

Federal Building, Room 224

Carson City, NV 89701

1 Sherman S.C. Wu

US Geological Survey

2255 N. Gemini Drive

Flagstaff, AZ 86001

1 J. H. Sass - USGS

Branch of Tectonophysics

2255 N Gemini Drive

Flagstaff, AZ 86001

1 DeWayne Campbell

Technical Project Officer - YMP

US Bureau of Reclamation

Code D-3790

P.O. Box 25007

Denver, CO 80225 
Records Specialist

US Geological Survey

421 Federal Center

P.O. Box 25046

Denver, CO 80225

1 W. R. Keefer - USGS

913 Federal Center

P.O. Box 25046

Denver, CO 80225

1

M. D. Voegele

Technical Project Officer - YMP

SAIC

101 Convention Center Drive

Suite 407

Las Vegas, NV 89109

2 L. D. Foust

Nevada Site Manager

TRW Environmental Safety

Systems

101 Convention Center Drive

Suite 540, MS 423

Las Vegas, NV 89109

1 C. E. Ezra

YMP Support Office Manager

EG\&G Energy Measurements Inc MS V-02

P.O. Box 1912

Las Vegas, NV 89125

1 E. L. Snow, Program Manager

Roy F. Weston Inc

955 L'Enfant Plaza SW

Washington, DC 20024

1 Technical Information Center

Roy F. Weston Inc

955 L'Enfant Plaza SW

Washington, DC 20024

1 D. Hedges, Vice President, QA

Roy F. Weston Inc

4425 Spring Mountain Road

Suite 300

Las Vegas, NV 89102

1 D. L. Fraser, General Manager

Reynolds Electrical \&

Engineering Co, Inc

MS 555

P.O. Box 98521

Las Vegas, NV 89193-8521
B. W. Colston, President and

General Manager

Las Vegas Branch

Raytheon Services Nevada

MS 416

P.O. Box 95487

Las Vegas, NV 89193-5487

1 R. L. Bullock

Technical Project Officer - YMP

Raytheon Services Nevada

Suite P-250, MS 403

101 Convention Center Drive

Las Vegas, NV 89109

1 Paul Eslinger, Manager

PASS Program

Pacific Northwest Laboratory

P.O. Box 999

Richland, WA 99352

1 A. T. Tamura

Science and Technology Division

OSTI

US Department of Energy

P.O. Box 62

Oak Ridge, TN 37831

1 Carlos G. Bell Jr

Professor of Civil Engineering

Civil and Mechanical Engineering

Dept.

University of Nevada, Las Vegas

4505 S Maryland Parkway

Las Vegas, NV 89154

1 P. J. Weeden, Acting Director

Nuclear Radiation Assessment Div.

US EPA

Environmental Monitoring

Systems Lab

P.O. Box 93478

Las Vegas, NV 89193-3478

1 ONWI Library

Battelle Columbus Laboratory

Office of Nuclear Waste Isolation

505 King Avenue

Columbus, $\mathrm{OH} 43201$

1 T. Hay, Executive Assistant

Office of the Governor

State of Nevada

Capitol Complex

Carson City, NV 89710 
Executive Director

Agency for Nuclear Projects

State of Nevada

Evergreen Center, Suite 252

1802 N. Carson Street

Carson City, NV 89710

1 C.H. Johnson

Technical Program Manager

Agency for Nuclear Projects

State of Nevada

Evergreen Center, Suite 252

1802 N. Carson Street

Carson City, NV 89710

1 John Fordham

Water Resources Center

Desert Research Institute

P.O. Box 60220

Reno, NV 89506

1 David Rhode

Desert Research Institute

P.O. Box 60220

Reno, NV 89506

1 Eric Anderson

Mountain West Research-

Southwest Inc

2901 N Central Avenue \#1000

Phoenix, AZ 85012-2730

1 The Honorable Cyril Schank

Chairman

Churchill County Board of

Commissioners

$1 \nsucc 0$ W First Street

Fallon, NV 89406

1 Dennis Bechtel, Coordinator

Nuclear Waste Division

Clark County Department of

Comprehensive Planning

301 E Clark Avenue, Suite 570

Las Vegas, NV 89101

1 Juanita D. Hoffman

Nuclear Waste Repository

Oversight Program

Esmeralda County

P.O. Box 490

Goldfield, NV 89013
1 Eureka County Board of

Commissioners

Yucca Mountain Information

Office

P.O. Box 714

Eureka, NV 89316

1 Brad Mettam

Inyo County Yucca Mountain Repository Assessment Office

Drawer L

Independence, CA 93526

1 Lander County Board of

Commissioners

315 South Humbolt

Battle Mountain, NV 89820

1 Vernon E. Poe

Office of Nuclear Projects

Mineral County

P.O. Box 1026

Hawthorne, NV 89415

1 Les W. Bradshaw

Program Manager

Nye County Nuclear Waste

Repository Program

P.O. Box 153

Tonopah, NV 89049

$1 \quad$ Florindo Mariani

White Pine County Nuclear

Waste Project Office

457 Fifth Street

Ely, NV 89301

1 Judy Foremaster

City of Caliente Nuclear Waste Project Office

P.O. Box 158

Caliente, NV 89008

1 Phillip A. Niedzielski-Eichner

Nye County Nuclear Waste

Repository Project Office

P.O. Box 221274

Chantilly, VA 22022-1274

1 Jason Pitts

Lincoln County Nuclear Waste

Project Office

Lincoln County Courthouse

Pioche, NV 89043 
1 Economic Development Dept.

City of Las Vegas

400 E. Stewart Avenue

Las Vegas, NV 89101

1 Commmunity Planning and

Development

City of North Las Vegas

P.O. Box 4086

North Las Vegas, NV 89030

1 Community Development and

Planning

City of Boulder City

P.O. Box 61350

Boulder City, NV 89006

1 Commission of the European

Communities

200 Rue de la Loi

B-1049 Brussells

BELGIUM

2 M. J. Dorsey, Librarian

YMP Research and Study Center

Reynolds Electrical \&

Engineering Co Inc

MS 407

P.O. Box 98521

Las Vegas, NV 89193-8521

1 Amy Anderson

Argonne National Laboratory

Building 362

9700 S Cass Avenue

Argonne, IL 60439

1 Steve Bradhurst

P.O. Box 1510

Reno, NV 89505

1 Michael L. Baughman

35 Clark Road

Fiskdale, MA 01518

$1 \quad$ Glenn Van Roekel

Director of Community

Development

City of Caliente

P.O. Box 158

Caliente, NV 89008

1 Ray Williams, Jr

P.O. Box 10

Austin, NV 89310
$1 \quad$ Nye County District Attorney

P.O. Box 593

Tonopah, NV 89049

1 William Offutt

Nye County Manager

Tonopah, NV 89049

1 Charles Thistlethwaite, AICP

Inyo County Planning Department

Drawer L

Independence, CA 93526

$1 \quad$ R. F. Pritchett

Technical Project Officer - YMP

Reynolds Electrical \&

Engineering Company Inc

MS 408

P.O. Box 98521

Las Vegas, NV 89193-8521

1 Dr. Moses Karakouzian

1751 E Reno \#125

Las Vegas, NV 89119

3 Brenda Bailey White

CCS

5301 Central NE

Suite 1520

Albuquerque, NM 87108

1 Clarence R. Allen

NWTRB

1000 E. California Blvd.

Pasadena, CA 91106

1 Johan Andersson

SKI

Division of Nuclear Waste

Sehlstedtgatan II

Box 27106

S-102 52 Stockholm

SWEDEN

1 Michael J. Apted

Intera Sciences

3609 S. Wadsworth Blvd

Denver, CO 80235

1 Dwayne Chesnut

Lawrence Livermore National

Laboratory

P.O. Box 808

M/S L202

Livermore, CA 94551 
$1 \quad$ Richard Codell

US Nuclear Regulatory

Commission

M/S 4-H-3

Washinton, DC 20555

1 Seth M. Coplan

US Nuclear Regulatory

Commission

M/S 4-H-3

Washington, DC 20555

$1 \quad$ Kevin Coppersmith

Geomatrix Consultants

100 Pine Street, 10th Floor

San Francisco, CA 94111

1 C.F. Costa

Nuclear Radiation Assessment

Division

US EPA

Environmental Monitoring

Systems Laboratory

P.O. Box 93478

Las Vegas, NV 89193-3478

$1 \quad$ Allen G. Croff

Chemical Technology Division

Oak Ridge National Laboratory

$4500 \mathrm{~N}, \mathrm{MS}-6235$

P.O. Box 2008

Oak Ridge, TN 37831-6235

1 Bruce M. Crowe

Los Alamos National Laboratory

101 Convention Center Drive

Suite 820

Las Vegas, NV 89109

1 Department of Comprehensive Planning

Clark County

225 Bridger Avenue, 7th Floor

Las Vegas, NV 89155

1 D.W. Engel

Pacific Northwest Laboratory

P.O. Box 999

M/S K7-34

Richland, WA 99352

1 Leonard J. Fiorenzi

P.O. Box 257

Eureka, NV 89316

\author{
A.B. Gureghian \\ CNWRA \\ 6220 Culebra Road
}

San Antonio, TX 78228-0510

5 William G. Halsey

Lawrence Livermore National

L.aboratory

P.O. Box 808

M/S L-204

Livermore, CA 94551

1 M.E. Harr

School of Civil Engineering

Purdue University

1284 Civil Engineering

Building

West Lafayette, IN 47907-1284

1 Dwight Hoxie

US Geological Survey

101 Convention Center Drive

Suite 860

Las Vegas, NV 89109

1 Edwin E. Kinter

Bradley Hill Road

P.O. Box 682

Nortwich, VT 05055

1 Donald Langmuir

Nuclear Waste Technical

Review Board

109 So. Lookout Mountain Cr.

Golden, CO 80401

1 Lincoln County Commission

Lincoln County

P.O. Box 90

Pioche, NV 89043

1 Ian Miller

Golder Associates Inc

4104148 Avenue NE

Redmond, WA 98052

1 R.W. Nelson

INTERA-M\&O

101 Convention Center Drive

Suite P110

Las Vegas, NV 89109

$1 \quad$ Claudia Newbury

Yucca Mountain Project Office

US Department of Energy

P.O. Box 98608

M/S 523

Las Vegas, NV 89193-8518 
D. Warner North NWTRB

Decision Focus Inc 4984 El Camino Real

Los Altos, CA 94062

2 William J. O'Connell

Lawrence Livermore National Laboratory

P.O. Box 808, M/S L-195

Livermore, CA 94551

$1 \quad$ Michael Revelli

Lawrence Livermore National

Laboratory

P.O. Box 808

M/S L-206

Livermore, CA 94551

1 Benjamin Ross

Disposal Safety Inc 1660 L STreet NW, Suite 314

Washington, DC 20036

$2 \quad$ SAIC-T \& MSS Library 101 Convention Center Drive Suite 407

Las Vegas, NV 89109

1 Frank W. Schwartz

195 Thornbury Lane

Powell, $\mathrm{OH} 43065$

1 Bjorn Selinder

190 W. First Street

Fallon, NV 89406

$1 \quad$ Ardyth Simmons

Yucca Mountain Project

US DOE

P.O. Box 98608

M/S 523

Las Vegas, NV 89193-8518

1 Scott Sinnock

TRW

101 Convention Center Drive

Suite P110

Las Vegas, NV 89109

$1 \quad$ Ellis D. Verink

Nuclear Waste Technical

Review Board

4401 NW 18th Place

Gainesville, FL 32605
1 Joseph Wang

Lawrence Berkeley Laboratory

Earth Sciences Division

1 Cyclotron Road

Berkeley, CA 94720

1 R.V. Watkins, Chief

Project Planning and Management

USGS

P.O. Box 25046

421 Federal Center

Denver, CO 80225

1 Ed Weeks -USGS

P.O. Box 25046

Federal Center M/S 413

Lakewood, CO 80225

1 C.L. West, Director

Office of External Affairs

DOE Field Office, Nevada

US DOE

P.O. Box 98518

Las Vegas, NV 89193-8518

1 Robert F. Williams

EPRI Nuclear Power Division P.O. Box 10412

Palo Alto, CA 94303

$1 \quad$ George Zyvoloski

Geoanalysis Group

Los Alamos National Lab

M/S F665

Los Alamos, NM 87545

1 Jean Younker

TRW

101 Convention Center Drive

Suite P110

Las Vegas, NV 89109

1 Dr. June Fabryka-Martin

Los Alamos National Lab

MS J-514

Los Alamos, NM 87545

1 Dr. F. Owen Hoffman

Oak Ridge National Lab

P.O. Box 2008

Oak Ridge, TN 37831-6036

1 Dr. Arjun Makhijani

Institute for Energy and

Environmental Research

6935 Laurel Avenue

Takoma Park, MD 20912 
Dr. James E. Martin

Assistant Professor of

Radiological Health

University of Michigan

School of Public Health

Ann Arbor, MI 48109

1 Dr. H. Robert Meyer

C.N.S.I.

750 East Park Drive

Suite 200

Harrisburg, PA 17111

1 Jess Riley

Heinman Research Labs

P.O. Box 35457

Charlotte, NC 28207

1 James E. Watson Jr

Environ. Science and Engineering

Campus Box 7400

University of North Carolina

Chapel Hill, NC 27599-7400

1 Dr. William M. Murphy

Center for Nuclear Waste

Regulatory Analyses

Southwest Research Institute

6220 Culebra Rcad

San Antonio, TX 78238-5166

1 Miroslav Kucerká, Consultant

Radioactive Waste Management

Botevova 3104

14300 Praha 4

Czech Republic

1 Dr. John Kessler

Nuclear Power Division

EPRI

P.O. Box 10412

Palo Alto, CA 94303-0813

$1 \quad$ Per-Eric Ahlstrom

Research Director

Swedish Nuclear Fuel and

Waste Management Co

Box 5864 S-102 48

Stockholm, Sweden

1 W.A. Seddon

AECL Technologies

9210 Corporate Boulevard

Suite 410

Rockville, MD 20850
1 Dr. Wilfried Albert

NAGRA

Hardstrasse 73

CH-5430 Wettingen

Switzerland

1 Runo Barrdahl

Swedish Radiation Protection

Institute

P.O. Box 60204

S-104 01 Stockholm

Sweden

1 Dr. John E. Gale

Fracflow Consultants Inc

36 Pearson Street

St. John's, Newfoundland

Canada A1A 3R1

1 Dr. Furruccio Gera

ISMES S.P.S.

Via dei Crociferi 44

00187 Rome, Italy

1 Dr. Gunnar Gustafson

Department of Geology

Chalmers University of Technology

and University of Goteborb

S-412 96 Goteborg

Sweden

1 Dr. Alan W. Herbert

AEA Technology

Theoretical Studies Department

Harwell Laboratory B424.4

Oxfordshire OX11 ORA

United Kingdom

1 David Hodgkinson

INTERA

Chiltern House

45 Station Road

Henley-on-Thames, Oxon

RG9 1AT

United Kingdom

1 Dr. Yong Soo Hwang

Korea Atomic Energy

Research Institute

P.O. Box 7

Daeduk-Danji

Taejeon, Korea

1 Dr. Katsumi Kamemura

Shinozuka Research Institute

5F Maguna Kogyo Building 1-31-13

Yoyogi, Shibuya-ku

Tokyo, 151, Japan 
Dr. Bill Lanyon

Geo-Science Limited

Falmouth Business Park

Bickland Water Road

Falmouth, Cornwall

TR11 4SZ, United Kingdom

1 Dr. Jussi Palmu

Imatran Voima Oy

Rajatorpantie 8

P.O. Box 112

SF-01601 Vantaa, Finland

1 Dr. Carmen Bajos Parada ENRESA

Emilio Vargas 7

28043 Madrid, Spain

1 Dr. Gunnar Ramqvist

ELTEKNO AB

Gruvvagen 1

S-714 00 Kopparberg

Sweden

1 Dr. Robert Rundberg

Los Alamos National Lab

Mail Stop J-514

Los Alamos, NM 87545

1 James A. Steadman

Building Research Establishment

Structural Performance Division

Garston, Watford WD2 7JR

United Kingdom

1 Dr. Ove Stephansson

Department of Engineering Geology

Royal Institute of Technology

S-100 44 Stockholm, Sweden

1 Dr. Juhani Vira

Teollisuuden Voiman Oy

Annankatu $42 \mathrm{C}$

SF-00100 Helsinki

Finland

1 Peter Wallman

Golder Associates

4104148 Avenue NE

Redmond WA 98052

1 Minoro Yamakuma

Geoscience Research Project

PNC Tokyo, Japan
1 David Leaver

Polestar

Four Main Street

Los Altos, CA 94022

1 James Gansemer

Lawrence Livermore National

Laboratory

P.O. Box 808

Livermore, CA 94551

1 Lynn C. Lewis

Lawrence Livermore National

Laboratory

P.O. Box 808

Livermore, CA 94551

1 Alan D. Lamont

Lawrence Livermore National

Laboratory

P.O. Box 808

Livermore, CA 94551

1 Ines Triay

Los Alamos National Laboratory

P.O. Box 1663

Los Alamos, NM 87545

1 David Morris

Los Alamos National Laboratory

P.O. Box 1663

Los Alamos, NM 87545

$1 \quad$ Ning Lu

USGS

P.O. Box 25046, MS 421

Denver Federal Center

Lakewood, CO 80225

1 Gary LeCain

USGS

P.O. Box 25046

Denver Federal Center

Lakewood, CO 80225

$1 \quad$ Edward Kwicklis

USGS

P.O. Box 25046

Denver Federal Center

Lakewood, CO 80225

1 Jerry McNeish

INTERA

M/S 423

101 Convention Center Drive

Las Vegas, NV 89109 
Yucca Mountain Project M/S 523

101 Convention Center Drive Las Vegas, NV 89109

1 Joseph J. Dlugosz

Yucca Mountain Project

M/S 523

101 Convention Center Drive

Las Vegas, NV 89109

1 Wendy R. Dixon

Yucca Mountain Project

M/S 523

101 Convention Center Drive

Las Vegas, NV 89109

1 Jeanne C. Nesbit

Yucca Mountain Project

M/S 523

101 Convention Center Drive

Las Vegas, NV 89109

1 Susan B. Jones

Yucca Mountain Project

M/S 523

101 Convention Center Drive

Las Vegas, NV 89109

1 William B. Simecka

Yucca Mountain Project

M/S 523

101 Convention Center Drive

Las Vegas, NV 89109

1 Dennis R. Williams

Yucca Mountain Project

M/S 523

101 Convention Center Drive

Las Vegas, NV 89109

1 C. Thomas Statton

Yucca Mountain Project

M\&O/WCFS

$\mathrm{M} / \mathrm{S} 423$

101 Convention Center Drive

Las Vegas, NV 89109

$1 \quad$ Yvonne Tsang

Lawrence Berkeley Laboratory

Earth Sciences Division

1 Cyclotron Road

Berkeley, CA 94720
1 Tom Bjerstedt

Yucca Mountain Project

US DOE

P.O. Box 98608

M/S 523

Las Vegas, NV 89193-8518

1 Maxwell Blanchard

Yucca Mountain Project

P.O. Box 98608

M/S 523

Las Vegas, NV 89193-8518

2 Jeremy Boak

Yucca Mountain Project

US DOE

P.O. Box 98608

M/S 523

Las Vegas, NV 89193-8518

1 Garry D. Brewer

Nuclear Waste Technical Review Board

University of Michigan

Dana Bldg, Room 3516

Ann Arbor, MI 48109-1115

1 Daniel B. Bullen

Iowa State University

P.O. Box 1768

Ames, IA 50010

1 Thomas A. Buscheck

Lawrence Livermore National Laboratory

P.O. Box 808

M/S L206

Livermore, CA 94550

1 John E. Cantlon, Chairman

Nuclear Waste Technical Review

Board

1795 Bramble Drive

East Lansing, MI 48823

1 K.W. Causseaux

NHP Reports Chief

U.S. Geological Survey

421 Federal Center

P.O. Box 25046

Denver, CO 80225

$1 \quad$ Pat Domenico

NWTRB

1100 Wilson Boulevard, Suite 910

Arlington, VA 22209 
A.L. Dudley SPECTRA Research Institute 1603 University NE

Albuquerque, NM 87102

$1 \quad$ William Dudley

US Geological Survey

P.O. Box 25046

M/S 425

Denver, CO 80225

1 J. Russell Dyer

Yucca Mountain Project Office

US DOE

P.O. Box 98608

M/S 425

Las Vegas, NV 89193-8518

1 Norman A. Eisenberg

US Nuclear Regulatory Commission M/S 4-H-3

Washington, DC 20555

1 W.W.-L. Lee

Environmental Evaluation Group

7007 Wyoming NE

Suite F-2

Albuquerque, NM 87109

1 R.E. Lowder

MAC Tec

101 Conventional Center Drive

Suite 1100

Las Vegas, NV 89109

$1 \quad$ R.R. Luckey

USGS

Building 53

Denver Federal Center

Room H2314/MS 5421

Denver, CO 80225

1 Annette Macintyre

Lawrence Livermore National

Laboratory

P.O. Box 808

M/S L-194

Livermore, CA 94551

1 Edward A. Mason

Amoco Resource Center

P.O. Box 451

46 Admirals Lane

Osterville, MA 02655-0451
1 Russell McFarland

NWTRB

100 Wilson Blvd, Suite 910

Arlington, VA 22209

1 Robin McGuire

Risk Engineering Inc

5255 Pine Ridge Road

Golden, CO 80403

1 John J. McKetta

NWTRB

Department of Chemical

Engineering

CRE Building 1450

Austin, TX 78712-1062

1 Ian McKinley

NAGRA

Hardstrasse 73

Wettingen, CH-5430

SWITZERLAND

1 Fred W. McLafferty

Department of Chemistry

Cornell University

2600 Baker Laboratory

Ithaca, NY 14853-1301

1 Arend Meijer

GCX Inc

P.O. Box $87198-2427$

Albuquerque, NM 87198

1 Dr. Martin Mifflin

Water Resources Center

Desert Research Center

2505 Chandler Avenue, Suite 1

Las Vegas, NV 89120

1 Suresh Pahwa

INTERA

6850 Austin Center Blvd

Suite 300

Austin, TX 78731

$1 \quad$ Planning Department

Nye County

P.O. Box 153

Tonopah, NV 89049

1 F. Joseph Pearson Jr 1304 Walnut Hill Lane

Suite 210

Irving, TX 75038 
Chris Pflum

SAlJ

101 Conventional Center Drive

Las Vegas, NV 89109

1 T.H. Pigford

University of California

Department of Nuclear Engineering

Berkeley, CA 94720

1 P.T. Prestholt

NRC Site Representative

301 E. Stewart Avenue, Room 203

Las Vegas, NV 89101

1 Dennis L. Price

NWTRB

1011 Evergreen Way

Blackburg, VA 24060

$1 \quad$ Karsten Pruess

Lawrence Berkeley Laboratory

Earth Sciences Division

1 Cyclotron Road

Berkeley, CA 94720

1 Norman C. Rasmussen

MIT

Department of Nuclear Engineering

Bldg 24-205

Cambridge, MA 02139

1 Leon Reiter

NWTRB

1100 Wilson Blvd, Suite 910

Arlington, VA 22209-2297

1 Everett Springer

Los Alamos National Laboratory

P.O. Box 1663

M/S J495

Los Alamos, NM 87545

1 Roger Staehle

University of Minnesota

Department of Chemical Engineering and Materials Science

22 Red Fox Road

North Oaks, MN 55127

1 Jane Summerson

US DOE

Forrestal RW-22, 7F-091/FORS

Washington, DC 20555
1

Aaron Thode

Los Alamos National Lab

M/S F607

P.O. Box 1663

Los Alamos, NM 87545

$1 \quad$ K.T. Thomas

National Academy of Sciences

2001 Wisconsin Ave NW

Harris Bldg, Roum 456

Washington, DC 20007

1 C.F. Tsang

Lawrence Berkeley Laboratory

Earth Sciences Division

1 Cyclotron Road

Berkeley, CA 94720

1 Greg Valentine

Los Alamos National Lab

P.O. Box 1663

M/S F665

Los Alamos, NM 87545

1 Richard Van Konynenburg

Lawrence Livermore National Lab

P.O. Box 808

Livermore, CA 94551

$1 \quad$ Abraham Van Luik

Intera-M\&O

101 Convention Center Drive

Suite \#P110

Las Vegas, NV 89109

1 C. John Mann

Department of Geology

245 Natural History Building

1301 West Green Street

Urbana, Illinois 61801

1 Henry Loo

Westinghouse Idaho Nuclear Co.

P.O. Box 4000

M/S 5219

Idaho Falls, ID 83415

1 Kjell Andersson

Karinta-Konsult

P.O. Box 6048

S-18306

Taby, Sweden

1 Dr. G. Ross Heath

College - Ocean/Fishery Sciences

583 Henderson Hall

University of Washington

Seattle, WA 98195 
Carl Anderson

National Academy of Sciences

2101 Constitution Ave NW

Harris Building, Room 456

Washington, DC 20418

1 Dorothy M. Clark

Secretary, Science Advisory Board US EPA

401 M Street SW, A-101F

Washington, DC 20460

1 Kathleen W. Conway

Science Advisory Board - EPA

401 M Street SW, A-101F

Washington, DC 20460

1 Dr. Chris Whipple

Clement International

160 Spear Street

Suite 1380

San Francisco, CA 94105-1535

13 Priscilla Bunton

US DOE, OCRWM (RW-331)

1000 Independence Ave SW

Washington, DC 20585

1 Linda Desell

US DOE, OCRWM (RW-331)

Suite 200

1000 Independence Ave SE

Washington, DC 20585

1 Robert J. Budnitz, President Future Resources Associates Inc 2000 Center Street, Suite 418

Berkeley, CA 94704

1 Thomas A. Cotton

JK Research Associates Inc 4429 Butterworth Place, NW Washington, DC 20016

1 Srikanta Mishra

M\&O/INTERA

$\mathrm{M} / \mathrm{S} 423$

101 Convention Center Drive

Las Vegas, NV 89109

200 Eric Smistad

Yucca Mountain Project

M/S 523

101 Convention Center Drive

Las Vegas, NV 89109
1 Margaret Federline

Nuclear Regulatory Commission

Washington, DC 20555-0001

1 Dr. Alan Hooper

United Kingdom Nirex Limited

Curie Avenue, Harwell

Didcot, Oxfordshire OX11 0RH

United Kingdom

1 Dr. Michael J. Bell

IAEA

Wagramerstrasse 5

P.O. Box 100

A-1400 Vienna

Austria

1 Dr. Neil Chapman

INTERA

Park View House

14B Burton Street

Melton Mowbray, Leicestershire United Kingdom LE13 1AE

1 Dr. James G.T. Chyr

Taiwan Power Company

AF 2 Alley 15

Lane 196 Sec 4

Roosevelt Road

Taipei, Taiwan

Republic of China

1 Dr. Nestor R. Correa

NAGRA

Hardstrasse 73

CH-5430 Wettingen

Switzerland

1 Kenneth W. Dormuth, AECL

Whiteshell Laboratories

Pinawa, Manitoba

Canada ROE 1LO

1 Dr. Esko Eloranta

Finnish Centre for Radiation

P.O. Box 268

SF-00101 Helsinki

Finland

1 Dr. Helmut D. Fuchs

Gesellschaft fur Nuklear-

Service $\mathrm{mbH}$

Lange Laube 7

D-3000 Hannover 1

Germany 
1 Ito Fumio

c/o Prof. Swoboda

University of Innsbruck

Technikerstr 13

A-6020 Innsbruck

Austria

1 Dr. Hilkka Leino-Forsman

VTT, Technical Research

Centre of Finland

Otakaari $3 \mathrm{~A}$

P.O. Box 200

SF-02151 Espoo, Finland

1

Dr. Robert W. Lieb

NAGRA

Hardstrasse 73

CH-5430 Wettingen

Switzerland

1 Dr. J.W. L.loyd

School of Earth Sciences

Edgbaston, Birmingham

B 15 2TT, United Kingdom

1 D. Ganpat S. Lodha, AECL

Whiteshell Laboratories

Pinawa, Manitoba

Canada ROE 1 LO

1 Douglas E. Metcalfe

Waste Management Division

P.O. Box 1046, Station B

270 Albert Street

Ottawa, Canada K1P 5S9

1 Dr. Ivars Neretnieks

Department of Chenical

Engineering

Royal Institute of Technology

Teknikringen 26

S-100 44 Stockholm

Sweden

1 Dr. Jean-Pierre Olivier

OECD/NEA

12 Boulevard des Iles

92130 Issy Les Molineaux

France

Dr. Olle Olsson

Conterra AB

P.O. Box 493

S-751 06 Uppsala, Sweden
Maria Onofrei, AECL

Whiteshell Laboratories

Pinawa, Manitoba

Canada ROE 1L0

1 Dr. Liu Wen-Chung

Radwaste Adminstration

Atomic Energy Council

6F 65 Lane 144 Keeling Load

Section 4 Taipei

Taiwan

1 Dr. Sidney H. Whitaker

AECL

Whiteshell Laboratories

Pinawa, Manitoba

Canada ROE 1LO

1 Dr. Roger Yearsley

Inspectorate of Pollution

Room A5.02

Romney House

43 Marsham Street

London SW1P 3Py

United Kingdom

1 Dr. Piet Zuidema

NAGRA

Hardstrasse 73

CH-543o Wettingen

Switzerland

1 Dr. Arthur Motta

Nuclear Engineering Department

Pennsylvania State University

231 Sackett Building

University Park, PA 16802

1 Dr. M.R. Chandratillake

Capcis March Limited

Bainbridge House, Granby Row

Manchester M1 2PW

United Kingdom

1 Serge Runge

Eurisys Consultants S.A.

14 rue du Printemps

74017 Paris, France

$1 \quad$ Peter Suci

Montana State University

Bozeman, MT

1 Dr. David Kreamer

Geoscience Department - UNLV

4505 South Maryland Parkway

Las Vegas, NV 89159 
Richard Forester

USGS

P.O. Box 25046

Denver Federal Center

Lakewood, CO 80225

$1 \quad$ Zell Peterman

USGS

P.O. Box 25046

Denver Federal Center

Lakewood, CO 80225

$1 \quad$ Kevin McCoy

B\&W Fuel Company

101 Convention Center Drive

Suite P110

Las Vegas, NV 89109

1 John Nitao

Lawrence Livermore National

Laboratory

P.O. Box 808

Livermore, CA 94551

1 Anne-Marie Meike

Lawrence Livermore National Laboratory

P.O. Box 808

Livermore, CA 94551

1 G.S. Bodvarsson

Lawrence Berkeley Laboratory

1 Cyclotron Road

Berkeley, CA 94720

1 Jiamin Wan

Lawrence Berkeley Laboratory

1 Cyclotron Road

Berkeley, CA 94720

1 Robert Andrews

INTERA

M/S 423

101 Convention Center Drive

Las Vegas, NV 89109

1 Tim Dale

INTERA

M/S 423

101 Convention Center Drive

Las Vegas, NV 89109

1 Dan McCright

Lawrence Livermore National Laboratory

P.O. Box 808

M/S L-204

Livermore, CA 94551
1 Ray Stout

Lawrence Livermore National

Laboratory

P.O. Box 808

M/S L-204

Livermore, CA 94551

\section{INTERNAL DISTRIBUTION}

$\begin{array}{lll} & \text { MS } & \\ 4 & 1330 & \text { G. M. Gerstner-Miller, 6352 } \\ & & \text { 100/12541/SAND93-2675/QA } \\ 20 & 1330 & \text { WMT Library, 6352 } \\ 1 & 0827 & \text { P. J. Hommert, 1502 } \\ 1 & 1375 & \text { D. A. Dahlgren, 4400 } \\ 5 & 0899 & \text { Technical Library, 7141 } \\ 1 & 0619 & \text { Technical Publications, 7151 } \\ 10 & 1119 & \text { Document Processing for } \\ & & \text { DOE/OSTI, 7613-2 } \\ 1 & 9018 & \text { Central Technical Files, 8523-2 } \\ & & \\ 1 & 0827 & \text { J. C. Cummings, 1502 } \\ 1 & 0827 & \text { J. S. Rottler, 1511 } \\ 1 & 0827 & \text { P. L. Hopkins, 1511 } \\ 1 & 0827 & \text { M. J. Martinez, 1511 } \\ 1 & 0835 & \text { R. R. Eaton, 1513 } \\ 1 & 0835 & \text { R. D. Skocypec, 1513 } \\ 1 & 1324 & \text { P. D. Davies, 6115 } \\ 1 & 1324 & \text { R. J. Glass, 6115 } \\ 1 & 1324 & \text { C. A. Rautman, 6115 } \\ 1 & 1324 & \text { V. C. Tidwell, 6115 } \\ 1 & 1324 & \text { C. Ho, 6115 } \\ 1 & 1320 & \text { M. D. Siegel, 6119 } \\ 1 & 1333 & \text { F. J. Schelling, 6302 } \\ 10 & 1326 & \text { H. A. Dockery, 6312 } \\ 10 & 1326 & \text { R. W. Barnard, 6312 } \\ 10 & 1326 & \text { G. E. Barr, 6312 } \\ 10 & 1326 & \text { J. H. Gauthier, 6312 } \\ 1 & 1326 & \text { P. G. Kaplan, 6312 } \\ 1 & 1326 & \text { T. H. Robey, 6312 } \\ 1 & 1326 & \text { L. H. Skinner, 6312 } \\ 1 & 1326 & \text { W. G. Perkins, 6312 } \\ 1 & 1326 & \text { A. R. Schenker, 6312 } \\ 1 & 1326 & \text { S. A. Shannon, 6312 } \\ 60 & 1326 & \text { M. L. Wilson, 6312 } \\ & & \\ 1 & 1325 & \text { L. S. Costin, 6313 } \\ 1 & 1325 & \text { R. E. Finley, 6313 } \\ 1 & 1325 & \text { E. Dunn, 6313 } \\ 1 & 1325 & \text { J. F. Holland, 6313 } \\ 1 & 1325 & \text { J. Pott, 6313 } \\ 1 & 1325 & \text { C. S. Chocas, 6313 } \\ 1 & 1325 & \text { E. E. Ryder, 6313 } \\ 1 & 1325 & \text { S. R. Sobolik, 6313 } \\ 1 & 1330 & \text { M. C. Brady, 6314 } \\ 1 & 1345 & \text { T. J. Brown, 6331 } \\ & & \end{array}$


1328 M. E. Fewell, 6342

1328 C. T. Stockman, 6342

1328 R. P. Rechard, 6342

1328 M. G. Marietta, 6342

0755 B. D. Zak, 6612

1315 T. E. Blejwas, 7500

9043 R. Nilson, 8745 

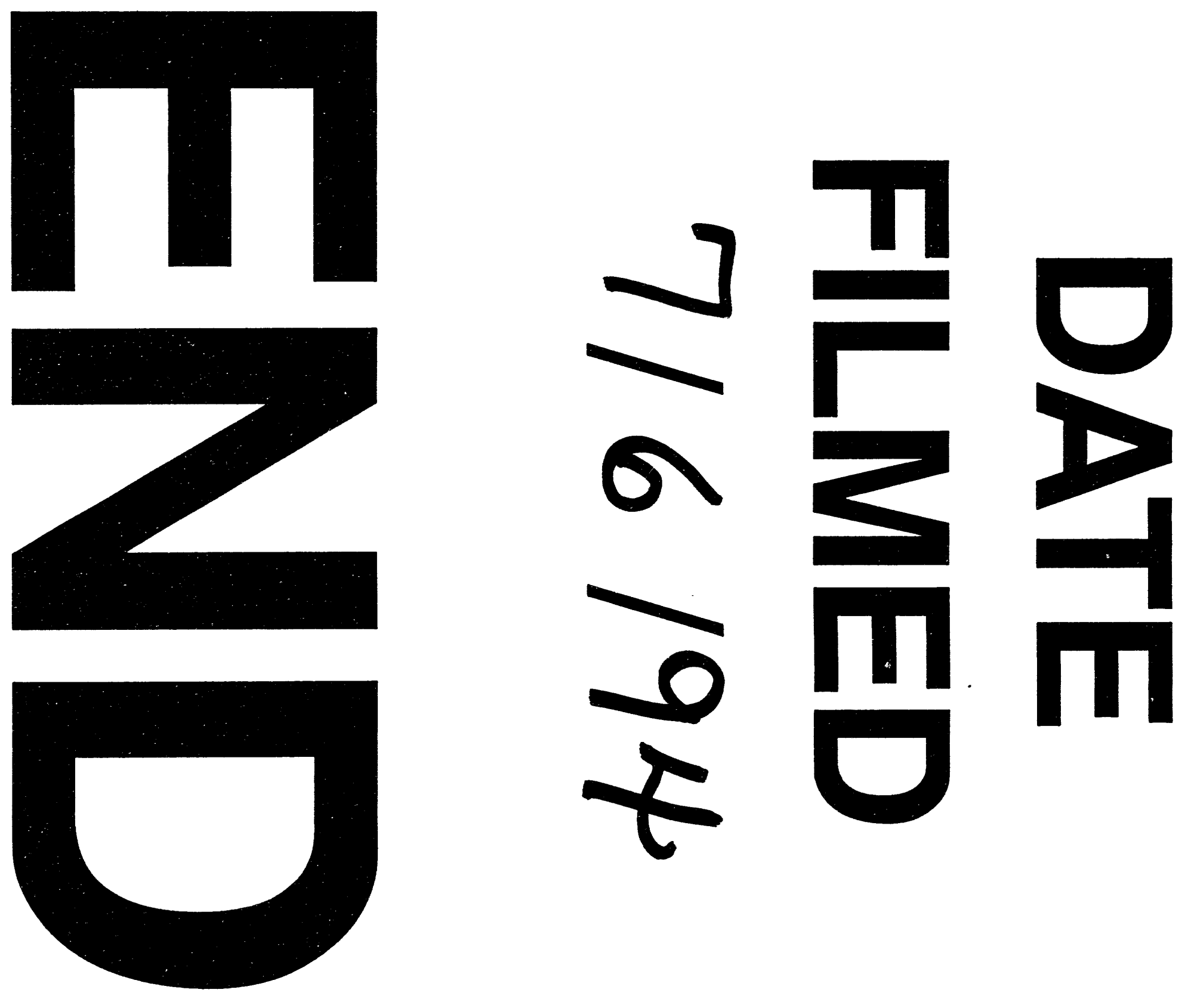
(1)

. 